\author{
UNIVERSIDADE DE SÃO PAULO \\ INSTITUTO DE ENERGIA E AMBIENTE \\ PROGRAMA DE PÓS-GRADUAÇÃO EM ENERGIA
}

TANNIA KARINA VINDEL HERNÁNDEZ

UMA PROPOSTA DE INTEGRAÇÃO DA GERAÇÃO DISTRIBUÍDA, POR MEIO DAS USINAS VIRTUAAS, AO SISTEMA ELÉTRICO DO ESTADO DE SÃO PAULO

SÃO PAULO

2015 
TANNIA KARINA VINDEL HERNÁNDEZ

\section{UMA PROPOSTA DE INTEGRAÇÃO DA GERAÇÃO DISTRIBUÍDA, POR MEIO DAS USINAS VIRTUAIS, AO SISTEMA ELÉTRICO DO ESTADO DE SÃO PAULO}

Dissertação apresentada ao Programa de Pós-Graduação em Energia do Instituto de Energia e Ambiente da Universidade de São Paulo - USP, para a obtenção do título de Mestre em Ciências.

Área de Concentração: Energia

Orientador:

Prof. Dr. Hédio Tatizawa

Versão Corrigida

(Versão original disponível na Biblioteca do Instituto de Energia e Ambiente da USP) 


\section{AUTORIZO A REPRODUÇÃO E DIVULGAÇÃO TOTAL OU PARCIAL DESTE TRABALHO, POR QUALQUER MEIO CONVENCIONAL OU ELETRÔNICO, PARA FINS DE ESTUDO E PESQUISA, DESDE QUE CITADA A FONTE.}

\section{FICHA CATALOGRÁFICA}

Vindel Hernández, Tannia Karina.

Uma proposta de integração da geração distribuída, por meio das usinas virtuais, ao Sistema Elétrico do Estado de São Paulo. / Tannia Karina Vindel Hernández; orientador: Hédio Tatizawa. - São Paulo, 2015.

152 f.: il.; $30 \mathrm{~cm}$.

Dissertação (Mestrado em Ciências) - Programa de Pós-Graduação em Energia - Instituto de Energia e Ambiente da Universidade de São Paulo

EP / FEA / IEE / IF da Universidade de São Paulo.

1. Sistemas elétricos - planejamento. 2. Fontes renováveis de energia.

3. Vinhaça. 4. Energia eólica 5. Usinas virtuais. I. Título. 
Folha de aprovação 


\section{Agradecimentos}

Agradeço a todos aqueles que fizeram possível a minha estada no Instituto de Energia e Ambiente.

A Deus por ter me brindado com todos os meios para conseguir chegar até aqui.

À minha família e amigos por todo o amor e apoio e especialmente aos meus pais por sempre me incentivarem a me superar e a minha irmã por todos os conselhos e cuidados.

Ao Professor Hédio pela paciência, orientação, conhecimentos compartilhados, ajuda ao longo do mestrado e muita dedicação.

Aos novos amigos que tive a oportunidade de conhecer no Brasil, pelos conselhos, trocas de experiências, bons momentos e muito mais...

Aos funcionários e colegas do IEE, por toda a sua colaboração e conhecimento transmitido.

À Organização de Estados Americanos, ao Grupo COIMBRA de Universidades Brasileiras, à Fundação de Apoio à Universidade de São Paulo, pelo apoio econômico sem o qual teria sido muito difícil a culminação desse logro. 


\section{RESUMO}

Vindel Hernández, Tannia Karina. Uma proposta de integração da geração distribuída, por meio das usinas virtuais, ao Sistema Elétrico do Estado de São Paulo. 2015. 143 f. Dissertação (Mestrado em Ciências) - Programa de PósGraduação em Energia da Universidade de São Paulo, São Paulo, 2015.

Esta dissertação apresenta uma contribuição aos estudos de planejamento do sistema elétrico do Estado de São Paulo, ressaltando os benefícios que se obteria, com uma maior integração das fontes renováveis à matriz elétrica desse estado (notadamente as fontes de energia solar fotovoltaica, eólica, aproveitamento dos resíduos sólidos urbano - RSU e vinhaça), visando o aumento da segurança e independência energética, redução de perdas, e benefícios ambientais. Para tanto, apresenta-se o conceito das usinas virtuais, cujo propósito é obter um melhor e maior aproveitamento dos recursos energéticos normalmente dispersos espacialmente - incluindo nesse rol a microgeração distribuída, a autoprodução e cogeração, e mesmo as fontes não renováveis que se encontram perto dos centros de consumo - com o objetivo de coordenar o seu funcionamento conjunto para satisfazer os requisitos da demanda de energia, por meio do uso da Tecnologia da Informação e Telecomunicações ou das Redes Inteligentes (Smart Grid), e, além disso, configurando a usina virtual de maneira que ela atue, no que diz respeito ao sistema interconectado de energia elétrica, rede de transmissão ou distribuição, como se fosse uma planta de geração de grande porte. Apresenta-se uma análise e projeções da operação e do suprimento do subsistema Sudeste/Centro Oeste (SE/CO), com foco especial no Sistema Elétrico do Estado de São Paulo, com suas interações com o SIN.

Palavras-chave: Sistemas Elétricos. Planejamento. Fontes renováveis de energia. Usinas virtuais. Geração distribuída. Redes inteligentes. São Paulo. Energia Eólica, Fotovoltaica, Vinhaça. Resíduos sólidos urbanos. 


\begin{abstract}
Vindel Hernández, Tannia Karina. A proposal for the integration of distributed generation, through virtual power plant, to São Paulo State Electrical System. 2015. 143 f. Master of Science Thesis - Energy Graduate Program, Universidade de São Paulo, São Paulo, 2015.
\end{abstract}

This Thesis presents contributions for the planning of the electrical system of São Paulo State - Brazil, emphasizing benefits obtained with a better integration of renewables (mainly solar photovoltaics, wind energy, from municipal solid waste and sugarcane vinasse) aiming energy security and independence, loss reduction and environmental benefits. For this, the concept of VPP - Virtual Power Plant is introduced, in which a better and broader use of energetic resources, geographically dispersed, including distributed microgeneration, autoproduction, cogeneration, and even nonrenewable sources, is facilitated. Those disperse energy resources, in general located near the consumer, are grouped and jointly managed, in order of to satisfy the demand requirements, using Smart Grid and Information and Telecommunication Technologies, and making the VPP to act, for the transmission or distribution system point of view, as a conventional large electrical power plant. An analysis and forecasts of the operation of the Brazilian Southeast/Center West (SE/CO) subsystem, with special focus on São Paulo State electrical system, and its interactions with the Brazilian Interconnected Electrical System (SIN), is presented.

Keywords: Electrical Power Systems. Planning. Renewable Energy Sources, Virtual Power Plants, Distributed Generation, Smart Grid. São Paulo. Wind Energy. Photovoltaic energy, sugarcane vinasse, Municipal Solid Waste. 


\section{Lista de Figuras}

Figura 1: Evolução do sistema de energia elétrica e o que se espera seja seu futuro.

Fonte: Adaptado de IEA b, 2011.

Figura 2: Comparação da estrutura de medição dos medidores convencionais e os medidores inteligentes. Fonte: Adaptado de Depuru et al., 2011

Figura 3: Domínios da rede inteligente segundo NIST. Fonte: adaptado de NISTIR 7628, 2010.

Figura 4: Exemplo de participação da usina virtual no sistema interligado de energia (J. Corera, 2006).

Figura 5: Analogia de uma usina virtual com uma usina centralizada. Fonte: Adaptado de J. Corera, 2006.

Figura 6: Tecnologias que podem conformar uma usina virtual (adaptado de El

Bakari, k. and Kling, W. L., 2010).

Figura 7: Aplicações dos SAE por beneficiário do uso. Fonte: adaptado de KoohiKamali et al., 2013.

Figura 8: Aplicações dos SAEs por tipo de benefício brindado e tempo de duração.

Fonte: adapto de EPRI.

Figura 9: Usina Virtual Centralizada. Fonte: adaptado de ADHI, E. 2007...............76

Figura 10: Usina Virtual Descentralizado. Fonte: adaptado de ADHI, E. 2007. ........77

Figura 11: Rede de distribuição de Álava, Espanha. Fonte: O. Abarratégui, J. Marti, A. González, 2009.

Figura 12: Arquitetura da Usina Virtual em demonstração em Álava (O. Abarratégui, J. Marti, A. González, 2009).

Figura 13: Incidência Solar global média por municípios e Velocidade média do vento no Verão a 100 m no Estado de São Paulo. Fonte: Adaptação de SEE, 2011 e SEE, 2012.

Figura 14: Incidência Solar global média por municípios e Velocidade média do vento no Outono a 100 m no Estado de São Paulo. Fonte: Adaptação de SEE, 2011 e SEE, 2012.

Figura 15: Incidência Solar global média por municípios e Velocidade média do vento no Inverno a $100 \mathrm{~m}$ no Estado de São Paulo. Fonte: Adaptação de SEE, 2011 e SEE, 2012.

Figura 16: Incidência Solar global média por municípios e Velocidade média do vento na Primavera a 100 m no Estado de São Paulo. Fonte: Adaptação de SEE, 2011 e SEE, 2012. 


\section{Lista de Quadros}

Quadro 1: Algumas tecnologias de geração e suas características (Pepermans, G., Driesen, J., Haeseldonckx, D., Belmans, R., D'haeseleer, W., 2005). .26 Quadro 2: Resumo de algumas tecnologias de geração e sua função no sistema (ADHI, E. 2007).... 63 Quadro 3: Ciclo de vida e eficiência de alguns sistemas de armazenamento (ADHI, E. 2007). 66 Quadro 4: Características dos Sistemas de Armazenamento de Energia. Fonte: Beaudin et al., 2010.

Quadro 5: Características dos Sistemas de Armazenamento de Energia. Fonte: Beaudin et al., 2010. 68

Quadro 6: Classificação das necessidades e requisitos de comunicação das VPP. Fonte: ADHI, E. 2007. 


\section{Lista de Tabelas}

Tabela 1: Potencial de geração de energia eólica a $100 \mathrm{~m}$ de altura por faixa de velocidade. Fonte: SEE, 2012. 116

Tabela 2: Potencial de produção de eletricidade com a vinhaça por meio da biodigestão a fluxo ascendente. Fonte: Elaboração própria com dados de SEE, 2011, ÚNICA e PPE 2020 124

Tabela 3: Aproveitamentos energéticos de RSU. Fonte: PPE 2020, McCallum, D., 2011, Korai et al 2014 e The World Bank, 1999.

Tabela 4: População e volume de RSU gerado nas principais regiões metropolitanas do Estado de São Paulo. Fonte: SEE, 2011.

Tabela 5: Potencial de geração de eletricidade através da incineração do RSU das principais regiões metropolitanas do ESP. Fonte: Elaboração própria. 


\section{Lista de Gráficos}

Gráfico 1: Evolução da carga de energia do SIN por subsistemas. Fonte: Elaboração própria com dados da ONS.

Gráfico 2: Evolução da geração de eletricidade por tipo de geração e participação do SE/CO na geração do SIN. Fonte: Elaboração própria com dados da ONS. 90 Gráfico 3: Carga de energia e Geração de energia no SE/CO 2009 -2014. Fonte: Elaboração própria com dados do ONS.

Gráfico 4: Balanço de intercâmbio de energia nos subsistemas. Fonte: Elaboração própria com dados da ONS.

Gráfico 5: Porcentagem de perdas na rede básica de energia no ano 2012. Fonte: Elaboração própria dados CCEE.

Gráfico 6: Porcentagem de perdas na rede básica por subsistemas ano 2012: Fonte: elaboração própria com dados do CCEE.

Gráfico 7: Porcentagem de perdas na rede básica de energia do subsistema SE/CO por patamar de carga no ano 2012. Fonte: Elaboração própria com dados da CEEE.

Gráfico 8: Balanço de garantia física SE/CO + Itaipu. Fonte: Adaptado do PDE 2023.

Gráfico 9: Balanço de garantia física de $\mathrm{SE} / \mathrm{CO}+$ Itaipu+ AC/RO + T. Pires + Tapajós. Fonte: Adaptado do PDE 2023.

Gráfico 10: Distribuição dos fluxos de energia na interligação Imperatriz $\rightarrow$ SE/CO (MWmed) - curvas de permanência. Fonte: Adaptado de PDE 2022. .99 Gráfico 11: Intercambio da interligação Imperatriz- SE/CO para os períodos úmido e seco. Fonte: PDE2022. 100

Gráfico 12: Necessidades de uso das interligações no horário de ponta. Fonte: Adaptado de PDE 2022. 101 Gráfico 13: Uso da interligação Imperatriz - SE/CO versus os excedentes de potência no SUL. Fonte: PDE 2022. 102 Gráfico 14: Energia elétrica disponível para consumo no estado de São Paulo. Fonte: Adaptado do BEESP, 2014.

Gráfico 15: Evolução mensal da geração, importação e consumo de energia do Estado de São Paulo. Fonte: Elaboração própria com dados da SEE. 105 Gráfico 16: Evolução da participação da cogeração com gás natural no ESP. Fonte: Adaptado de PPE 2020. 108

Gráfico 17: Projeção do balanço energético do ESP de acordo ao cenário provável. Adaptado de PPE 2020. 109 Gráfico 18: Projeção da evolução da carga por patamar no ESP. Fonte: Adaptado de PDE 2023 com dados da EPE.

Gráfico 19: Projeção da origem da energia importada pelo Estado de São Paulo. Fonte: Adaptado de PPE 2020.

Gráfico 20: Projeção do destino das exportações de energia do ESP. Fonte: adaptado de PPE 2020. 
Gráfico 21: Resultado 1. Potencial de geração das fontes fotovoltaicas, eólica, incineração de RSU e geração de biogás com vinhaça. Fonte: Elaboração própria. 129

Gráfico 22: Comparação do levantamento do potencial do Gráfico 21, importações 2013 e possibilidade de importação 2023. Fonte: Elaboração própria. 131 Gráfico 23: Resultado 2: Potencial de geração das fontes fotovoltaicas, eólica, incineração de RSU e geração de biogás com vinhaça. Fonte: Elaboração própria. 133

Gráfico 24: Comparação do levantamento do potencial do Gráfico 23, importações 2013 e possibilidade de importação 2023. Fonte: Elaboração própria 135 


\section{Abreviaturas e acrônimos}

BAN: Building Area Network

CAES: Compressed Air Energy Storage

CCC: Centro de Coordenação de Controle

CDC: Controlador Direto da Carga

CGD: Controlador de Geração Distribuída

CIM: Common Information Model

DEMS: Distributed Energy Management System

DER: Distributed Energy Resources

DMA Direct Memory Access

DMT: Distribution Management Tool

DR: Demand Response

DSR: Demand Side Response

EMS: Energy Management System

EPS: Electric power System

ESP: Estado de São Paulo

FENIX: Flexible Electricity Network to Integrate the eXpected energy evolution

FB: FENIX Box

GD: Geração Distribuída

GDD: Gerador Distribuído Doméstico

GDP: Gerador Distribuído Público 
GPRS: General Packet Radio System

HAN: Home Area Network

HESS: Hydrogen-Based Energy Storage System

IAN: Industrial Area Network

ICCP: Inter Control Center Communication Protocol

ICT: Information and Communication Technologies

IEC: International Electrotechnical Commission

LC: Local Controller

LSVPP: Large Scale Virtual Power Plant

MARS: Multiple Address Radio System

MVA: Megavolt ampère (potência aparente)

Mvar: Megavar (potência reativa)

MW: Megawatt $=10^{6}$ watts (potência ativa)

MWh: Megawatt hora $=10^{6}$ watts por hora (energia)

$\mathrm{MWh} / \mathrm{h}$ : Megawatt hora por hora (potência média na hora)

MWmed: Megawatt médio $-1 \mathrm{MWmed-ano}=8.760 \mathrm{MWh} /$ ano (energia média no intervalo de tempo considerado)

MWmês: Megawatt mês $-1 \mathrm{MW} /$ mês $=720 \mathrm{MWh} /$ mês (medida de armazenamento)

NSM: Network Safety Management Systems

PHS: Pumped Hydro system

PLC: Power Line Communication

RAD: Rede Ativa de Distribuição

RSU: Resíduos Sólidos Urbanos 
SAE: Sistema de Armazenamento de Energia

SAS: Substation Automation System

SCADA: Supervisory Control and Data Acquisition

SCL: Substation Configuration Description Language

SG: Smart Grid

SGE: Sistema de Gestão de Energia

SIN: Sistema Interligado Nacional

SMES: Superconducting Magnetic Energy Storage

TI: Tecnologia da Informação

UNICA: UNião da Industria de Cana e Açucar

UVC: Usina Virtual Comercial

UVT: Usina Virtual Técnica

VBR: valve battery regulated

VPP: Virtual Power Plant

VVC: Volt VAR Control 


\section{Sumário}

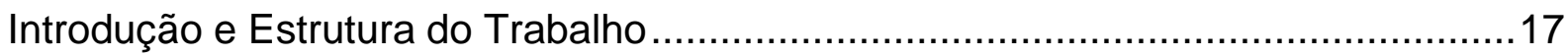

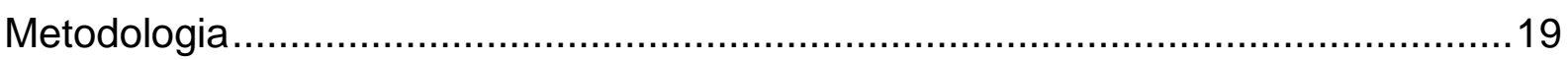

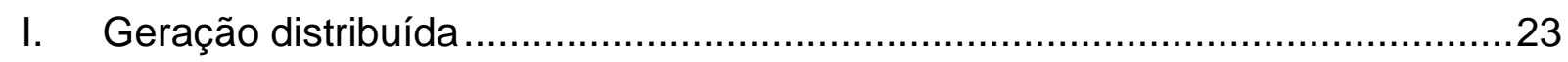

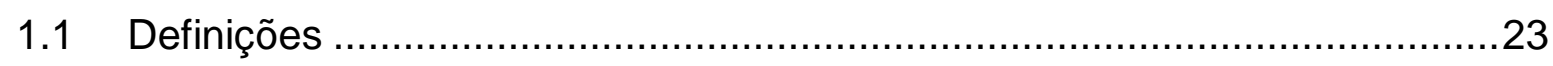

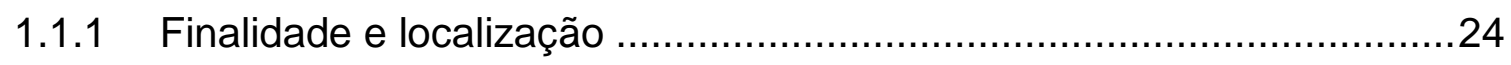

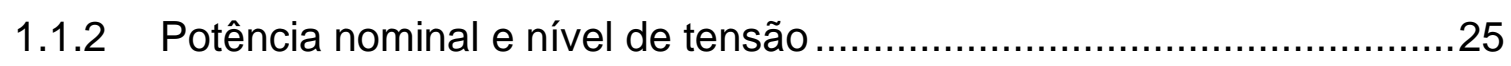

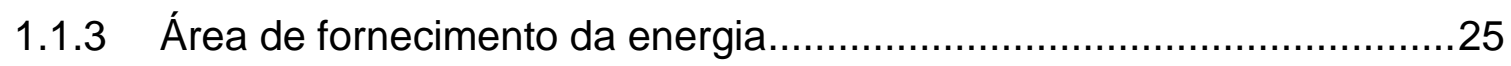

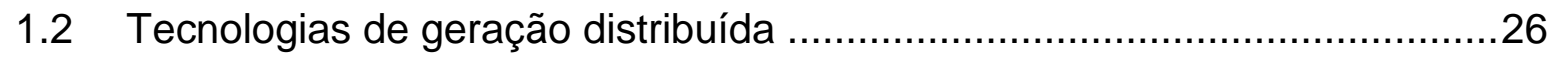

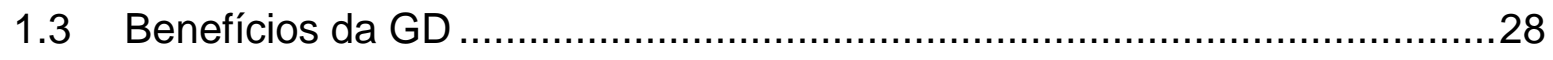

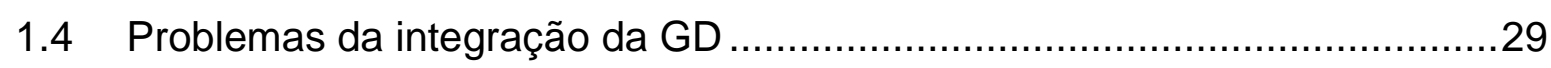

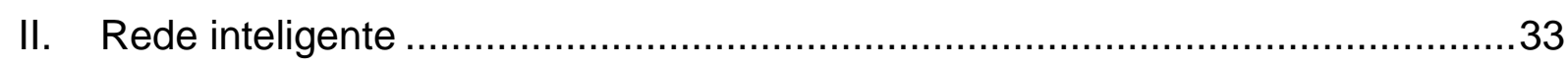

2.1 Medição (AMI Advanced Metering Infrastructure) ….................................36

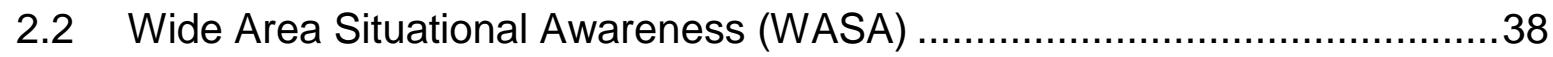

2.3 Integração de tecnologias de Comunicação .............................................39

2.3.1 Redes com tecnologias sem fio: ........................................................

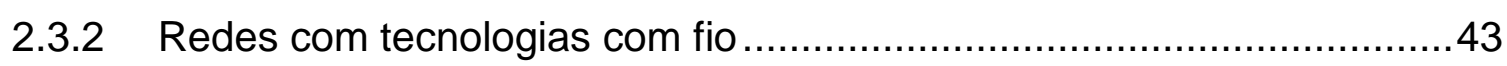

2.3.3 Worldwide Interoperability for Microwave Access (WiMAX) .................46

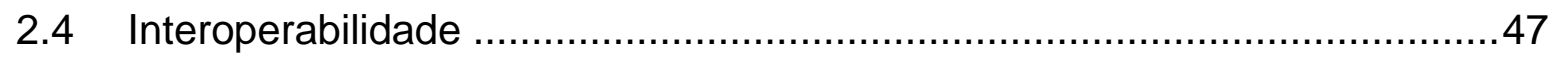

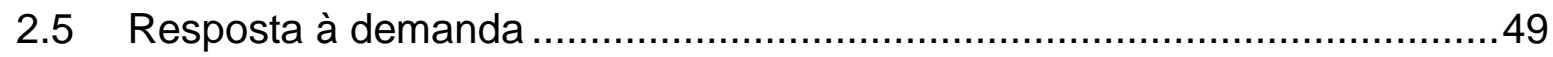

2.6 Considerações de segurança e privacidade em SG .................................53

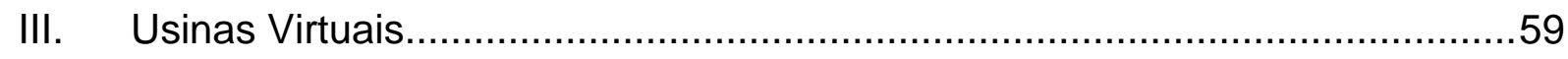

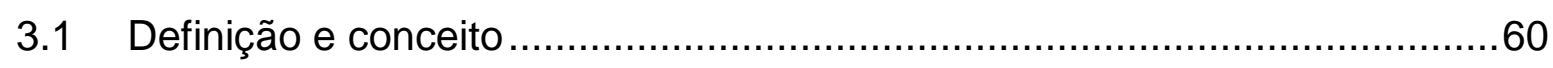

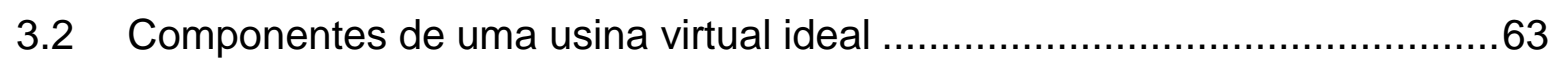

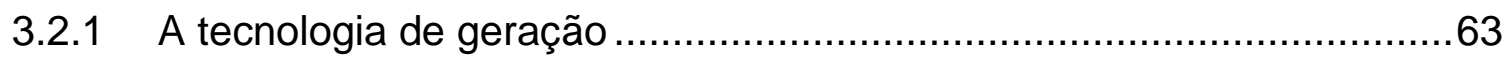

3.2.2 Tecnologias de armazenamento de energia.......................................65

3.2.3 Aplicações dos sistemas de armazenamento de energia (SAE) ............69

3.2.4 Tecnologias de comunicação da informação........................................74

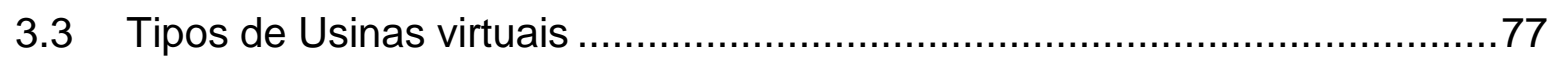

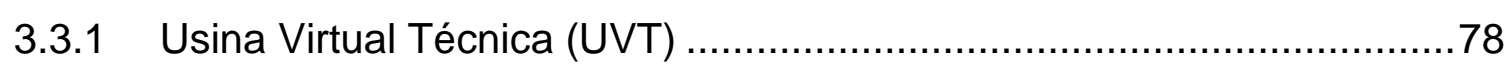

3.3.2 Usina Virtual Comercial (UVC) ……….......................................

3.4 Algumas experiências de aplicação das usinas virtuais na Europa ..............81

3.4.1 O projeto FENIX, demonstração de Usinas virtuais.................................81 
3.4.2 Usina virtual de RWE Energy e Siemens na Alemanha .......................85

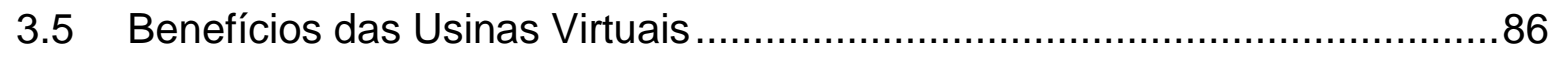

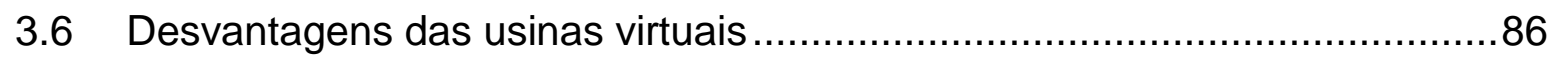

3.7 Considerações sobre a utilização das usinas virtuais .................................87

IV. Histórico e projeções da operação do subsistema Sudeste/Centro Oeste

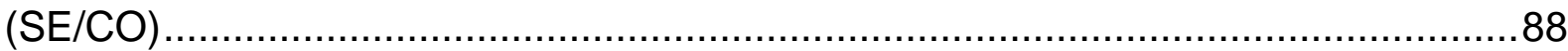

4.1 Histórico de operação do sistema elétrico do subsistema SE/CO ...............88

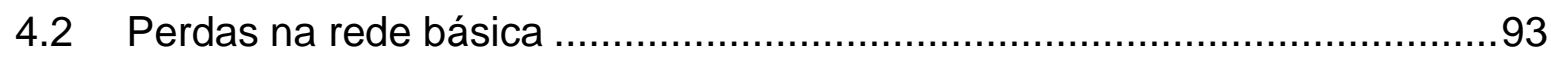

4.3 Projeções do atendimento do subsistema SE/CO ……............................96

4.4 Sistema Elétrico do Estado de São Paulo .............................................102

4.4.1 Histórico de operação do sistema do Estado de São Paulo .................103

4.4.2 Projeção do mercado de energia elétrica no ESP ..............................106

V. Estimativas dos potenciais de geração por fontes renováveis pouco convencionais no Estado de São Paulo ...................................................115

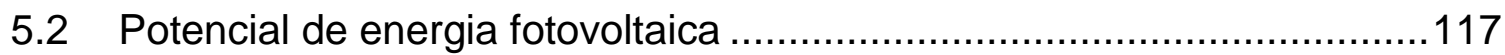

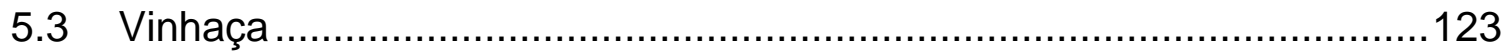

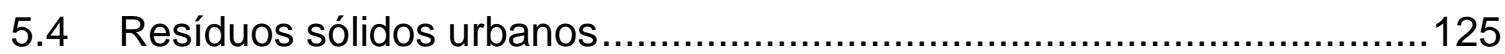

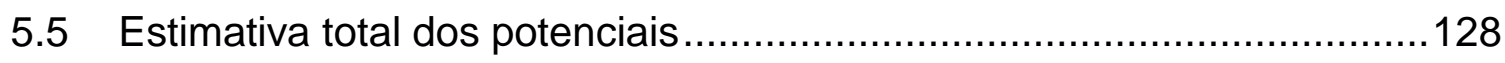

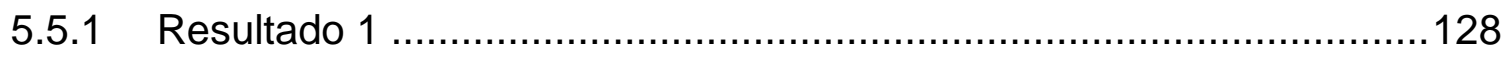

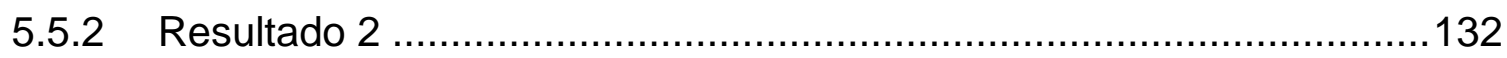

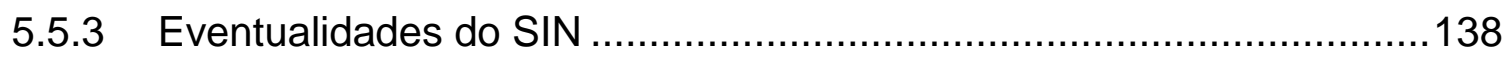

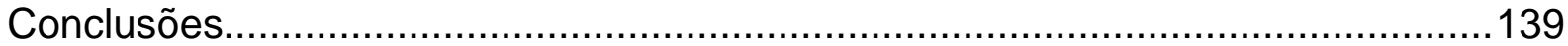

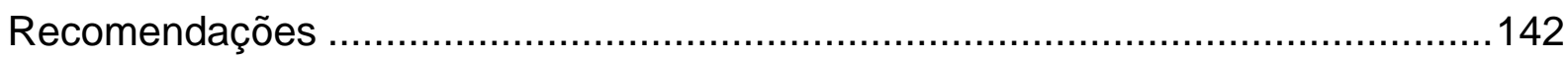

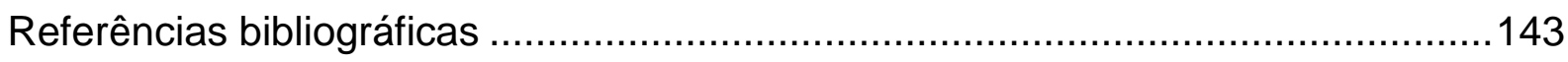

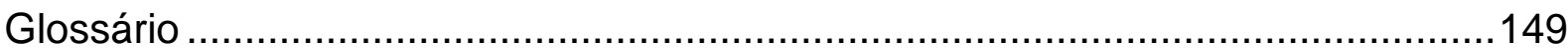




\section{Introdução e Estrutura do Trabalho}

A crescente demanda de energia vem impondo profundas mudanças no setor elétrico, provocadas essencialmente, pelo desequilíbrio entre oferta e demanda. Os recursos naturais viáveis aos grandes empreendimentos hidrelétricos ou termoelétricos estão sob o foco das preocupações relativas às consequências ao meio ambiente, ocorrendo o mesmo com a implementação de usinas nucleares.

Essas mudanças vêm sendo impulsionadas pela crescente tendência, em médio e longo prazo, da incorporação à rede elétrica de volumes significativos de energia oriunda de novas fontes renováveis, quase sempre de natureza temporal intermitente ou sujeitas a forte sazonalidade, a exemplo da geração fotovoltaica e eólica, as quais exigem maior flexibilidade e agilidade no controle dos fluxos de potência ativa e reativa nessas redes elétricas. Essas mudanças exigem adaptações da antiga infraestrutura tecnológica existente, composta principalmente por sistemas de controle e de monitoramento com tecnologia eletromecânica (quando existentes), os quais estão sendo substituídos pelos sistemas de medição e controle eletrônicos digitais, associados aos recursos de telecomunicação bidirecional e processamento de dados.

A tendência ao aumento da participação das novas fontes alternativas renováveis intermitentes está transformando o setor elétrico, nos segmentos da Geração, pela incorporação da capilaridade da geração distribuída instalada mais próxima aos pontos de consumo; na Transmissão, pela necessidade do controle dos fluxos de potência de forma mais ágil; na Distribuição, agora incorporando fluxos de potência bidirecionais e sujeita a problemas adicionais de qualidade de tensão; na Comercialização de Energia, pela diversidade de tipos e portes das fontes renováveis;e nos Consumidores, pela possibilidade da autoprodução e venda dos excedentes.

As usinas virtuais (VPP - Virtual Power Plant, no inglês) abordadas neste trabalho encontram-se ainda em nível experimental, de plantas piloto e plantas demonstração, notadamente na Europa, mas podem futuramente constituir-se numa resposta, ou num incentivo, ao desafio de viabilizar técnica e economicamente a 
inserção das fontes renováveis não convencionais, incluindo nesse rol a microgeração distribuída, a autoprodução e cogeração, e mesmo fontes não renováveis.

O propósito das usinas virtuais é obter um melhor e maior aproveitamento dos recursos energéticos normalmente dispersos espacialmente (e encontrados perto dos centros de consumo), com o objetivo principal de coordenar o seu funcionamento conjunto para satisfazer os requisitos da demanda de energia. $A$ partir de uma configuração que vise o menor custo de geração ou a menor produção de gases de efeito estufa de maneira a atuar, no que diz respeito ao sistema interconectado de energia elétrica ou rede de transmissão, como se fosse uma planta de geração de grande porte.

Este trabalho apresenta os conceitos associados às usinas virtuais, e um levantamento das tecnologias associadas, emergentes em muitos casos. Essas tecnologias são comumente associadas, também, às redes inteligentes (smart grid). Esta dissertação está estruturada em tópicos, onde no Capítulo I são apresentados conceitos sobre geração distribuída, no Capítulo II abordam-se as redes inteligentes, e no Capítulo III desenvolvem-se conceitos sobre as usinas virtuais.

O Capítulo IV apresenta uma análise da operação e do suprimento do subsistema Sudeste/Centro Oeste (SE/CO), e do Sistema Elétrico do Estado de São Paulo, com suas interações com o SIN.

O Capítulo V apresenta uma contribuição desta dissertação aos estudos de planejamento do sistema elétrico do Estado de São Paulo, com base em dados históricos e em projeções, dos intercâmbios de energia e potência com o SIN, na forma de um exercício teórico conceitual dos benefícios que se obteria, com uma maior contribuição das fontes renováveis à matriz elétrica do estado de São Paulo, notadamente quanto aos aspectos da segurança energética, redução de perdas, e benefícios ambientais, baseado em estimativas dos potenciais das fontes renováveis não convencionais, e nos intercâmbios de potência/energia do estado de São Paulo com o SIN - Sistema Interligado Nacional.

Nas Conclusões, são apresentados os resultados, comentários, recomendações e propostas de trabalhos futuros associados. 


\section{Metodologia}

O trabalho se divide em três partes. Inicialmente se realizou um levantamento do estado da arte das redes inteligentes e os seus componentes, assim como das tecnologias referentes à geração distribuída e os benefícios e desvantagens que podem apresentar o uso desse tipo de geração inserida nas redes ao seguir 0 enfoque de fit and forget.

A pesquisa continua com a revisão bibliográfica de usinas virtuais e apresentação de alguns casos de estudo de projetos em demonstração das usinas virtuais implementados na Europa, além dos principais benefícios e considerações ao se implementar uma usina virtual.

Continuou-se com a análise do histórico de operação do subsistema Sudeste/Centro Oeste (SE/CO) -geração, consumo e intercâmbios de energia entre subsistemas-, bem como com a apresentação das projeções de operação e atendimento do subsistema. A seguir se faz uma análise mais específica do histórico e projeções de operação do Estado de São Paulo (ESP), em que é possível observar que o crescimento da oferta não acompanha nem está projetado para acompanhar o crescimento da demanda e que, portanto, será necessário o aproveitamento de outros potenciais de geração existentes no ESP ou um grande crescimento em geração em outros subsistemas e no sistema de transmissão para conseguir o atendimento adequado da sua carga.

Finalmente, na terceira parte se realiza a estimativa dos potenciais de geração existentes no ESP e os efeitos que os aproveitamentos desses potenciais terão no atendimento da demanda de energia e a segurança do subsistema SE/CO e inclusive do SIN.

Nesse ponto foi realizado o levantamento de quatro fontes de geração de energia elétrica presentes no ESP, os que foram escolhidos pela disponibilidade de dados dos seus potenciais. Essas fontes de geração são: 


\section{Eólica}

Os dados do potencial de geração de energia eólica foram obtidos do Atlas Eólico do Estado de São Paulo publicado no ano 2012 pela Secretaria de Energia, considerando a instalação de aerogeradores de eficiência padrão a uma altura de 100 m. As variações estacionais no potencial de geração foram obtidas através da observação dos mapas de variação da velocidade do vento por estação do ano. Foram consideradas duas possibilidades de aproveitamento do recurso: em parques eólicos, para os que é recomendável um fator de capacidade maior a $30 \%$, e o aproveitamento com usinas virtuais, que facilitará a inserção de parques com fatores de capacidade menores a $30 \%$

\section{Fotovoltaica}

O potencial que foi considerado economica e tecnicamente viável para o seu aproveitamento com células fotovoltaicas de silício é aquele em que existe radiação solar anual incidente 5,61 - 5,70 kWh/(m².dia), (SEE, 2013). A estimativa da variação por estações do ano foi obtida através da observação dos mapas de incidência solar por estação do ano.

\section{Vinhaça}

Considerou-se a produção de etanol total obtida na safra 2012-2013 apresentando as possibilidades de obtenção de vinhaça por tipo de processo de obtenção de etanol, do qual depende a quantidade de vinhaça produzida, a obtenção do potencial de geração de energia se obtém da relação: $1 \mathrm{~m}^{3}$ de vinhaça é capaz de produzir 0,015 MWh. As projeções de potencial de geração para os anos 2020 e 2035 foram obtidos através da projeção de expansão de produção de etanol do cenário base de SEE, 2011, com a estimativa de produção de etanol para esses anos, foi considerado depois o método de produção do etanol e o volume de vinhaça a ser obtido que foi multiplicado pela relação $0,015 \mathrm{MWh} /\left(1 \mathrm{~m}^{3}\right.$ de vinhaça). 


\section{Resíduos Sólidos Urbanos (RSU)}

Para obter o potencial de geração através da incineração de RSU foram consideradas as seguintes premissas:

a. Segundo Fundap, 2010, o crescimento econômico da Região Metropolitana de Campinas (RMC), acompanhará o crescimento geral do Brasil com uma projeção de crescimento anual do PIB de $3,8 \%$, maior que o crescimento esperado para o estado de São Paulo de $3,5 \%$ ao ano, de acordo com o cenário base apresentado na Matriz 2035. Portanto, para a RMC será usado a projeção de crescimento do PIB igual a $3,8 \%$ por ano e para as regiões metropolitanas de São Paulo e a Baixada Santista será usado o crescimento do PIB esperado para o estado todo, ou seja, 3,5\%.

b. As estimativas de crescimento populacional foram obtidas das projeções do SEADE até 2030, a estimativa de crescimento para 2035 foi estimada com a mesma porcentagem de crescimento do quinquênio anterior.

c. O índice de geração de RSU per capita é obtido a partir da seguinte fórmula apresentada em SEE, 2011:

$$
\mathrm{RGpc}_{i+1}=\mathrm{RGpc}_{i}{ }^{*}\left(1+\mathrm{txPIBpc}_{i}\right) \text {, donde: }
$$

- RGpc representa a quantidade de lixo per capita ( $\mathrm{kg} / \mathrm{hab}$ por ano)

- txPIBpc representa a taxa de crescimento anual do PIB per capita (\%) determinada a partir dos cenários econômicos.

E

txPIBpci $=\frac{\% \Delta P I B_{i+1}-\% \Delta P o p_{i+1}}{1+\% \Delta P o p_{i+1}}$

Em que: 
- $\% \Delta \mathrm{PIB}_{i+1}$ é a porcentagem de crescimento do PIB do ano i+1 em relação ao ano i, e

- $\quad \% \triangle P O P P_{i+1}$ é a porcentagem de crescimento da população do ano i+1 em relação ao ano $i$.

Fazendo o uso do índice de geração de RSU per capita obtido para cada região metropolitana no ano 2010 e considerando as projeções do crescimento do PIB e da população para cada região -dados obtidos da SEADE-, é possível obter a quantidade de RSU total que é gerado nas regiões metropolitanas escolhidas.

Finalmente, apresenta-se a consolidação de dois resultados que propõem o aproveitamento dos potenciais calculados para o ano 2035. Esses resultados foram obtidos tendo em consideração a variação de aproveitamento dos potenciais de geração eólica e compará-los, com o objetivo de demonstrar a importância que esses aproveitamentos terão, com as importações realizadas em 2013 e a estimativa de importação de energia calculada já para o ano 2023. Espera-se evidenciar, com esses resultados, a necessidade de criar atrativos, de forma suficientemente antecipada, para despertar o interesse de investidores na realização desses aproveitamentos, e motivar o poder público a criar incentivos para impulsar -ainda mais- as energias renováveis e de dar tempo para a instalação das usinas, assim como, da maior implementação das redes inteligentes no sistema elétrico do ESP. 


\section{Geração distribuída}

A integração da geração distribuída é um dos principais agentes para realizar importantes mudanças dentro dos sistemas de distribuição de energia, para o estabelecimento de uma rede ativa e de uma rede inteligente.

Neste capítulo são apresentadas definições de geração distribuída, tecnologias, possíveis problemas de integração, benefícios deste tipo de geração, e normas que fomentarão a expansão da integração da GD nos sistemas de energia.

A crescente preocupação com as interrupções de longa duração, e as penalizações impostas aos operadores das redes de distribuição, impõem ações para o aumento da confiabilidade no suprimento. Isso pode ser alcançado com maiores investimentos na automação da distribuição, de forma a torná-la mais ativa. Por exemplo, a melhoria nos métodos de localização de faltas, e o posicionamento e operação mais inteligentes das chaves de manobra através da rede de distribuição pode reduzir as interrupções no fornecimento.

\subsection{Definições}

Ainda que a idéia da geração distribuída não seja um conceito novo, até agora não há uma definição única do que seja a geração distribuída, embora existam várias definições que têm sido usadas para distinguir a geração distribuída - também chamada de recursos distribuídos - da geração de energia centralizada. A seguir apresentam-se algumas definições encontradas na literatura:

- Segundo IEADSM-Task XVII é a geração de energia de baixa capacidade conectada na rede de transmissão ou distribuição incluindo fontes renováveis e unidades de cogeração. A definição de baixa capacidade geralmente varia entre $1 \mathrm{e}$ 50 MW. Também conhecida como DER.

- Na norma IEEE 1547 define-se a GD como a geração de eletricidade por plantas significativamente menores do que as plantas de geração centralizada, usualmente 
$10 \mathrm{MW}$ ou menos, o que estima-se suficiente para permitir a sua interconexão em quase qualquer ponto do sistema de energia.

Os principais aspectos a serem considerados na definição de geração distribuída segundo EUR 23234 EN, 2007, são:

- Finalidade e localização

- Potência nominal e nível de tensão

- Área de fornecimento da energia

\subsubsection{Finalidade e localização}

A finalidade da GD é proporcionar uma fonte de energia elétrica; esse é o mesmo objetivo das grandes geradoras centralizadas. A potência de uma rede é composta pela potência ativa e potência reativa. Todas as tecnologias de geração de GD geram potência ativa e várias produzem também potência reativa.

Como o principal conceito que fundamenta a GD é a localização da geração perto da carga, considera-se que a GD será conectada diretamente na rede de distribuição ou no lado do cliente do medidor. Isto possui como requisito, portanto, uma distinção clara entre os sistemas de transmissão e distribuição. Em termos gerais, de acordo com a Diretiva Europeia 2003/54/EC, a transmissão pode ser definida como o transporte de energia elétrica no sistema interconectado em extra-alta tensão e em alta tensão com vistas à sua entrega aos consumidores finais ou aos distribuidores, mas não incluindo o fornecimento. De outra maneira, a distribuição é definida como o transporte de energia em alta, média e baixa tensão com vistas à sua entrega aos consumidores finais mas não incluindo o fornecimento.

A distinção entre o sistema de transmissão e distribuição pode também ser baseado em características técnicas ou em bases legais, de acordo com o sistema e o país onde se quer aplicar o conceito. 


\subsubsection{Potência nominal e nível de tensão}

Neste trabalho a potência máxima injetada pela GD em um ponto de conexão é avaliada em termos de sua potência ativa líquida (MW). Essa potência líquida resulta da diferença nodal entre a produção de potência da GD e a carga que alimenta (no caso de haver uma carga interna), que também é conhecida como capacidade nodal agregada de uma instalação da GD.Tal nível de potência depende da capacidade da rede e, portanto, do nível de tensão do sistema de distribuição, o qual varia de acordo com o sistema de cada país. Neste sentido, não é possível estipular uma potência líquida máxima, embora diversas categorias de GD tenham sido propostas, geralmente variando de alguns $\mathrm{kW}$ a dezenas de MW.

Atualmente, as redes de distribuição na Europa geralmente conectam unidades de geração com capacidades de até 20-30 MW, se a capacidade líquida é maior a conexão é gerida pela companhia de transmissão. No entanto, já existem iniciativas para a inclusão de unidades de até $50 \mathrm{MW}$.

\subsection{3 Área de fornecimento da energia}

Em alguns casos, a área de fornecimento da geração distribuída é considerada como a rede de distribuição na qual se encontra conectada - ou parte dela -, onde toda a energia gerada pela GD é entregue. Isto se deve ao fato de que a GD destina-se, em geral, ao uso próximo ao ponto de geração. No entanto, esse conceito de área de fornecimento representa uma restrição para aplicação da geração distribuída por não considerar a possibilidade de exportar a energia produzida pela GD para o sistema de transmissão - por exemplo, no caso de uma demanda local baixa. Esse suporte que a GD pode proporcionar à rede de transmissão é um fator chave na implementação da GD nos sistemas de energia elétrica. Ademais, uma análise complexa do fluxo de energia nas redes de distribuição será necessária para uma definição precisa da área de fornecimento.

Por estas razões, a área de fornecimento de energia deve ser considerada dependendo do caso e dependendo também do nível de penetração de cada tecnologia de geração distribuída presente na rede. Em alguns países a noção de área de fornecimento de energia é um limite fixado para a máxima quantidade de 
unidades modulares (por exemplo, turbinas eólicas) que podem se conectar a um determinado ponto da rede de distribuição.

\subsection{Tecnologias de geração distribuída}

Embora as tecnologias de geração não sejam estritamente relevantes e específicas para o uso único em geração distribuída, apresenta-se no Quadro 1 um resumo das tecnologias de geração com algumas de suas características.

Quadro 1: Algumas tecnologias de geração e suas características (Pepermans, G., Driesen, J., Haeseldonckx, D., Belmans, R., D'haeseleer, W., 2005).

\begin{tabular}{|c|c|c|c|c|c|c|}
\hline & $\begin{array}{l}\text { Informação } \\
\text { Geral }\end{array}$ & $\begin{array}{l}\text { Faixa de } \\
\text { Aplicação }\end{array}$ & $\begin{array}{c}\text { Eficiência de } \\
\text { conversão } \\
\text { elétrica }\end{array}$ & Aplicação & Combustível & Comentários \\
\hline \multirow{6}{*}{$\begin{array}{l}\text { Células } \\
\text { Combustíveis }\end{array}$} & $\begin{array}{l}\text { Carbonatos } \\
\text { fundidos: } \\
\text { MCFC }\end{array}$ & $\begin{array}{l}50 \mathrm{~kW}_{\mathrm{e}}-1+ \\
\mathrm{MWe}(\mathrm{IEA})\end{array}$ & 35-60\% (IEA) & $\begin{array}{l}\text { PEMFC: } \\
\text { Aplicações de } \\
\text { baixa temperatura } \\
\text { em transporte e } \\
\text { uso estacionário }\end{array}$ & Metanol & \\
\hline & $\begin{array}{l}\text { Membrana de } \\
\text { intercâmbio } \\
\text { de prótons: } \\
\text { PEMFC }\end{array}$ & $\begin{array}{c}\text { PAFC: } \\
200 \mathrm{~kW}_{\mathrm{e}}-2 \mathrm{MW} \\
\mathrm{e}\end{array}$ & $\begin{array}{c}\text { MCFC: } \pm 50-55 \% \\
\text { (IEA) }\end{array}$ & $\begin{array}{l}\text { MCFC: Alta } \\
\text { temperatura }\end{array}$ & $\begin{array}{l}\text { Hidrogêno ou gás } \\
\text { natural. A reforma } \\
\text { de } \mathrm{CH}_{4} \text { em } \mathrm{H}_{2} \text { leva } \\
\text { a uma diminuição } \\
\text { na eficiência }\end{array}$ & \\
\hline & $\begin{array}{l}\text { Óxido Sólido: } \\
\text { SOFC }\end{array}$ & $\begin{array}{c}\text { MCFC: } \\
250 \mathrm{~kW}_{\mathrm{e}}-2 \mathrm{MW} \\
\mathrm{e}\end{array}$ & $\begin{array}{l}\text { PAFC: } \pm 35 \% \\
\text { (IEA) }\end{array}$ & $\begin{array}{l}\text { O setor de } \\
\text { transporte é o } \\
\text { mercado com } \\
\text { maior potencial }\end{array}$ & & \\
\hline & $\begin{array}{l}\text { Ácido } \\
\text { Fosfórico: } \\
\text { PAFC }\end{array}$ & $\begin{array}{c}\text { PEMFC: } \\
1 \mathrm{~kW}_{\mathrm{e}}-250 \mathrm{~kW} \\
\mathrm{e}(\mathrm{A})\end{array}$ & $\begin{array}{l}\text { PEMFC: } \pm 35 \% \\
\quad \text { (IEA) }\end{array}$ & $\begin{array}{l}\text { SOFC: Altas } \\
\text { temperaturas }\end{array}$ & & \\
\hline & $\begin{array}{l}\text { Metanol } \\
\text { Direto: DMFC }\end{array}$ & $\begin{array}{c}\text { SOFC: } \\
1 \mathrm{~kW}_{\mathrm{e}}-5 \mathrm{Mwe} \\
\text { (A) }\end{array}$ & $\begin{array}{c}\text { SOFC: } \pm 50-55 \% \\
\text { (IEA) }\end{array}$ & $\begin{array}{l}\text { A aplicação com } \\
\text { maiores } \\
\text { possibilidades } \\
\text { imediatas é a } \\
\text { geração de } \\
\text { energia }\end{array}$ & & \\
\hline & $\begin{array}{l}\text { Apenas PAFC } \\
\text { encontra-se } \\
\text { comercialmen } \\
\text { te disponível }\end{array}$ & & $\begin{array}{l}\text { Em aplicações } \\
\text { de pequena } \\
\text { escala: } 25 \%\end{array}$ & Cogeração, UPS & & \\
\hline
\end{tabular}

Continua... 
Continuação

Quadro 1: Algumas tecnologias de geração e suas características (Pepermans, G., Driesen, J., Haeseldonckx, D., Belmans, R., D'haeseleer, W., 2005)

\begin{tabular}{|c|c|c|c|c|c|c|}
\hline & $\begin{array}{l}\text { Informação } \\
\text { Geral }\end{array}$ & $\begin{array}{l}\text { Faixa de } \\
\text { Aplicação }\end{array}$ & $\begin{array}{l}\text { Eficiência de } \\
\text { conversão } \\
\text { elétrica } \\
\end{array}$ & Aplicação & Combustível & Comentários \\
\hline \multirow[b]{2}{*}{$\begin{array}{l}\text { Motores } \\
\text { Alternados }\end{array}$} & & $\begin{array}{c}\text { Diesel: } 20 \mathrm{~kW}_{\mathrm{e}}- \\
10+\mathrm{MW}_{\mathrm{e}}(\mathrm{IEA})\end{array} \mid$ & $\begin{array}{c}\text { Diesel: } \\
36 \%-43 \% \text { (IEA) }\end{array}$ & $\begin{array}{l}\text { Serviços de } \\
\text { emergência e } \\
\text { disponibilidade }\end{array}$ & $\begin{array}{l}\text { Diesel, óleo } \\
\text { combustível pesado } \\
\text { e também biodiesel }\end{array}$ & \multirow{2}{*}{$\begin{array}{l}\text { É a tecnologia mais } \\
\text { comum com } \\
\text { capacidades abaixo } \\
\text { de } 1 \mathrm{MWe}\end{array}$} \\
\hline & & $\begin{array}{c}\text { Gás: } \\
5 \mathrm{~kW}_{\mathrm{e}}-5+\mathrm{MW}_{\mathrm{e}}( \\
\mathrm{IEA})\end{array}$ & $\begin{array}{c}\text { Gás: } 28 \%-42 \% \\
\text { (IEA) }\end{array}$ & Cogeração & $\begin{array}{l}\text { Gás, principalmente } \\
\text { gás natural, biogás } \\
\text { e também pode ser } \\
\text { usado o gás de } \\
\text { aterros sanitários }\end{array}$ & \\
\hline Turbinas a gás & & 1-20 Mwe (IEA) & $21-40 \%$ (IEA) & Cogeração & Gás, querosene & \begin{tabular}{|l} 
Unidades \\
fornecedoras de \\
energia de pico
\end{tabular} \\
\hline \multirow[t]{2}{*}{ Micro turbinas } & & $\begin{array}{c}30 \mathrm{kWe}-200 \\
\mathrm{kWe}(\mathrm{IEA})\end{array}$ & $25-30 \%$ (IEA) & $\begin{array}{l}\text { Geração de } \\
\text { energia, } \\
\text { possivelmente } \\
\text { com cogeração }\end{array}$ & $\begin{array}{l}\text { Geralmente utiliza } \\
\text { gás natural, mas } \\
\text { também se pode } \\
\text { usar gás de aterro e } \\
\text { biogás }\end{array}$ & \multirow[t]{2}{*}{$\begin{array}{l}\text { Também disponível } \\
\text { para aplicações de } \\
\text { pequena escala de } \\
\text { até }<1 \mathrm{kWe}\end{array}$} \\
\hline & & $\begin{array}{c}35 \mathrm{~kW}_{\mathrm{e}}-1 \mathrm{MW}_{\mathrm{e}} \\
\text { (A) }\end{array}$ & & & & \\
\hline \multirow[t]{2}{*}{ Fotovoltaico } & \multirow[t]{2}{*}{$\begin{array}{l}\text { Não gera } \\
\text { calor }\end{array}$} & $1+\mathrm{kW}(\mathrm{IEA})$ & Não se aplica & $\begin{array}{l}\text { Pequenas } \\
\text { aplicações } \\
\text { comerciais e } \\
\text { residenciais }\end{array}$ & Sol & $\begin{array}{l}\text { Produção não } \\
\text { previsível }\end{array}$ \\
\hline & & $20+k W(A)$ & & $\begin{array}{l}\text { Aplicações fora } \\
\text { de rede }\end{array}$ & & \\
\hline Eólicas & $\begin{array}{l}\text { on shore e off } \\
\text { shore }\end{array}$ & $\begin{array}{c}200 \text { W-3MW } \\
\text { (A) }\end{array}$ & Não se aplica & & Vento & \begin{tabular}{|l|} 
Produção \\
imprevisível, Fator \\
de Capacidade 20- \\
$30 \%$ on shore \\
\end{tabular} \\
\hline $\begin{array}{l}\text { Outras } \\
\text { renováveis }\end{array}$ & $\begin{array}{l}\text { Inclui Solar } \\
\text { térmica, PCH, } \\
\text { geotérmicas, } \\
\text { oceânicas... }\end{array}$ & & Não se aplica & & & \\
\hline
\end{tabular}

Mais informação das tecnologias de geração e as suas possíveis aplicações podem ser encontradas no El-Khattam W. e Salama M.M.A., 2004. 


\subsection{Benefícios da GD}

A geração distribuída oferece uma série de benefícios para os participantes do sistema de energia, segundo INEE (2002), esses benefícios podem ser os seguintes: Para o sistema elétrico:

- atendimento mais rápido ao crescimento da demanda (ou à demanda reprimida) por ter um tempo de implantação inferior ao de acréscimos à geração centralizada e reforços das respectivas redes de transmissão e distribuição.

- aumento da confiabilidade do suprimento aos consumidores próximos à geração local, por adicionar fonte não sujeita a falhas na transmissão e distribuição.

- redução das perdas na transmissão e dos respectivos custos, e adiamento no investimento para reforçar o sistema de transmissão.

- redução dos investimentos:

Para cogeração, inclusive as relativas às concessionárias para o suprimento de ponta, dado que este pode passar a ser compartilhado ("peak shaving").

Em certos casos, também para reservas de geração, quando estas puderem ser alocadas em comum.

- redução dos riscos de planejamento do sistema.

- aumento da estabilidade do sistema elétrico, nos casos em que haja reservas de geração distribuída constituídas por máquinas síncronas de certo porte.

Dos benefícios anteriormente listados resultam beneficiados tanto os consumidores como as concessionárias ou permissionárias. Para os cogeradores, há mais uma vantagem:

O aumento da eficiência energética, redução simultânea dos custos das energias elétrica e térmica, e possibilidade de colocação dos excedentes da primeira no mercado. 
Outro tipo de benefícios como os ambientais e econômicos também podem ser obtidos, por exemplo:

- A redução de impactos ambientais da geração, pelo uso de energia eólica ou solar e benefícios na geração térmica quando forem usados combustíveis menos poluentes (como o gás natural), ou quando houver melhor utilização dos combustíveis tradicionais e, em certos tipos de cogeração, com a eliminação de resíduos industriais poluidores;

- benefícios gerais decorrentes da maior eficiência energética obtida pela conjugação bem coordenada da geração distribuída com a geração centralizada, e das economias resultantes;

- maiores oportunidades de comercialização e de ação da concorrência no mercado de energia elétrica, na diretriz das Leis que reestruturaram o setor elétrico.

\subsection{Problemas da integração da GD}

Os problemas da integração da GD apresentados a seguir foram listados no IEEE Std 1547.2 (2008) e são referentes especialmente aos efeitos negativos que podem ser ocasionados no sistema de energia elétrica.

Coordenação imprópria dos dispositivos de proteção: As contribuições de correntes de falha dos DER podem ter um efeito negativo na coordenação dos dispositivos de proteção contra falhas na área de concessão. Esse efeito geralmente pode ser mitigado recalibrando os dispositivos de proteção afetados, mas algumas vezes pode ser necessário substituir os dispositivos de proteção na concessionária.

Dessensibilização da proteção da área de concessão: As contribuições de correntes de falha dos DER podem dessensibilizar os dispositivos de proteção da área de concessão. Esse problema aumenta ao incrementar o tamanho dos DER em relação à carga da área de concessão.

Religamento: essa prática foi projetada para restaurar o serviço aos clientes tão rápido quanto possível após uma interrupção causada por uma falha 
momentânea. Se os dispositivos de religamento da área de concessão tentam religar antes que os DER sejam separados da rede, os equipamentos da concessionária e os DER podem ser danificados.

Sobretensão dos equipamentos: Dependendo dos métodos de aterramento dos DER, estes podem causar sobretensões na área de concessão, ou causar condições de falha a terra difíceis de detectar.

Ressonância de sobretensão: Dependendo dos métodos de aterramento dos DER e das características de construção da área de concessão, os DER podem causar condições que resultem na ressonância entre transformadores (incluindo os transformadores associados aos DER) e a capacitância da área de concessão.

Harmônicos: as tecnologias DER baseadas em inversores, devido aos métodos para formar a forma de onda $\mathrm{AC}$ de $\mathrm{DC}$, produzem vários harmônicos de frequência. Se o DER cumpre com o IEEE Std 1547-2003 4.3, os harmônicos não deveriam ser um problema.

Religadores: são frequentemente instalados na área das concessionárias para minimizar o número de clientes afetados por uma falha permanente, e dispõem de dispositivos contadores da quantidade de interrupções de energia completas num determinado período de tempo. Se um DER permanecer fornecendo energia à rede durante a falha, o religador não detectará condições de tensão zero e não quantificará as ocorrências como é esperado.

Capacidade de carga do feeder: a maioria das cargas dos clientes permanecerá ligada numa área desenergizada da rede após uma queda de energia. Quando o feeder é reenergizado, muitas dessas cargas demandarão mais corrente que no seu estado normal de funcionamento, ao que se refere geralmente como Cold load pick-up. Se a área da concessionária assume um nível de penetração de DERs, e todos os DERs se encontram desligados durante a queda de energia, a capacidade de carga do feeder da área de concessão pode ser excedida quando o sistema é reenergizado. O problema é menor nos sistemas com pouca penetração de DERs, em que a concessionária projeta a rede para servir a carga conectada sem a presença dos DERs. Geralmente se converte num problema 
somente se os DERs usados na área de concessão têm uma potência de geração importante em relação à quantidade de carga.

Operação do relé de subtensão nos $D E R$ : falhas em outros feeders alimentados pelo mesmo barramento podem causar quedas de tensão nos feeders não afetados pela falha, causando operação errônea dos relés de subtensão. Esse efeito geralmente é mitigado atrasando o mecanismo de disparo por subtensão no DER afetado, porém, isso poderá afetar adversamente a capacidade do DER para detectar falhas.

Suporte de potência reativa da área de concessão: os geradores indutivos e inversores podem exigir potência reativa capacitiva da rede para suprir seus requisitos do sistema de excitação. As deficiências na potência reativa capacitiva podem causar problemas de subtensão significativos na área de concessão.

Perda de sincronismo da unidade DER: durante ou imediatamente depois das operações de liberação de falhas, o DER pode não manter a estabilidade devido a falhas em feeders adjacentes alimentados pelo mesmo barramento.

Variações de tensão na área de concessão devido aos DER: quando cargas significativas são energizadas ou desenergizadas na área de concessão, é possível que se apresentem variações de tensão consideráveis devido às mudanças na corrente de carga, essas variações podem ocorrer antes que os equipamentos de regulação de tensão possam responder. Os DER podem causar problemas similares, durante sua sincronização e desconexão, de modo que esses problemas devem ser mitigados para evitar problemas nas instalações de outros clientes.

Existem outras considerações da integração dos recursos energéticos distribuídos que são descritas e discutidas no IEEE Std 1547.2 (2008) e IEEE Std 1547 (2003).

\section{Requisitos para a inserção de DER}

Os requisitos para a inserção de um DER num sistema de potência se encontram na norma IEEE 1547-2003, a qual provê requisitos obrigatórios e recomendações de segurança para a rede e segurança das pessoas. Está focado principalmente em 
interconexões com alimentação radial. Dentre dos requisitos que devem ser cumpridos se encontram: a regulação de tensão, o aterramento do ponto de interconexão do DER com o sistema elétrico de potência, manter o sincronismo com a rede, o fato de que os DER não devem energizar a área atendida pelo sistema elétrico de potência quando estiver desenergizado, o monitoramento do seu status de funcionamento, o dispositivo de isolamento. Para os recursos distribuídos interconectados com a rede, todos os requisitos da norma IEEE 1547 necessitam serem atendidos. Ademais, a norma IEEE 2547.6-2011 fornece recomendações e orientações para os recursos distribuídos interligados nas redes. 


\section{Rede inteligente}

A definição de rede inteligente varia dentre organizações e pesquisadores. Mas eles compartilham o entendimento de que a rede inteligente necessita ser integrada com uma infraestrutura de comunicação e informação com o fim de ser mais "inteligente". Algumas das definições de rede inteligente encontradas na literatura são as seguintes:

Uma rede inteligente ou smart grid (SG) nos sistemas de energia elétrica é um tipo de rede que tenta prever e responder inteligentemente o comportamento e as ações de todos os usuários de energia elétrica nela conectados (fornecedores, consumidores e aqueles que têm essas duas funções) com o objetivo de produzir eficientemente serviços de energia elétrica confiáveis, econômicos e sustentáveis. Refere-se à aplicação da tecnologia digital no setor de energia elétrica para aprimorar a sua confiabilidade, reduzir custos, incrementar eficiência e permitir novos componentes e aplicações. (Markovic et al., 2013).

Segundo Aggarwal et al. 2010, a rede inteligente deve fornecer comunicação em ambos sentidos em conjunto com controle e sensoriamento, nos pontos entre a geração de energia e o usuário final. Portanto, é uma mistura de comunicações, software e hardware relacionados à energia. Essa mistura só será possível com a criação de uma nova arquitetura de sistemas de comunicação, integração e protocolos. A rede atual permite a comunicação num sentido, somente desde o sistema de geração aos pontos intermediários de distribuição. Isto é considerado insuficiente num sistema em que um ponto de consumo pode ser também um ponto de geração.

Segundo IEA b, 2011, uma rede inteligente é uma rede de energia elétrica que faz uso de tecnologias digitais, dentre outras tecnologias avançadas, para monitorar e gerenciar o transporte de energia de todas as fontes de geração, visando satisfazer a demanda de energia variável dos usuários finais. Uma rede inteligente coordena as necessidades e capacidades dos geradores de energia, operadores da rede, 
usuários finais e operadores do mercado de energia, com o objetivo de operar todas as partes do sistema tão eficientemente como for possível, minimizando os custos e impactos ambientais ao mesmo tempo em que se maximiza a rentabilidade, flexibilidade e estabilidade do sistema.

$\mathrm{Na}$ figura 1, mostra-se o sistema elétrico através do tempo e o futuro ao qual se espera chegar com o sistema de energia com uma integração total dos sistemas de comunicações, o que facilitará o desenvolvimento de aplicações tanto no que tange aos consumidores como no que se refere às concessionárias de energia e demais participantes do sistema.

Segundo Gaoa et al., 2012, em resumo, os requisitos desejados numa rede inteligente são:

- Medição

- Wide area situational awareness

- Integração de tecnologias da Comunicação

- Interoperabilidade

- e resposta à demanda

A seguir se faz uma breve descrição de cada um desses requisitos e o seu papel para contribuir a tornar a rede de energia em uma rede inteligente. 


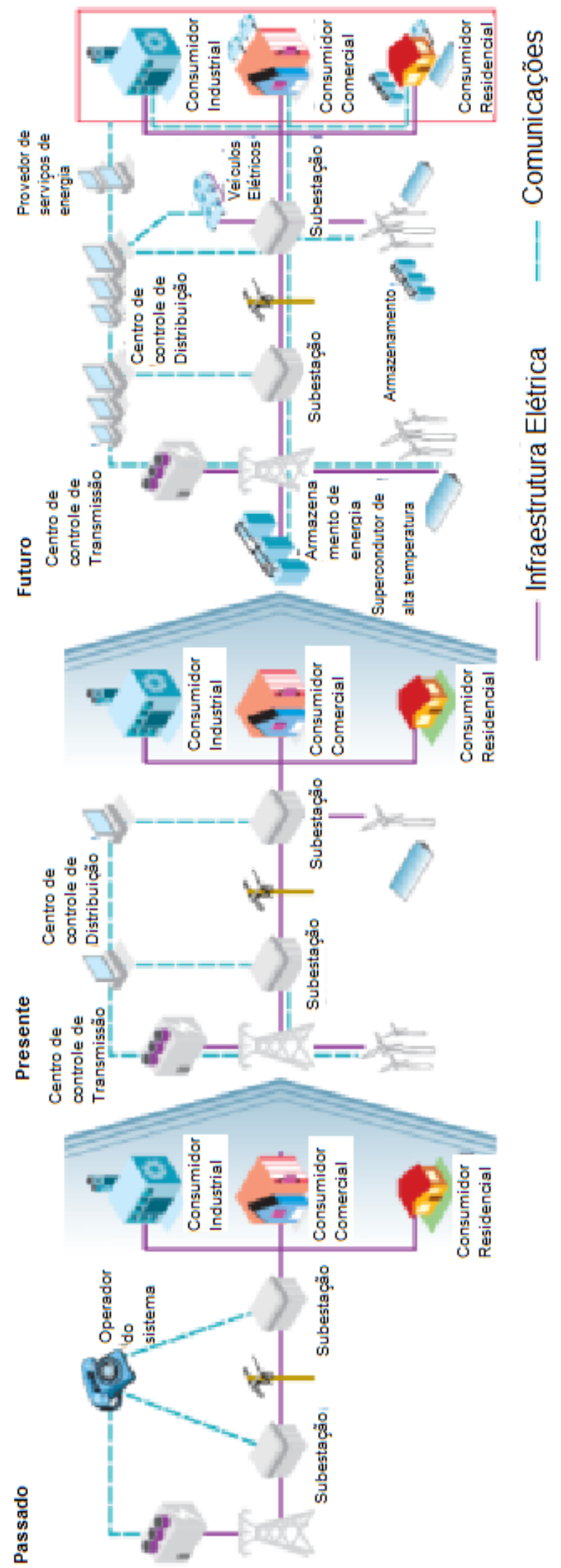

Figura 1: Evolução do sistema de energia elétrica e o que se espera seja seu futuro. Fonte: Adaptado de IEA b, 2011. 


\subsection{Medição (AMI Advanced Metering Infrastructure)}

Segundo Römer et al., 2012, a AMl inclui os medidores inteligentes (compostos de um medidor eletrônico e um gateway de comunicação) combinados com um avançado sistema de gestão da medição e infraestrutura de medição. Portanto, espera-se que as seguintes três tarefas possam ser realizadas por meio desta tecnologia: registro e medição de dados de uso de energia em tempo real, oferecimento aos clientes da possibilidade de participar em programas de resposta à demanda, e o fornecimento de dados para monitorar tensão e facilitar a prestação de outros serviços.

Um medidor inteligente é um medidor de energia avançado que mede o consumo de energia de uma forma muito mais detalhada que um medidor convencional e que, além disso, comunica a informação obtida às concessionárias para fins de monitoramento e faturamento. Os medidores inteligentes podem ler o consumo de energia em tempo real, incluindo os valores de tensão, ângulo de fase e frequência, e comunicar de forma segura esses dados. A habilidade de comunicação bidirecional de dados dos medidores inteligentes permite a coleta de informação sobre a eletricidade que é fornecida à rede pelas instalações dos clientes. Os medidores inteligentes podem comunicar e executar comandos de controle remotamente bem como localmente, também podem ser utilizados para monitorar e controlar as aplicações e dispositivos do lado do cliente. São capazes de coletar informação de diagnóstico da rede de distribuição, aplicações domésticas e podem se comunicar com outros medidores a seu alcance (Depuru et al, 2011).

Devido ao fato de os medidores inteligentes serem capazes de se comunicar bidireccionalmente, podem, por sua vez, dar suporte às fontes de geração decentralizadas e aos dispositivos de armazenamento de energia, permitindo desta forma, a criação de sistemas de tarifação ou de compensação (net metering, por exemplo) pela prestação de serviços relativos à esfera do cliente. Os medidores inteligentes podem ser programados de tal forma que só a energia consumida da rede da concessionária é faturada, enquanto a energia consumida das fontes de geração distribuída ou dos dispositivos de armazenamento de energia na esfera do cliente não é faturada (Depuru et al., 2011). Além disso, também podem limitar o 
consumo máximo de eletricidade e cortar ou reconectar o fornecimento de energia para qualquer cliente de forma remota.

Nas futuras redes de distribuição de energia, os medidores inteligentes terão um papel importante no monitoramento do desempenho e das caraterísticas de uso da energia na rede. A coleta dos dados de consumo de energia de todos os clientes de forma regular permitirá às concessionárias gerenciar a demanda de eletricidade de uma forma mais eficiente, além de poder aconselhar aos consumidores sobre formas economicamente eficientes de usar suas aplicações (Depuru et al., 2011).

Dado que os medidores inteligentes são os gateways centrais localizados nas instalações dos clientes e que suportam a comunicação bidirecional, é através destes que se viabiliza a comunicação entre os consumidores e as outras partes participantes nos sistemas de energia, o que é feito por meio de tecnologias de comunicação e informação. A nova infraestrutura de medição é essencial para medidas de eficiência energética, monitoramento e administração das redes, bem como para propósitos de balanceamento e deslocamento da carga (Römer et al., 2012). Deste modo, a AMI aumenta a transparência no intercâmbio de informação entre todos os players envolvidos e permite uma coordenação mais eficiente e antecipatória entre a geração e o consumo de energia (Yang et al., 2009).

Algumas pesquisas têm mostrado que a substituição dos medidores convencionais por medidores inteligentes pode diminuir o consumo de eletricidade em porcentagens de 3,7\% (Schleich et al. 2011) até 15-20\% (Gans et al., 2011), além de também poder ajudar a combater o furto de energia (Depuru et al., 2011).

Uma outra vantagem do uso dos medidores inteligentes é que facilitariam a implementação de diferentes sistemas de tarifação como, por exemplo: a tarifação em tempo real, ou a tarifação por horário de uso de energia, entre outras formas de tarifação dinâmica. Isso faz com que os consumidores se envolvam mais e possam decidir em que momento desejam consumir energia nas suas propriedades, ajudando assim a mudar os padrões de consumo. Na figura 2 mostra-se a analogia entre medidores convencionais

e medidores 
inteligentes:

\section{Medidores convencionais}

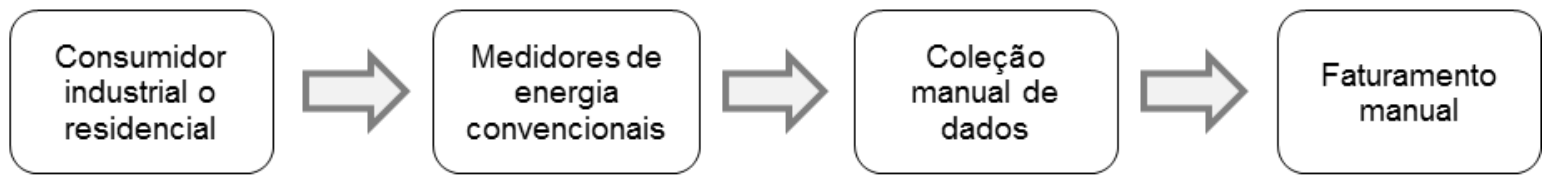

Sistemas de Medidores inteligentes

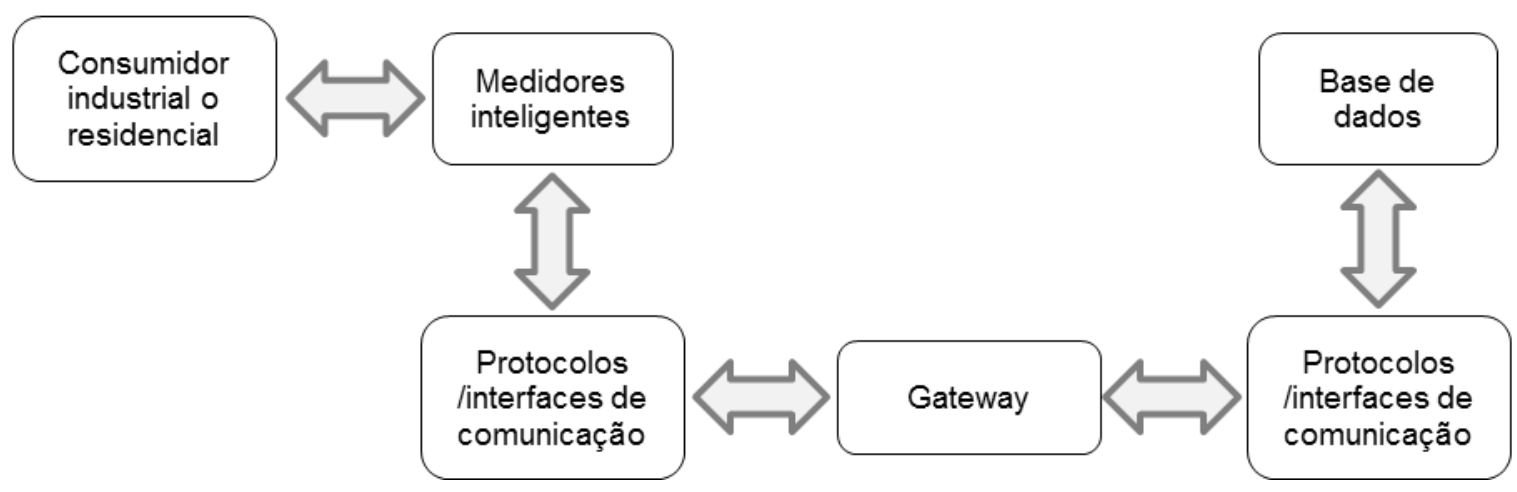

Figura 2: Comparação da estrutura de medição dos medidores convencionais e os medidores inteligentes. Fonte: Adaptado de Depuru et al., 2011.

\subsection{Wide Area Situational Awareness (WASA)}

Wide Area Situational Awareness (WASA), é o sistema que coleta uma grande quantidade de informação sobre o estado atual da rede de energia numa área ampla, desde subestações elétricas e linhas de transmissão. Por meio do uso desta informação funções de monitoramento (Wide Area Monitoring Systems - WAMS), controle (Wide Area Control Systems - WACS) e proteção (Wide Area Protection Systems - WAPS) podem ser implementadas. Desta forma, o WASA oferece às concessionárias a habilidade de reunir informações, analisá-las e prever qualquer futura perturbação ou interrupção de energia, prevenindo assim os apagões. Por exemplo, a informação pode ser usada para análises de contingência, que é a habilidade do sistema de energia de suportar a interrupção de elementos críticos. Este sistema também pode ser usado para o amortecimento de oscilações entre áreas (Wang et al., 2011). 
A automação dessas aplicações fornece a capacidade de self-healing na rede do futuro. O corte de carga e o isolamento dinâmico são exemplos das aplicações de self-healing. Tipicamente, as ações do WAPS incluem o desligamento automático de geradores e cargas interrompíveis. O sistema WASA usa redes WAN no domínio das concessionárias de transmissão para sua operação (Wang et al., 2011).

\subsection{Integração de tecnologias de Comunicação}

O NISTIR 7628, 2010, identifica sete domínios dentro da rede inteligente: Transmissão, Distribuição, Operações, Geração em grande escala, Mercados, Clientes e provedores de serviços. Um domínio de SG é um conjunto agrupado de organizações, edificações, indivíduos, sistemas, dispositivos ou qualquer outro ator, com objetivos similares e que dependem (ou participam em) aplicações similares. Os diferentes atores necessitam transmitir, armazenar, editar e processar a informação dentro da rede inteligente. Para permitir a funcionalidade da SG, os atores precisam interatuar com outros domínios.

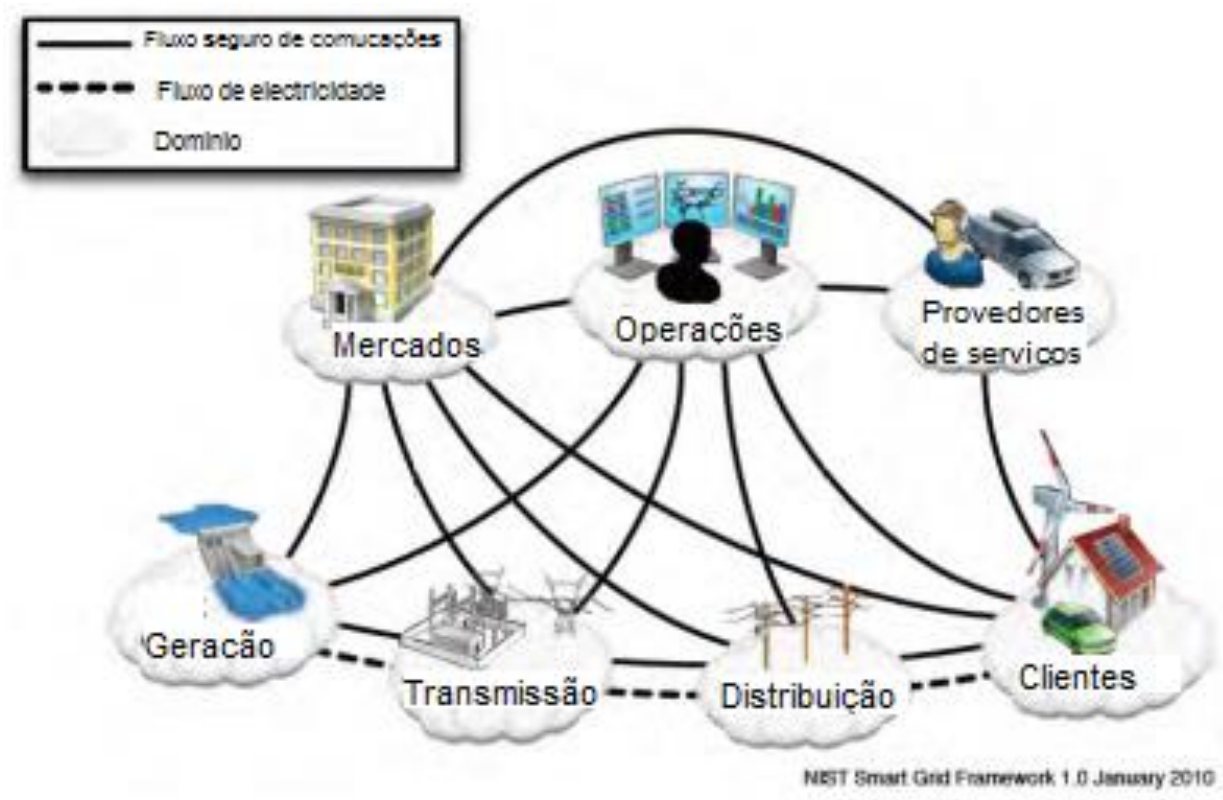

Figura 3: Domínios da rede inteligente segundo NIST. Fonte: adaptado de NISTIR 7628, 2010. 
Com o propósito de interconectar todos esses domínios, a rede de comunicações deve ser altamente distribuída e hierárquica. Wang W. e Lu Z., 2013, apresentam a rede de comunicação de SG como uma rede hierárquica e híbrida, incluindo a rede central e milhões de redes de área local.

A rede central é estabelecida por comunicações entre os domínios. Consiste de nós de infraestrutura que podem ser gateways para redes de área local ou para routers de banda larga para transmitir mensagens através dos vários domínios na SG. Na rede central, as tecnologias de comunicação convencionais, bem como as tecnologias com fibra ótica, podem ser usadas para alcançar uma alta velocidade de transmissão de dados e a entrega de informação em massa em vários domínios. Segundo Aggarwal et al. 2010, o requisito de largura de banda para as linhas de transmissão pode ser de pelo menos $100 \mathrm{Mbps}$, o que faz o uso de tecnologias como a fibra ótica fundamental para poder transmitir a quantidade de informação que será requerida e manter a escalabilidade do sistema.

As redes de área local são usadas para comunicação entre domínios. As redes de área local consistem em nós que podem ser medidores, sensores ou dispositivos eletrônicos inteligentes (IEDs pelas suas siglas em inglês), instalados ao largo da infraestrutura de energia. Geralmente, encontram-se equipadas com uma largura de banda limitada e capacidade computacional para certos propósitos de monitoramento ou proteção.

Os nós nas redes de área local não são limitados ao uso de comunicação de ponto a ponto. Na verdade, espera-se que muitos deles usem tecnologias wireless, como por exemplo: redes de sensores sem fio, sistemas celulares, e até rádio cognitivo. Atualmente vem se demonstrando que o uso das tecnologias sem fio apresenta muitas vantagens, incluindo 0 acesso sem restrições às informações da concessionária, a mobilidade, o custo reduzido, a pouca complexidade, e os produtos off-the-shelf -por exemplo WiFi e ZigBee. Alguns exemplos de aplicações destas redes são os sistemas $\mathrm{AMI}$, aplicações de resposta à demanda e medidores inteligentes (Wang W. e Lu Z., 2013).

Portanto, em comparação com os sistemas de energia convencionais, a rede inteligente aproveita tanto as redes de comunicação fixas como as sem fio para 
fornecer um paradigma revolucionário de infraestrutura de comunicação a grande escala, altamente distribuído e hierárquico para a entrega e gestão de energia.

As redes de comunicação em SG podem ser divididas em: redes residenciais (HANs: Home Área Networks), redes de prédios (BANs: Building Área Networks), e redes de áreas industrias (IANs: Industrial Área Networks). Podem ser redes com ou sem fio nas instalações dos clientes (residências, prédios ou indústrias respectivamente), que suportam a troca de mensagens entre medidores inteligentes, eletrônicos, dispositivos de gestão de energia, eletrodomésticos, aplicações e com o cliente ou consumidor. Essas redes conectam as instalações dos clientes com os sistemas das concessionárias com o propósito de suportar uma ampla variedade de aplicações de controle e comunicação. Essas tecnologias de comunicação podem ser divididas entre redes com fio e redes sem fio.

\subsubsection{Redes com tecnologias sem fio:}

É uma tecnologia que tem se mostrado muito prática para a criação de aplicações e permite a conexão de diversos dispositivos numa mesma rede sem a necessidade de instalar fios. Essa categoria inclui as seguintes tecnologias:

Rede celular: com a existência e disponibilidade de 2G, 3G, 4G e a evolução desse meio de comunicação, o seu uso na transmissão de dados em SG pode proporcionar as seguintes funcionalidades: suporte de uma grande quantidade de conexões celulares simultaneamente, ampliação da cobertura de serviço, conhecimento do estado das aplicações e roteamento priorizado de dados. Porém, essa tecnologia apresenta alguns problemas de qualidade de serviço e falta de confiabilidade na transmissão de dados, vulnerável a eventos de congestão da rede de comunicação, por exemplo: em atividades festivas, eventos naturais, etc. (Gao et al., 2012).

ZigBee: Essa tecnologia apresenta relativamente baixo consumo de energia, taxa de transmissão de dados, complexidade e custo de implementação. É considerada ideal para aplicações como: a iluminação inteligente, monitoramento de energia, automação de residências e a leitura automática dos medidores, entre outras. $\mathrm{O}$ NIST tem reconhecido ZigBee e ZibBee Smart Energy Profile (SEP) como os 
padrões de comunicação mais indicados para as redes residenciais no domínio de SG. Além disso, os medidores inteligentes integrados com ZigBee podem se comunicar com os outros dispositivos que sejam integrados com ZigBee e controlálos também. ZigBee SEP fornece às concessionárias a possibilidade de enviar mensagens aos clientes, e os clientes podem acessar à informação do seu consumo de energia em tempo real. Possui um limitado alcance entre 1 e $100 \mathrm{~m}$, uma baixa capacidade de processamento e armazenamento de dados e está sujeito a interferência de outros tipos de aplicações (Güngör et al., 2011).

Rede sem fio Mesh: É uma rede flexível que consiste de um grupo de nós, na qual nós novos podem unir-se ao grupo e cada nó pode atuar como um roteador independente. Sua característica de self-healing permite que os sinais de comunicação encontrem outra rota através dos nós ativos, se algum nó deixar a rede. As redes Mesh são uma solução rentável com auto organização dinâmica, self healing, auto configurável, com serviços de alta escalabilidade e que devido a suas características proporciona redundância na transmissão de dados.

Wi-Fi: Redes de área local sem fio ou Wi-Fi são o padrão mais popular entre os desenvolvidos pela norma IEEE 802.11. Faz uso da técnica de modulação DSSS (Direct Sequence Spread Spectrum) com taxas de dados que podem alcançar até 11 Mbps em ambientes fechados e até 1 Mbps em ambientes abertos, com um raio de alcance de 30-40 m e de 90-100 m respectivamente. Wi-Fi proporciona um sólido desempenho em ambientes com espectros de frequência compartilhados e canais de RF com ruído. Suporta todos os protocolos baseados em IP e uma numerosa variedade de aplicações, por exemplo, leitura de AMI e gerenciamento de aplicações domésticas. Características de segurança para a comunicação de dados segura e autêntica podem ser implementadas, fazendo-as uma das opções mais fortes dentro das tecnologias de comunicação para SG. Adicionalmente, a maioria dos dispositivos tem uma natureza de plug and play e são economicamente acessíveis (Usman A. e Shami S.H, 2013).

DASH7: é uma nova tecnologia de rede de sensores sem fio que usa a normativa ISO/IEC 18000-7. Permite aos dispositivos ou nós de sensores, ter um alcance típico de $250 \mathrm{~m}$ que pode se estender para $5 \mathrm{~km}$ com uma taxa de transmissão de dados nominal de $28 \mathrm{kbps}$ e um máximo de $200 \mathrm{kbps}$. DASH7 são considerados dispositivos 
de baixo consumo de energia, com pequenas baterias cuja vida pode durar anos. Em DASH7 os dados são transferidos em rajadas de pequenos pacotes de forma assíncrona, os dispositivos DASH7 são fáceis de gerenciar e o requisito de uma estação central fixa não se aplica num sentido estrito. DASH7 é uma boa alternativa às soluções baseadas em ZigBee (Usman A. e Shami S.H, 2013).

Rede McWiLL: É um sistema de comunicação de tronco de banda larga que usa a alocação dinâmica de canais e antenas inteligentes para aumentar a sua taxa de transferência de dados. Alguns dos benefícios do uso de McWiLL em SG são: o uso compartilhado de canais para o suporte da transmissão dos dados, exibição de status rica e intuitiva, sua largura de banda, compartilhamento de IP, etc.

\subsubsection{Redes com tecnologias com fio}

Fibra ótica: A tecnologia de comunicação em fibra ótica permite que a informação seja enviada usando pulsos de luz através de uma fibra fina e transparente de vidro ou de plástico. Demonstra ser mais eficiente, em termos de distância e largura de banda, se comparada aos tradicionais pares de fios de cobre usados nos sistemas de comunicação.

Os elementos básicos de um sistema de comunicação por fibra ótica são: transmissor ótico (fonte de luz e circuito de modulação associado), cabo de fibras ópticas, receptor ótico (fotodetector), juntas e conectores óticos (as juntas promovem uniões permanentes e os conectores temporários ou semipermanentes), acopladores ou divisores ópticos, multiplexadores /demultiplexadores ópticos e amplificadores ópticos.

A comunicação via cabo óptico apresenta vantagens como:

- Grande largura de banda - a gama de frequências da portadora óptica é de $10^{13} \mathrm{a}$ $10^{16} \mathrm{~Hz}$ que resulta um maior potencial de largura de banda, excedendo, em várias ordens de grandeza, as de condutores metálicos e até mesmo as de ondas de rádio;

- Baixa atenuação - apresentam pequena atenuação (baixas perdas) quando comparadas com meios de transmissão convencionais (cabos metálicos, micro ondas e radiofrequência), o que permite cobrir longas distâncias de transmissão (da 
ordem das centenas de $\mathrm{km}$ ) sem uma elevada quantidade de repetidores e amplificadores, reduzindo-se, assim, o custo e a complexidade do sistema;

- Tamanho e peso reduzidos - as dimensões são da ordem de um cabelo humano, com algumas centenas de micrômetros, sendo uma vantagem considerável sobre os cabos metálicos;

- Imunidade a interferências eletromagnéticas - por serem compostas de material dielétrico, são imunes a ruídos de outros sinais, conhecidos como "crosstalk", às descargas elétricas, e aos ruídos decorrentes de acionamentos de interruptores e motores;

- Segurança na transmissão - existe um excelente confinamento do sinal luminoso propagado pelas fibras ópticas, não irradiando externamente; as fibras ópticas agrupadas em cabos ópticos não interferem opticamente umas nas outras, sem a corrupção de dados, sendo de fácil detecção qualquer tentativa de captação de mensagens ao longo de uma fibra óptica;

- Isolamento elétrico - por serem constituídas por vidro, que é um material isolante elétrico, não é necessário cuidado com malhas de terra ou com curtos-circuitos;

- Confiabilidade e facilidade de manutenção - resulta de sua baixa atenuação, o que implica na menor quantidade de repetidores ou amplificadores ao longo do sistema (maior confiabilidade), com tempos de vida médios de 20 a 30 anos;

- Matéria prima abundante - a principal matéria prima é a sílica que é extraída de areia comum, material abundante e de baixo custo comercial.

A robustez mecânica da fibra, o processo difícil e oneroso de junção das fibras, a falta de padronização dos componentes ópticos e a adaptação complexa a sistemas de múltiplo acesso são algumas desvantagens apontadas para a utilização de fibras ópticas. O processo de fabricação das fibras ópticas é complexo e oneroso, assim como o custo dos componentes ativos é elevado. Isto torna os sistemas por fibras ópticas competitivos apenas em aplicações específicas. O uso de fibra óptica ainda é considerado oneroso, tornando-se menos rentável para o uso residencial. Esta realidade, no entanto, está mudando em especial nos mercados asiáticos. 
Comunicação via rede elétrica: É o uso da infraestrutura das distribuidoras para utilização da rede elétrica para transmissão de dados, voz e imagem e acesso à Internet em alta velocidade sob a denominação de sistemas Broadband over Power Lines (BPL), segundo a ANATEL, ou Power Line Communications (PLC).

A regulamentação dos sistemas de banda larga via rede elétrica de média e baixa tensão contribuirá para a implantação de Redes Elétricas Inteligentes, visto que representará um marco para a evolução da automação dos sistemas elétricos de média e baixa tensão, tanto em termos quantitativos, devido ao maior alcance proporcionado pela capilaridade da rede elétrica, como qualitativos provenientes de novas funcionalidades advindos das REI.

A comunicação via PLC é uma tecnologia que utiliza a estrutura da rede elétrica de distribuição, tipicamente redes de média e baixa tensão, como meio de transporte para a transmissão de dados em alta velocidade (ANDRADE, 2010).

No Brasil, a energia elétrica é transmitida na frequência de $60 \mathrm{~Hz}$, enquanto que a transmissão de dados via rede segundo a resolução $n^{\circ} 527$, Anatel, deve ocorrer na faixa de frequência compreendida entre 1,705 MHz a $50 \mathrm{MHz}$. Logo, ambos os sinais de eletricidade e de dados, distintos, podem trafegar simultaneamente no mesmo meio sem interferências mútuas. Em caso de interrupção de energia, o sinal de dados pode trafegar sem que as transmissões deste tipo sejam interrompidas.

A rede PLC é dividida em três níveis: rede de transporte, rede de distribuição e rede de acesso. A rede de transporte compreende o operador de telecomunicações, onde é localizada a infraestrutura de backbone entre as redes PLC e a internet.

Para utilização da tecnologia PLC em redes de comunicações, são necessários os seguintes equipamentos (ANDRADE, 2010): modem PLC, concentrador, repetidor, equipamento de subestação e unidades de acoplamento.

Existem duas aplicações de PLC, a interior (indoor) e a exterior (outdoor). $\mathrm{Na}$ primeira aplicação, a transmissão de dados, em poucos kbps, é realizada através da instalação elétrica interna do cliente, seja ele residencial (casa, apartamento, escola), comercial, ou industrial, podendo, em tese, chegar a todas as tomadas, permitindo acesso a serviços como: internet em alta velocidade, automação residencial, recepção de canais interativos de televisão, e proporcionando a inclusão 
digital nas escolas. Na segunda aplicação, a transmissão de dados é realizada, em Mbps, por meio da rede de média e baixa tensão da concessionária de energia elétrica para a supervisão e o controle da rede elétrica dentro do conceito de REI.

Uma vantagem considerável desta tecnologia de comunicação é a redução de custos com a implantação do sistema, uma vez que há a utilização da infraestrutura cabeada já existente da rede elétrica. As altas taxas de transmissões relacionadas a esta proposta, estimando-se taxas de até $200 \mathrm{Mbps}$, é outro fator apontado com vantagem desta tecnologia.

A falta de tecnologia comprovada para a implantação em média tensão (13,8 kV, 34 $\mathrm{kV}$ ); a forte atenuação do sinal transmitido nas redes capilares de distribuição; e, a base regulatória estabelecida às concessionárias de energia impedindo-as de operarem no nicho das comunicações, são apontadas, no momento, como desvantagens para a tecnologia PLC.

É importante que a rede de comunicação seja capaz de suportar outras aplicações de REI que não somente a dos de medidores. A tendência para a tecnologia PLC será a de aperfeiçoamento dos chipsets micro controlados, das técnicas de processamento de sinais digitais e dos tratamentos de ruídos presentes nas redes aéreas e subterrâneas (SMART GRID NEWS, 2011g).

\subsubsection{Worldwide Interoperability for Microwave Access (WiMAX)}

É uma tecnologia de comunicação desenvolvida na norma IEEE 802.16 para dispositivos sem fio de banda larga. WiMAX envolve normativas de encriptação de dados (Data Encryption Standard - DES) e técnicas de encriptação AES para fornecer uma comunicação de dados confiável e segura. WiMAX foi especialmente projetado para comunicações ponto-a-multiponto em aplicações fixas ou móveis, com uma taxa de dados de até 70 Mbps em um raio de até $50 \mathrm{~km}$.

WiMAX é mais vista como uma solução central para as comunicações em SG; seu longo alcance de comunicação, sua natureza interoperável inerente e a habilidade para suportar taxas altas de transmissão de dados, além da capacidade de comunicação ponto-a-multiponto, fazem sua utilização muito confiável. Também 
pode ser considerado como uma opção viável para a comunicação entre os DERs em locações remotas e como uma opção para fornecer um enlace de redundância com taxas altas de transmissão de dados na rede central das concessionárias. A implementação de WiMAX apresenta custo elevado (Usman A. e Shami S.H, 2013).

\section{$2.4 \quad$ Interoperabilidade}

Interoperabilidade em uma rede inteligente é a habilidade de diversos sistemas para trabalhar em conjunto, usar suas partes, intercambiar informação ou equipamentos entre eles, e, além disso, trabalhar cooperativamente para realizar uma tarefa. Permite a integração, cooperação efetiva e comunicação bidirecional entre todos os elementos interconectados no sistema elétrico de energia (Aggarwal et al. 2010).

Conforme a norma IEEE Std 2030, 2011, interoperabilidade é a capacidade de duas ou mais redes, sistemas, dispositivos ou componentes de intercambiar informação externamente e usá-la rapidamente de forma segura e eficaz.

A interoperabilidade na rede inteligente proporciona às organizações a capacidade de se comunicar efetivamente e transferir dados significativos, ainda quando possa estar sendo utilizada uma variedade de diferentes sistemas de informação sobre diferentes infraestruturas, às vezes através de diferentes culturas e regiões geográficas. A interoperabilidade das redes inteligentes é frequentemente associada com as seguintes caraterísticas:

- Componentes, sistemas e plataformas de hardware/software que permitam que tenha lugar a comunicação de máquina a máquina. Este tipo de interoperabilidade frequentemente é centrado em protocolos (de comunicação) e a infraestrutura necessária para que esses protocolos operem.

- Formatos de dados, onde as mensagens transferidas pelos protocolos de comunicação necessitam ter uma codificação e sintaxes bem definida.

A interoperabilidade da rede inteligente permitirá às concessionárias, consumidores e outros players comprar hardware e software no mercado e incorporá-los nas diferentes áreas da rede inteligente para que possam trabalhar com outros componentes da rede inteligente. A diversidade das tecnologias de rede inteligente 
em desenvolvimento destinados ao uso ao longo de toda a rede de energia (desde a transmissão à distribuição e, finalmente, aos dispositivos usados nas instalações dos clientes) apresenta desafios significativos para alcançar a interoperabilidade.

Para fazer a transição das redes tradicionais a uma infraestrutura de energia elétrica mais inteligente e segura, os objetivos de smart grid devem satisfazer às necessidades de todos os players (partes interessadas), incluindo clientes e comunidades, e desenvolver a abordagem de rede inteligente baseada em standards, baseado em soluções interoperáveis e processos de negociação flexíveis.

Regulações técnicas em conjunto com regulações de mercado, podem ter um impacto significativo no desenvolvimento de sistemas de geração distribuída. Esses protocolos técnicos refletem a interoperabilidade emergente através dos elementos do sistema elétrico, o qual afeta a facilidade com que os dispositivos podem ser conectados e a informação pode fluir através do sistema. Para que os DER consigam operar com sucesso e venham a contribuir mais efetivamente na rede, necessitarão tanto de sistemas estandardizados de interconexão física com a rede, quanto de protocolos de intercâmbio de informação estandardizados.

A interoperabilidade pode acelerar a integração dos DER, a falta dela pode retardar ou obstruir a instalação da geração distribuída, bem como a efetiva interação entre dispositivos.

Um grande número de normativas internacionais foram ou estão sendo desenvolvidas para a conexão de diferentes tipos de geração distribuída. De fato, a adoção destas é voluntária a não ser que uma organização ou legislação específica requeira a adoção dessas normativas (IEADSM-Task XVII). 


\subsection{Resposta à demanda}

A disponibilidade dos recursos de resposta à demanda (e em menor grau, eficiência energética) significa que os consumidores ou clientes podem ter certa flexibilidade em seus hábitos de consumo de energia elétrica. Isto significa que dadas tanto a habilidade de gerenciar facilmente o uso de energia nas suas propriedades quanto a informação do valor de dita energia, eles possam ter interesse em mudar seus hábitos de consumo de energia. Uma parte da energia consumida pelos clientes com disposição de participar nos programas de resposta à demanda pode ser deslocada no tempo ou simplesmente suprimida.

Tipicamente as cargas flexíveis incluem diferentes tipos de processos industriais, por exemplo, plantas trituradoras de madeira e de polpação mecânica, fornos a arco, moinhos de rolamento, plantas de moagem, extrusoras, compressores de ar, entre outras. Nos setores residencial e comercial as cargas flexíveis podem incluir dispositivos de aquecimento de espaços, aquecimento de água, resfriamento, ventilação, iluminação, entre outras.

Segundo IEADSM-Task XVII teoricamente, quase todo o consumo de energia elétrica é flexível se o preço da eletricidade é o suficientemente alto como para motivar a mudança nos hábitos de consumo. Nesse sentido, o potencial das aplicações de resposta à demanda é enorme. Na prática o potencial depende de diversos fatores tais como informação ou alertas antecipados da resposta à demanda real, tempo e duração da resposta à demanda, processos técnicos e de TIC, soluções de automação e medição a nível de usuário final, e benefícios econômicos e contratos/preços da prestação desse serviço, além da disponibilidade de tecnologias facilitadoras tais como dispositivos de automação nas instalações dos clientes com a capacidade de responder aos sinais de preço dadas pela concessionária e outros acionadores da resposta à demanda.

Na prática, diferentes tipos de potenciais de aplicação dos programas de resposta à demanda podem ser definidos. O potencial técnico é a quantidade de redução de carga que seria realizada se todos os clientes elegíveis adotassem medidas de resposta à demanda, sem ter em conta as barreiras econômicas ou de mercado. $O$ 
potencial econômico relaciona-se à quantidade do potencial técnico resultante de medidas de resposta à demanda que reúnem critérios econômicos específicos, tais como o recebimento de receita antecipada da participação no programa de DR e o tempo de retorno do investimento. O potencial de mercado ou potencial alcançável é a quantidade de redução de carga que pode ser alcançada realisticamente por um programa de DR real ao longo de um determinado período de tempo.

A implementação de programas de DR é vantajoso para as concessionárias de energia e para os clientes. Os programas de DR permitem às concessionárias controlar as condições de pico de demanda na rede e aplanar a curva de consumo ao deslocar os horários de consumo. Assim a concessionaria é, portanto, capaz de evitar um pico de curta duração por meio do retardo de alguns usos existentes da energia, desta forma criando tempo para pôr em marcha plantas de energia adicionais. Isso evita a operação ineficiente de acionar as plantas de energia emergenciais para cobrir as cargas pico da rede (Wang et al., 2011).

Por outro lado, os clientes podem usar uma interface de gerenciamento de energia e aplicações inteligentes (as quais se comunicam com um medidor inteligente) e programar o uso de energia em sincronia com a sinalização de preço baixo no sistema. O processo pode ser automatizado ou controlado pela concessionária de acordo com as preferências do cliente. Ainda mais, instalando DERs e dispositivos de armazenamento de energia nas suas propriedades, os clientes terão a possibilidade de vender ou intercambiar o excesso de energia com a rede servida pelas concessionárias.

Segundo Khan R. H. e Khan J. Y., 2013, os programas de resposta à demanda podem ser aplicados das seguintes formas:

Tarifação dinâmica: São programas nos quais os clientes decidem que ações tomar para regular o seu consumo de energia, isso depois de receber os sinais dos preços da energia. Atualmente, existem vários programas de tarifação dinâmica, por exemplo: 
- Horário de uso ou Time Of Use (TOU): o dia é dividido em blocos horários contíguos nos quais varia o preço, sendo que o preço mais alto corresponde ao bloco de horário de pico.

- Tarifação em tempo real ou Real Time Pricing (RTP): O preço pode variar de forma horária e está atrelado ao custo real no mercado da energia fornecida.

- Tarifação do pico crítico ou Critical Peak Pricing (CPP): é parecido com o TOU, mas só é aplicado num número relativamente baixo de "eventos" no dia.

- Descontos de pico ou Peak Time Rebates (PTRs): Os clientes recebem descontos na conta de energia elétrica por não usar energia durante os períodos de pico.

Controle remoto da carga: São programas em que os dispositivos dos clientes respondem aos sinais de forma automatizada com a ajuda da comunicação de máquina a máquina e técnicas de controle de dispositivos inteligentes. Nesse tipo de programa, baseando-se na habilidade para serem reguladas, as cargas podem ser classificadas da seguinte forma:

- Cargas interrompíveis: Podem ser interrompidas no período do pico e mudar seu consumo para outro período. Exemplo: bombas de água, secadoras e lavadoras de roupa. Contudo, essas cargas voltam à rede quando o período de pico acabar. Esses tipos de cargas requerem sinais de controle de carga simples para interromper e reprogramar o processo.

- Cargas Redutíveis: Podem ser reduzidas a um nível menor de consumo por certo tempo. Por exemplo: durante o horário de pico os termostatos de sistemas de resfriamento ou de ar acondicionado podem ser colocados numa temperatura maior. Esse tipo de carga precisa de interação periódica com o servidor remoto de DR durante o tempo de regulação.

- Cargas parcialmente interrompíveis: Essas cargas podem ser parcialmente interrompidas durante o período de pico ao limitar seu ciclo de operação. Por exemplo: aquecedores de água, aparelhos de ar condicionado e fogões elétricos. Essas cargas requerem dois sinais de controle para marcar o início e o final do modo cíclico. 
OpenADR: Para as aplicações de DR, a norma Open Automated Demand Response (OpenADR) é pioneira. Nela são fornecidas as guias e especificações para a automação de programas de DR. Diferentemente dos programas de controle de carga, a resposta no sistema OpenADR é determinada pelo cliente. O sistema OpenADR transmite os sinais de preço e ocorrência de eventos para o sistema de gestão de energia do cliente, isso ativa as ações pré-programadas pela configuração do cliente. Essa norma define as três seguintes entidades no sistema DR:

- Concessionária: Configura e gerencia os programas de DR. É auxiliada pelo sistema de informação da concessionária o qual envia a informação do preço em tempo real e de ocorrência de eventos para o servidor de DR e coordena os programas de DR e de tarifação dinâmica usando os detalhes de consumo de cada participante.

- Servidor de automação de DR (DRAS): Envia a informação da concessionária aos dispositivos dos clientes e, além disso, coleta relatórios de estado.

-Participantes: São os usuários finais que participam nos programas de DR. São auxiliados pelo DRAS para receber sinais do preço em tempo real e notificação de eventos, executam também o programa de DR e enviam um relatório de estado para o DRAS.

Entre as aplicações de DR, os requisitos de comunicação variam de acordo com o tipo de carga e o método de DR utilizado. Para os programas baseados em incentivo por preço, a exigência de comunicação é reduzida já que uma notificação da ocorrência de um evento seguida de uma mensagem de confirmação é suficiente para cada sessão da aplicação. Uma troca de mensagens mais intensa é exigida para os programas de controle de carga. Dentro desse tipo de programas, os requisitos de comunicação para as cargas interrompíveis são menores, já que alguns poucos sinais de controle de carga são suficientes para interromper e reassumir a operação da carga por um período de tempo. Para as cargas redutíveis e parcialmente interrompíveis, a exigência de comunicações será maior, uma vez que precisam do intercâmbio frequente de mensagens de controle durante o período de regulação de carga. 


\subsection{Considerações de segurança e privacidade em SG}

A crescente interconexão e integração dos sistemas de comunicações e informação com o sistema de energia introduz vulnerabilidades cibernéticas no sistema de energia também. A incapacidade de lidar com esses problemas dificultará a modernização do sistema de energia existente. Os problemas de segurança incluem: o acesso não autorizado aos dados dos medidores inteligentes, desligamento de dispositivos por ataques à rede, rejeição dos dados dos medidores inteligentes (devido a falhas de comunicação, ataques, etc.), furto de energia sem que o prejudicado receba notificação nenhuma, ataques a infraestrutura da rede inteligente como tal para causar apagões, etc. Existem também algumas preocupações referentes a problemas de privacidade na rede inteligente, por exemplo: a informação de medição pode filtrar informação privada e sensível.

O sistema de energia elétrica tem exigências de desempenho e segurança bastante únicos, podendo demandar medidas de segurança que diferem das medidas tradicionais das empresas de IT. Soluções de segurança como a criptografia forte e infraestruturas públicas com acesso mediante chave (física ou digital), que têm sido implantadas efetivamente para assegurar a infraestrutura de IT de algumas empresas e aplicações empresariais, frequentemente encontram limitações de desempenho e recursos quando são aplicadas a sistemas de energia. Muitos sistemas antigos não foram projetados com segurança como recurso básico, contudo, a segurança desses sistemas pode ser reforçada com medidas de compensação tais como o controle de acesso e encriptação de dados (IEEE Std 2030).

Segundo o NIST uma estratégia de segurança deve ter os seguintes componentes:

Prevenção: refere-se às ações tomadas e às medidas postas em prática para a avaliação contínua e disponibilidade das ações necessárias para reduzir o risco de ameaças e vulnerabilidades; com o propósito de intervir e deter uma ocorrência ou para mitigar os seus efeitos.

Detecção: são as abordagens para identificar anomalias no comportamento e descobrir intrusões, detectar códigos maliciosos, e outras atividades ou eventos que 
podem interromper as operações da rede de energia, assim como técnicas para a coleta de evidências digitais.

Resposta: são as atividades que atendem os efeitos diretos de curto prazo de um incidente, incluindo as ações imediatas para salvar vidas, proteger as propriedades e satisfazer as necessidades humanas básicas. A resposta também inclui a execução de planos de operações de emergência e atividades de mitigação do incidente destinadas a limitar a perda de vidas, danos pessoais, danos à propriedade e outros resultados desfavoráveis.

Recuperação: refere-se ao desenvolvimento, coordenação e execução de serviços e planos de restauração in loco para as instalações e serviços afetados, compreendendo a reconstituição das operações e serviços da rede inteligente através das ações de indivíduos, setor privado, não governamental e setor público.

Alguns exemplos de requisitos de segurança da rede inteligente implementados para viabilizar essas estratégias são detalhados em NISTIR 7628, 2010 e são resumidos a seguir:

Controle de acesso: O foco do controle de acesso é assegurar que os recursos são acessados unicamente pelo pessoal apropriado, e que esse pessoal está corretamente identificado. Devem ser postos em prática mecanismos para monitorar atividades e detectar atividades inapropriadas.

Conscientização e treinamento: A conscientização da importância de segurança no Sistema de informação da rede inteligente é uma parte crítica para prevenir incidentes. A implementação de um programa de segurança no sistema de informação de SG pode mudar a forma em que o pessoal acessa os programas e aplicativos, portanto, as organizações necessitarão criar programas de treinamento efetivos baseados nas responsabilidades e funções individuais.

Auditoria e Prestação de contas: Realizações periódicas de registros e auditorias da informação do sistema de SG devem ser implementadas para validar que os mecanismos de segurança presentes durante os testes de validação do sistema de informação de SG estejam instalados e operando corretamente. Essas auditorias de 
segurança revisam e examinam os registros e atividades do sistema de informação de SG para determinar se os requisitos de segurança do sistema de informação de SG são adequados e para se assegurar da conformidade com as medidas e políticas de segurança estabelecidas. As auditorias também são usadas para detectar brechas nos serviços de segurança ao examinar os registros do sistema de informação de SG. A realização de registros é necessária para a detecção de anomalias, bem como para análise forense.

Avaliação de segurança e autorização: As avaliações de segurança incluem o monitoramento e revisão do desempenho do sistema de informação de SG. Os métodos de revisão internos, tais como auditorias de conformidade e investigações de incidentes, permitem à organização determinar a eficácia do programa de segurança. Finalmente, a organização pode revisar regularmente, por meio do monitoramento contínuo, a conformidade do sistema de informação de SG.

Gerenciamento de configuração: O programa de segurança necessita implementar políticas e procedimentos através dos quais a organização gerencia e documenta todas as mudanças na configuração do sistema de informação de SG. O sistema de informação necessita ser configurado apropriadamente para manter sua operação ótima, portanto, somente as mudanças que foram testadas e aprovadas deverão ser permitidas.

Continuidade das operações:Refere-se à capacidade de SG de continuar ou reassumir as operações do sistema de informação no caso da interrupção da operação normal do sistema.

Identificação e autenticação: É o processo de verificação da identidade dos usuários, processos ou dispositivos, como um pré-requisito para a concessão de acesso aos recursos no sistema de informação de SG.

Gestão da informação e dos documentos: Geralmente é parte do sistema de gestão de documentos e retenção de registros da organização. A informação digital e em papel associada com o desenvolvimento e execução do sistema de informação de SG é importante e privilegiada, e deve ser cuidadosamente administrada. Essa informação deve ser protegida e com garantia de que as versões corretas são conservadas. 
Resposta a incidentes: Refere-se à capacidade de continuar ou reassumir as operações do sistema de informação de SG no caso de interrupção na sua operação normal, sem importar a natureza da interrupção (desastres naturais, ataques ao sistema ou vandalismo, etc.). A resposta a incidentes implica a preparação, teste, e manutenção de políticas e procedimentos específicos para permitir que a organização recupere seu estado operacional do sistema de informação após a ocorrência da interrupção.

Desenvolvimento e gestão do sistema de informação de SG: A estratégia de segurança é mais efetiva quando é projetada no sistema de informação de SG, e mantida através da manutenção efetiva ao longo do ciclo de vida do sistema de informação. As atividades de manutenção envolvem políticas e procedimentos apropriados para a realização de manutenções preventivas e de rotina nos componentes do sistema de informação de SG. Isso inclui o uso tanto de ferramentas de manutenção remotas como locais.

Proteção de mídia: Refere-se aos procedimentos para limitar o acesso à mídia somente para usuários autorizados. As medidas de segurança existem para os requisitos de manejo e distribuição da informação, bem como para mídias de armazenamento, transporte, sanitização, destruição e disposição dos dados.

Segurança física e ambiental: Envolve a proteção dos bens físicos contra dano, uso indevido ou furto. A segurança ambiental aborda a segurança dos ativos de danos causados por problemas ambientais.

Planejamento: Seu propósito é manter as operações do sistema de informação num nível ótimo e prevenir ou se recuperar com sucesso das interrupções indesejadas. Os tipos de planejamentos considerados são: planejamento de segurança para prevenir interrupções indesejadas; planejamento da continuidade das operações para manter a operação do sistema de informação de SG durante e após interrupções; e planejamento para identificar estratégias de mitigação.

Gestão do sistema de segurança: Estabelece as bases para a proteção corporativa da organização e dos ativos do sistema de informação de SG. Os procedimentos de segurança definem como uma organização implementa o programa de segurança. 
Segurança do pessoal: Aborda as funções e responsabilidades do programa de segurança implementadas durante todas as fases de emprego do pessoal, incluindo as fases de recrutamento e cessão da prestação dos serviços.

Gestão e avaliação de riscos: O planejamento da gestão de riscos é um aspecto chave para assegurar que os meios técnicos e os processos para assegurar o sistema de informação de SG têm lidado com sucesso com os riscos e vulnerabilidades do sistema de informação. A organização deve identificar e classificar os riscos para poder desenvolver as medidas apropriadas de segurança, incluindo seu próprio sistema de informação e interconexões, com o objetivo de identificar os componentes críticos ou qualquer ponto fraco na segurança.

Sistema de informação e aquisição de serviços de SG: Cobre a contratação e aquisição de componentes do sistema, software, firmware, e serviços de empregados, empreiteiros ou terceirizados.

Proteção do sistema de informação e comunicação de SG: Consiste nos passos tomados para proteger de intrusões cibernéticas o sistema de informação de SG e os enlaces de comunicação entre os seus componentes.

Sistema de informação e integridade da informação em SG: Mantém o sistema de informação de SG, incluindo a integridade da informação, incrementa a confiança de que os dados sensíveis não sejam modificados ou apagados de forma não autorizada ou sem ser detectada. Inclui procedimentos para detectar, reportar e corrigir falhas no sistema de informação de SG, bem como para detectar a presença de códigos maliciosos.

Dado que a rede de comunicação da rede inteligente é uma rede crítica para o intercâmbio de informação na infraestrutura de energia, para assegurar uma operação segura e confiável, é essencial entender quais são os objetivos e requisitos de segurança no contexto do gerenciamento e transporte de energia. A seguir serão descritos os requisitos e objetivos de segurança da rede inteligente:

O grupo de segurança cibernética do NIST na sua guia de segurança cibernética para a rede inteligente (NISTIR 7628) fornece os três requisitos primários para manter a rede inteligente de forma segura: 
- Disponibilidade: Garantir o acesso confiável e em tempo à informação, porque a perda de disponibilidade significa a interrupção ao acesso ou ao uso da informação, o qual pode comprometer o transporte de energia.

- Integridade: Proteger contra a imprópria modificação ou destruição da informação é assegurar a autenticidade e não rejeição dessa informação. A perda de integridade é a modificação ou destruição não autorizada da informação e pode induzir decisões incorretas sobre o gerenciamento da energia.

- Confidencialidade: Preservar as restrições autorizadas no acesso e divulgação da informação com o objetivo principal de proteger a privacidade pessoal e informação dos proprietários, com o propósito de evitar a divulgação não autorizada de informação que está disponível somente a pessoas com privilégios determinados. 


\section{Usinas Virtuais}

A penetração dos recursos energéticos distribuídos (DER pelas suas siglas no inglês) aumenta dia a dia no mundo, o que é principalmente associado com o requisito de um sistema de energia que gere cada vez menos poluição, tenha uma maior diversificação de fontes de energia e incremente a eficiência do uso e geração de energia (Saboori, H., Mohammadi, M. and Taghe, R. 2011). Este incremento, por sua vez, também se associa a fazer um melhor aproveitamento dos recursos disponíveis localmente e à liberação da dependência das importações de energéticos.

O propósito das usinas virtuais é obter um melhor e maior aproveitamento dos DERs que se encontram perto dos centros de consumo, com o objetivo principal de coordenar o seu funcionamento conjunto para satisfazer os requisitos da demanda de energia, o que deve ser configurado de acordo com o menor custo de geração ou com a menor produção de gases de efeito estufa e atuar, no que diz respeito ao sistema interconectado de energia elétrica ou rede de transmissão, como se fosse, uma planta de geração de grande porte como se mostra na Figura 4 e Figura 5.

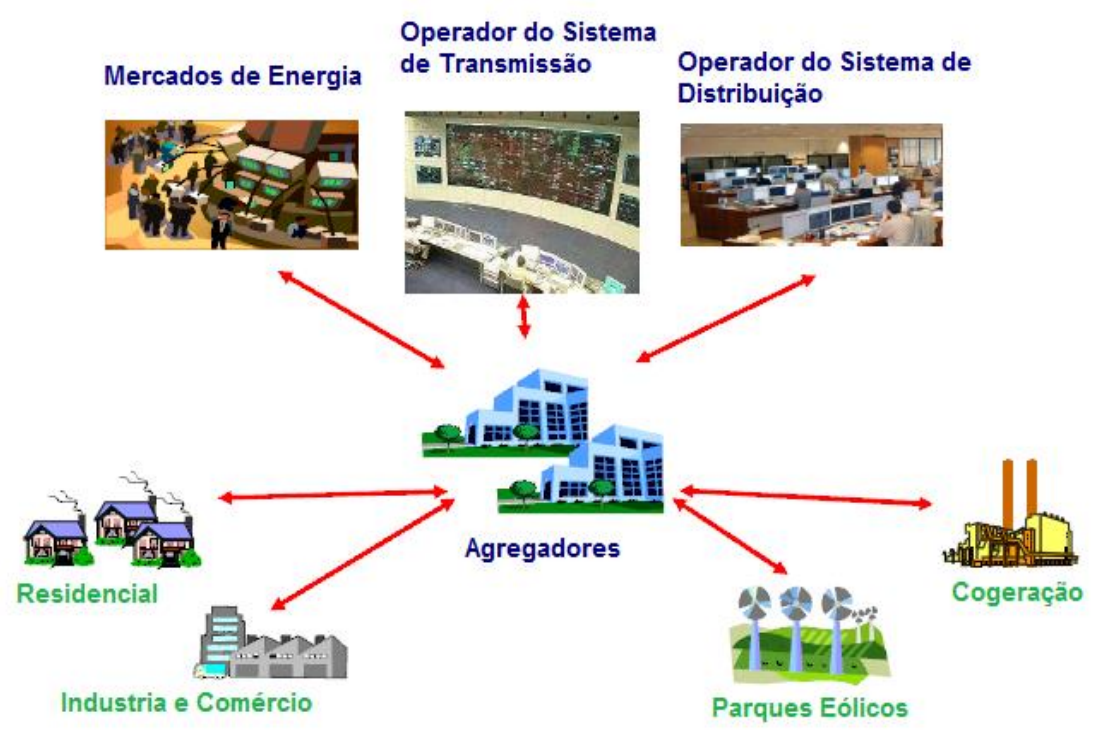

Figura 4: Exemplo de participação da usina virtual no sistema interligado de energia (J. Corera, 2006). 


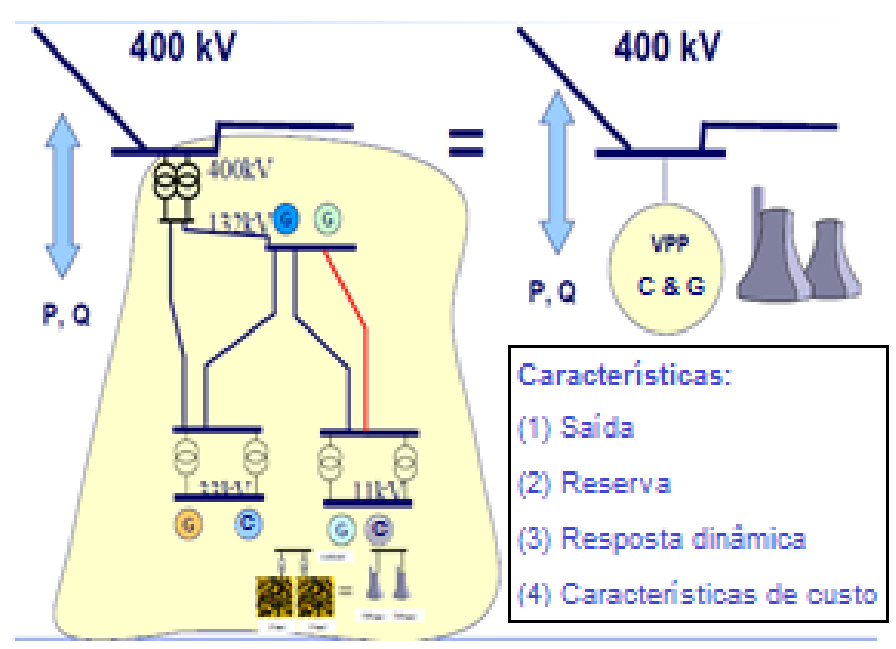

Figura 5: Analogia de uma usina virtual com uma usina centralizada. Fonte: Adaptado de J. Corera, 2006.

\subsection{Definição e conceito}

\section{Definição}

Como as usinas virtuais (também conhecidas como VPP pelas suas siglas no inglês) estão ainda na etapa de hipóteses, não se tem uma definição única no marco da literatura existente. Apresentam-se na sequência algumas das definições encontradas:

- O termo usina virtual refere-se a um interessante e promissor conceito no qual se combinam diferentes tipos de geração -renováveis e não renováveis- e dispositivos de armazenamento de energia no intuito de que sejam capazes de aparecer ante o mercado como uma única usina com o horário de funcionamento definido. Em outras palavras, é um conjunto de diferentes usinas e dispositivos de armazenamento de energia com diferentes debilidades (como ser geração estocástica) e fortalezas que são combinadas complementando-se de uma forma inteligente e eficaz (Koeppel, G. 2003).

- É uma representação flexível de um conjunto de DERs. Uma VPP não apenas agrega a capacidade de muitos DERs, como também cria um só perfil de operação do composto de parâmetros que caracterizam cada DER e 
incorpora as limitações espaciais ou físicas (p.ex. limitações da rede) na descrição da capacidade do conjunto de operação (PUDJIANTO, D., RAMSAY, C. \& STRBAC, G, 2006).

- É uma usina que tem o controle da agregação de certo número de unidades de geração conectadas à rede de distribuição e instaladas perto das cargas. A agregação de controle pode ser por meio de um sistema centralizado ou descentralizado respaldado por uma infraestrutura de controle e algoritmos de controle lógico, e tratadas depois como uma única usina de grande capacidade (ADHI, E. 2007).

- VPP é um conceito que permite a integração dos DER no sistema de energia, por meio deste conceito os DER individuais podem obter acesso e visibilidade no mercado de energia, e beneficiar-se do mercado inteligente criado pela VPP para otimizar a sua locação e maximizar suas oportunidades de ganhos econômicos. Da mesma maneira o sistema pode se beneficiar do uso ótimo de toda a capacidade de geração disponível na rede e desta forma aumentar a eficiência na operação do sistema (FENIX, 2009).

\section{Conceito geral}

Uma usina virtual (VPP) é um conjunto de unidades de geração, cargas controláveis e sistemas de armazenamento dispersas na rede e agregados com o fim de operar como uma única usina. As pequenas usinas que a compõem podem utilizar tanto fontes renováveis como não renováveis. O coração de uma VPP é o sistema de gestão de energia (EMS pelas suas siglas em inglês) que coordena o fluxo de energia proveniente das usinas, cargas controláveis e sistemas de armazenamento. A comunicação é bidirecional, assim a VPP não só recebe informação do estado atual de cada unidade ligada a ela, mas também pode enviar sinais de controle aos objetos como se mostra na figura 5 (Saboori, H., Mohammadi, M. and Taghe, R. 2011).

O EMS pode operar de acordo com a meta que se deseja atingir, a qual pode ser minimizar custos de geração, minimizar a produção de gases de efeito estufa ou a maximização de lucro. Com o objetivo de alcançar a meta estabelecida o EMS 
necessita receber informação do estado de cada uma das unidades de geração por uma parte, e, por outra, necessita também da previsão da produção de energia de cada usina. Isto é especialmente importante para as unidades de geração intermitentes como usinas eólicas e fotovoltaicas, bem como também se faz essencial a informação sobre os possíveis pontos de sobrecarga na rede, o que tem um papel relevante no processo de otimização da operação da VPP. Nesse sentido, o EMS pode escolher o modo de operação ótimo para cada sistema em particular.

Dada à natureza flutuante de algumas fontes de energia renovável, a previsão da geração de energia não é um procedimento fácil. Atualmente, para parques eólicos o erro na previsão encontra-se entre $9 \%$ e $19 \%$ e, devido a esses erros, as redes de energia com uma alta penetração de fontes renováveis podem facilmente ter um excesso de energia gerada, causando uma sobrecarga na rede e problemas de estabilidade. Esses problemas podem ser solucionados usando-se Sistemas de Armazenamento de Energia (SAE) ou o Sistema de gestão de segurança da rede (NSM pelas siglas em inglês). Embora os SAEs e NSM sejam os instrumentos mais usados, em alguns casos também podem ser utilizadassoluções alternativas, por exemplo: em regiões que tem pouca disponibilidade de água potável, plantas de destilação que são acionadas com o excedente de energia produzido podem ser uma ótima solução para encarar as situações de congestionamento da rede.

As VPP podem, por sua vez, formar parte de uma usina virtual de grande porte ou Large Scale Virtual Power Plant (LSVPP) com o propósito de obter uma maior integração dos DERs no sistema. Para conseguir isso, a arquitetura dos sistemas de controle distribuídos deve ser concebida e a infraestrutura de comunicação e informação deve ser desenvolvida para permitir a implementação do controle distribuído. Ademais, uma apropriada estrutura de mercado e comercial deve ser adotada para poder manter o intercâmbio de serviços entre todos os atores, incluindo o operador do sistema de transmissão, o operador do sistema de distribuição e as usinas virtuais. 


\subsection{Componentes de uma usina virtual ideal}

De acordo com ADHI, E., 2007, uma usina virtual ideal consiste dos elementos a seguir:

\subsubsection{A tecnologia de geração}

O conceito de geração distribuída é útil para demonstrar em termos gerais as diversas tecnologias atuais e a gama de aplicações, mostradas no Quadro 2. O Quadro 2 mostra as tecnologias de geração que estão tipicamente na categoria de geração distribuída, com algumas especificações e o tipo de interface de conexão com a rede elétrica, uma vez que desempenha um papel importante quando se consideram os aspectos operacionais da rede relacionados com a geração dispersa.

Quadro 2: Resumo de algumas tecnologias de geração e sua função no sistema (ADHI, E. 2007).

\begin{tabular}{|l|l|}
\hline \multicolumn{1}{|c|}{ Tecnologia } & \multicolumn{1}{c|}{ Função no sistema Elétrico } \\
\hline Cogeração com biomassa & $\begin{array}{l}\text { Com carga de base ou meio pico, conectada na rede de } \\
\text { média ou alta tensão }\end{array}$ \\
\hline Geotérmica & $\begin{array}{l}\text { Com carga de base ou meio pico, conectada na rede de } \\
\text { média ou alta tensão }\end{array}$ \\
\hline Eólica & Meio pico e superior, conectada na rede de média tensão \\
\hline Microturbina a gás & $\begin{array}{l}\text { Com carga de pico ou meio pico, conectada na rede de } \\
\text { média tensão }\end{array}$ \\
\hline Células combustíveis & $\begin{array}{l}\text { Com carga de pico ou meio pico, conectada na rede de } \\
\text { média tensão }\end{array}$ \\
\hline Células combustíveis de grande porte & $\begin{array}{l}\text { Com carga de base ou meio pico, conectada na rede de } \\
\text { média ou baixa tensão }\end{array}$ \\
\hline
\end{tabular}

Nesse aspecto, todas as unidades de geração podem ser classificadas em duas categorias, as quais são definidas da seguinte forma:

a. Gerador Distribuído Doméstico (GDD): é toda unidade de geração distribuída que serve a um usuário individual, para uso em residências, comércios ou indústrias. $O$ excesso de energia produzido pelos GDD pode ser injetado na rede, assim como o déficit de energia pode ser compensado pela rede. 
b. Gerador Distribuído Público (GDP): é uma unidade de geração que não pertence a um usuário individual e seu objetivo primário é injetar a energia produzida na rede. Geralmente tanto os GDPs como os GDDs podem ser equipados com dispositivos para armazenamento de energia, os quais geralmente se encontram conectados na rede de distribuição de baixa tensão. Por outro lado, os GDPs compreendem os geradores e eventualmente um armazenador de energia, que normalmente pode se conectar à rede de distribuição de média tensão. As diferenças entre GDPs e GDDs são as seguintes:

- O objetivo dos proprietários dos GDD é prover uma solução economicamente viável a suas necessidades de energia eléctrica e provavelmente às suas necessidades de calefação e esfriamento, bem como provavelmente incrementar a confiabilidade de serviço. Geralmente estão desinformados das normas de participação no mercado de energia. Por outro lado, o objetivo dos proprietários dos GDP é vender a energia que produzem ao mercado de energia.

- Geralmente, a capacidade de geração dos GDDs é pequena em comparação com a dos GDPs. Assim um GDD dificilmente terá a oportunidade de participar no mercado de energia de maneira independente, ao contrário do que pode acontecer com um GDP.

Alguns GDPs ou GDDs têm uma natureza de geração estocástica, por exemplo, as unidades de geração eólica e fotovoltaica as quais não estão equipadas com sistemas de armazenamento de energia. Alguns outros, como as células combustíveis e micro turbinas, são despacháveis, ou seja, são capazes de variar seu regime de operação rapidamente. Neste sentido, os GDP e GDD podem ser subdivididos em duas categorias: GDPs despacháveis (GDPDs) e GDPs estocásticos (GDPE), existindo, por sua vez, as mesmas categorias para GDD. Na Figura 6 são mostradas algumas das tecnologias de geração que podem estar presentes numa usina virtual. 


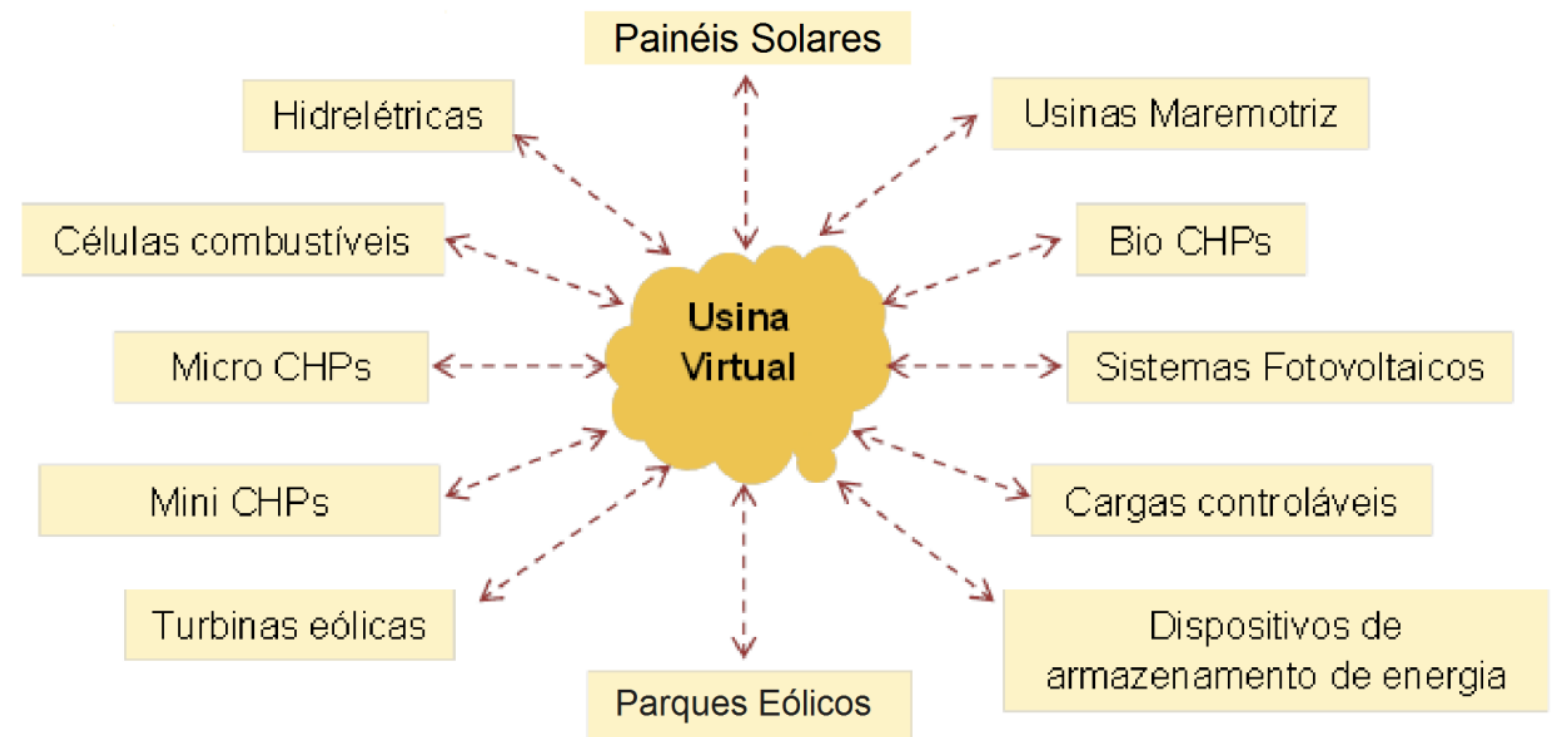

Figura 6: Tecnologias que podem conformar uma usina virtual (adaptado de El Bakari, k. and Kling, W. L., 2010).

\subsubsection{Tecnologias de armazenamento de energia}

$\mathrm{Na}$ atualidade, os sistemas de armazenamento de energia podem ser considerados como um novo meio de adaptar as variações na demanda de energia a um determinado nível de geração. No caso das energias renováveis ou outras fontes de geração distribuída, podem ser utilizadas também como fontes adicionais ou como método de regulação no caso de geração não programável, por exemplo, células combustíveis e energia fotovoltaica especialmente em redes fracas em relação com a geração distribuída e fontes de energia renováveis. No quadro 3,mostram-se os ciclos de vida e eficiência de algumas tecnologias de armazenamento mais utilizadas. 
Quadro 3: Ciclo de vida e eficiência de alguns sistemas de armazenamento (ADHI, E. 2007).

\begin{tabular}{|l|c|c|}
\hline \multicolumn{1}{|c|}{ Sistemas de armazenamento } & Vida (Ciclos) & Eficiência (\%) \\
\hline Hidroelétricas com bombeamento & 75 anos & $70-80$ \\
\hline Ar comprimido & 40 anos & - \\
\hline Baterias de Fluxo & $1500-2500$ & $75-85$ \\
\hline Baterias de óxido de metal & $100-200$ & 50 \\
\hline Baterias de sulfuro de sódio & $2000-3000$ & 89 \\
\hline Outras baterias avançadas & $500-1500$ & $90-95$ \\
\hline Baterias de acido de chumbo & $300-1500$ & $60-95$ \\
\hline Supercapacitores & $10000-100000$ & $93-98$ \\
\hline
\end{tabular}

Uma das principais preocupações do uso das fontes renováveis intermitentes é a flutuação de potência que é gerada por esse tipo de geradores de energia. As oscilações de energia têm como resultado a instabilidade do sistema de energia e consequentemente podem prejudicar equipamentos como geradores e motores. $\mathrm{O}$ uso de sistemas de armazenamento de energia é considerado como uma solução para fazer frente ante essa dificuldade e balancear o fluxo de energia na rede (Koohi-Kamali et al., 2013).

As tecnologias de armazenamento de energia também são capazes de corrigir os perfis de tensão da carga proporcionando um rápido controle da potência reativa e permitindo, portanto, que as usinas mantenham o balanço com a carga do sistema e sua velocidade normal. $\mathrm{O}$ armazenamento de energia é visto, na atualidade, mais como uma ferramenta para aumentar a estabilidade do sistema, ajudar na transferência de energia e aprimorar a qualidade do serviço nos sistemas de energia. Os Quadro 4 e 5, listam algumas das tecnologias de armazenamento de energia com as suas características de custo, potência existente, velocidade de reação e maturidade da tecnologia, dentre outras.

Para mais informação da forma de funcionamento e uma descrição mais profunda dos sistemas de armazenamento de energia, vide: Koohi-Kamali et al., 2013, Beaudin et al., 2010, Hadjipaschalis et al., 2009 e Barton, J. P. e Infield D. G., 2004. 
Quadro 4: Características dos Sistemas de Armazenamento de Energia. Fonte: Beaudin et al., 2010.

\begin{tabular}{|c|c|c|c|c|c|}
\hline $\begin{array}{c}\text { Tecnologia de } \\
\text { Armazenamento de } \\
\text { energia }\end{array}$ & $\begin{array}{c}\text { Custo da capacidade de } \\
\text { potência }(\$ / \mathrm{KW})\end{array}$ & $\begin{array}{c}\text { Descarga a } \\
\text { Capacidade nominal } \\
\text { (horas) }\end{array}$ & Capacidade nominal (MW) & $\begin{array}{l}\text { Tempo de } \\
\text { resposta }\end{array}$ & Maturidade \\
\hline $\begin{array}{l}\text { Hidroelétricas com } \\
\text { bombeamento }\end{array}$ & $\begin{array}{l}\text { 5-100 (Chen et al., 2009), } \\
10-12 \text { (Shoenung, 2001), } \\
\text { 50-100 (Faias et al., 2008) }\end{array}$ & $\begin{array}{l}\text { 1-24+ (Chen et al., } \\
2009), 12+\text { (Shoenung, } \\
2001)\end{array}$ & $\begin{array}{l}100-5000 \text { (Chen et al., 2009), } \\
1-4000 \text { (Shoenung, 2001), } \\
1000-3000 \text { (Faias et al., 2008) }\end{array}$ & $\begin{array}{l}\text { Minutos } \\
\text { (Shoenung, } \\
2001 \text { ) }\end{array}$ & Madura \\
\hline Ar Comprimido (CAES) & $\begin{array}{l}\text { 2-50 (Chen et al., 2009), } 3 \\
\text { (Shoenung, 2001), 15-100 } \\
\text { (Faias et al., 2008) }\end{array}$ & $\begin{array}{l}\text { 1-24+ (Chen et al., } \\
2009), \\
24+(\text { Shoenung, 2001) }\end{array}$ & $\begin{array}{l}\text { 5-300 (Chen et al., 2009), } 220 \\
\text { (Shoenung, 2001), 100-3000 } \\
\text { (Faias et al., 2008), 50-350 } \\
\text { (Lipman et al., 2005) }\end{array}$ & $\begin{array}{l}\text { Segundos - } \\
\text { minutos } \\
\text { (Shoenung, } \\
\text { 2001) }\end{array}$ & Usada \\
\hline $\begin{array}{l}\text { Baterias de ácido de } \\
\text { chumbo }\end{array}$ & $\begin{array}{l}200-400 \text { (Chen et al., 2009), } \\
175-250 \text { (Shoenung, 2001), } \\
50-100 \text { (Hadjipaschalis et } \\
\begin{array}{l}\text { al., 2009), 456-1574 } \\
\text { (Parker, 2001) }\end{array}\end{array}$ & $\begin{array}{l}0,0027-2+(\text { Chen et al., } \\
2009), \\
1-5 \text { (Barton and Infield, } \\
2004), \\
4-8 \text { (Shoenung, 2001) }\end{array}$ & $\begin{array}{l}\text { 0-20 (Chen et al., 2009; } \\
\text { Shoenung, 2001), 0-40 } \\
\text { (Parker, 2001) }\end{array}$ & $\begin{array}{l}<1 / 4 \text { ciclo } \\
\text { (Shoenung, } \\
2001)\end{array}$ & Madura \\
\hline $\begin{array}{l}\text { Baterias de Níquel- } \\
\text { Cadmio }\end{array}$ & \begin{tabular}{|l|}
$800-1500$ (Chen et al., \\
$2009)$, \\
$400-2400$ (Hadjipaschalis et \\
al., 2009)
\end{tabular} & $\begin{array}{l}0,0027-2+\text { (Chen et al., } \\
2009), \\
1-10 \text { (Barton and Infield, } \\
2004), \\
6-8 \text { (Smith et al., 2008) }\end{array}$ & 0-40 (Chen et al., 2009) & $<1 / 4$ ciclo & Usada \\
\hline $\begin{array}{l}\text { Baterias de sódio- } \\
\text { enxofre }\end{array}$ & $\begin{array}{l}300-500 \text { (Chen et al., 2009), } \\
245 \text { (Shoenung, 2001) }\end{array}$ & $\begin{array}{l}0,0027-2+(\text { Chen et al., } \\
2009), \\
4-8 \text { (Barton and Infield, } \\
2004), \\
1 \text { (Shoenung, 2001), } 6 \\
(\text { NGK, 2009C) }\end{array}$ & $\begin{array}{l}\text { 0,050-8 (Chen et al., 2009), } \\
\text { 0-34 (NGK, 2009c) }\end{array}$ & \begin{tabular}{|l|}
$<1 / 4$ ciclo (NGK, \\
$2009 \mathrm{c})$
\end{tabular} & Comercializado \\
\hline Baterias de lítio & \begin{tabular}{|l}
$600-2500$ (Chen et al., \\
$2009)$, \\
$900-1300$ (Hadjipaschalis et \\
al., \\
$2009)$
\end{tabular} & $\begin{array}{l}0,017-2+(\text { Chen et al., } \\
2009)\end{array}$ & 0-0,1 (Chen et al., 2009) & $<1 / 4$ ciclo & Comercializado \\
\hline Célula Combustível & $\begin{array}{l}425-725 \text { (Shoenung, 2001) } \\
15 \text { (Shoenung, 2001) }\end{array}$ & \begin{tabular}{|l|}
$0,0027-24+($ Chen et al., \\
$2009)$, \\
$12+($ Barton and Infield, \\
$2004)$
\end{tabular} & $\begin{array}{l}0-50 \text { (Chen et al., 2009; } \\
\text { Faias et al., 2008), } 0.2 \\
\text { (Shoenung, 2001) }\end{array}$ & $\begin{array}{l}<1 / 4 \text { ciclo } \\
\text { (Shoenung, } \\
2001)\end{array}$ & Desenvolvimento \\
\hline $\begin{array}{l}\text { Bateria redox de } \\
\text { vanádio }\end{array}$ & 150-1000 (Chen et al., 2009) & \begin{tabular}{|l|}
$0,0027-10$ (Chen et al., \\
$2009)$, \\
$2-12$ (Barton and Infield, \\
$2004)$
\end{tabular} & 0,03-3 (Chen et al., 2009) & $<1 / 4$ ciclo & Desenvolvimento \\
\hline Bateria de zinco-bromo & $\begin{array}{l}150-1000 \text { (Chen et al., } \\
2009), \\
200 \text { (Shoenung, 2001), } \\
400 \text { (Lipman et al., 2005) }\end{array}$ & $\begin{array}{l}0,027-10 \text { (Chen et al., } \\
2009), \\
2-5 \text { (Barton and Infield, } \\
2004), \\
2 \text { (Shoenung, 2001), } 5 \\
(P P, 2009)\end{array}$ & $\begin{array}{l}\text { 0,05-2 (Chen et al., 2009), } \\
0,05 \text { (Shoenung, 2001), } \\
0-0.5 \text { citeppp2009 }\end{array}$ & $\begin{array}{l}<1 / 4 \text { ciclo } \\
\text { (Shoenung, } \\
2001)\end{array}$ & Desenvolvimento \\
\hline SMES & $\begin{array}{l}\text { 1000-10,000 (Chen et al., } \\
2009), \\
500-72,000 \text { (Shoenung, } \\
2001 \text { ) }\end{array}$ & $\begin{array}{l}2.7 \times 10^{-7}-0,0022 \\
\text { (Chen et al., 2009) }\end{array}$ & $\begin{array}{l}\text { 0,1-10 (Chen et al., 2009), } \\
0-100 \text { (Faias et al., 2008) }\end{array}$ & $\begin{array}{l}<1 / 4 \text { ciclo } \\
\text { (Shoenung, } \\
2001)\end{array}$ & Desenvolvimento \\
\hline Volante de inércia & $\begin{array}{l}1000-5000 \text { (Chen et al., } \\
2009), \\
300-25,000 \text { (Shoenung, } \\
2001), \\
400-800 \text { (Hadjipaschalis et } \\
\text { al., 2009), } \\
100-800 \text { (Lipman et al., } \\
2005)\end{array}$ & $\begin{array}{l}2,7 \times 10^{-7}-0,25 \\
\text { (Chen et al., 2009), } \\
0.000-0.01 \text { (Barton } \\
\text { and Infield, 2004), } \\
0,00083-0,03 \\
\text { (Shoenung, 2001) }\end{array}$ & $\begin{array}{l}0-0,250 \text { (Chen et al., 2009; } \\
\text { Smith et al., 2008), 0-1,65 } \\
\text { (Shoenung, 2001), 0-10 } \\
\text { (Faias et al., 2008) }\end{array}$ & $\begin{array}{l}<1 / 4 \text { ciclo } \\
\text { (Shoenung, } \\
2001)\end{array}$ & Desenvolvimento \\
\hline Capacitores & 500-1000 (Chen et al., 2009) & $\begin{array}{l}2,7 \times 10^{-7}-1 \text { (Chen } \\
\text { et al., 2009) }\end{array}$ & $0-0,05$ (Chen et al., 2009) & $<1 / 4$ ciclo & Usada \\
\hline Supercapacitores & $\begin{array}{l}\text { 300-2000 (Chen et al., } \\
2009), \\
82.000 \text { (Shoenung, 2001), } \\
20.000 \text { (Hadjipaschalis et al., } \\
2009)\end{array}$ & $\begin{array}{l}2,7 \times 10^{-7}-1 \text { (Chen et } \\
\text { al., 2009), 0,0027 } \\
\text { (Shoenung, 2001) }\end{array}$ & $\begin{array}{l}0-0,3 \text { (Chen et al., 2009), } \\
0-0,1 \text { (Shoenung, 2001), } \\
0-10 \text { (Faias et al., 2008) }\end{array}$ & $\begin{array}{l}<1 / 4 \text { ciclo } \\
\text { (Shoenung, } \\
2001)\end{array}$ & Desenvolvimento \\
\hline
\end{tabular}


Quadro 5: Características dos Sistemas de Armazenamento de Energia. Fonte: Beaudin et al., 2010.

\begin{tabular}{|c|c|c|c|c|c|}
\hline $\begin{array}{c}\text { Tecnologia de } \\
\text { Armazenamento de } \\
\text { energia }\end{array}$ & $\begin{array}{c}\text { Perdas Parasitas } \\
\text { diárias }\end{array}$ & $\begin{array}{l}\text { Vida } \\
\text { (anos) }\end{array}$ & Eficiência por ciclo & Ciclos de vida & $\begin{array}{l}\text { Requerimentos } \\
\text { de espaço } \\
\text { (m2/kW h) }\end{array}$ \\
\hline $\begin{array}{l}\text { Hidroelétricas com } \\
\text { bombeamento }\end{array}$ & $\begin{array}{l}\text { Muito pouca (Chen } \\
\text { et al., 2009) }\end{array}$ & $\begin{array}{l}40-60 \text { (Chen et al., 2009), } \\
35 \text { (Anderson and Leach, 2004), } \\
60 \text { (Denholm and Kulcinski, } \\
2004), \\
30 \text { (Shoenung, 2001), } 40 \text { (Faias } \\
\text { et al., 2008), } 50 \text { (Schaber et al., } \\
2004 \text { ) }\end{array}$ & $\begin{array}{l}\text { 71-85 (Chen et al., 2009), } \\
70-80 \text { (Smith et al., 2008), } \\
75 \text { (Anderson and Leach, 2004; } \\
\text { Schaber et al., 2004), 78 } \\
\text { (Denholm and Kulcinski, 2004), } \\
87 \text { (Shoenung, 2001), } \\
80 \text { (Faias et al., 2008) }\end{array}$ & $10.000-30.000$ & $\begin{array}{l}0,02 \\
\text { (Shoenung, 2001) }\end{array}$ \\
\hline Ar Comprimido (CAES) & $\begin{array}{l}\text { Poucas (Chen et al., } \\
\text { 2009) }\end{array}$ & $\begin{array}{l}20-40 \text { (Chen et al., 2009), } \\
30 \text { (Shoenung, 2001; Faias } \\
\text { et al., 2008), } 20 \text { (Schaber } \\
\text { et al., 2004) }\end{array}$ & $\begin{array}{l}70-89 \text { (Chen et al., 2009), } \\
85 \text { (Smith et al., 2008), } \\
71 \text { (Denholm and Kulcinski, } \\
\text { 2004), } 75 \text { (Faias et al., 2008; } \\
\text { Schaber et al., 2004), } 84 \\
\text { (Mason et al., 2008), } \\
\text { 88(Moutoux, 2007) }\end{array}$ & $8.000-12.000$ & $\begin{array}{l}0,01 \\
\text { (Shoenung, 2001) }\end{array}$ \\
\hline $\begin{array}{l}\text { Baterias de ácido de } \\
\text { chumbo }\end{array}$ & $\begin{array}{l}0,1-0,3 \% \text { (BU, 2008; } \\
\text { Chen et al., 2009), } \\
0,007 \% \\
\text { (Hadjipaschalis } \\
\text { et al., 2009) }\end{array}$ & $\begin{array}{l}5-15 \text { (Chen et al., 2009; } \\
\text { Hadjipaschalis et al., 2009), } \\
5 \text { (Shoenung, 2001), } 20 \\
\text { (Parker, 2001) }\end{array}$ & $\begin{array}{l}70-90 \text { (Chen et al., 2009) } \\
63 \text { (Barton and Infield, 2004), } \\
85 \text { (Shoenung, 2001), 85-90 } \\
\text { (Hadjipaschalis et al., 2009) }\end{array}$ & $\begin{array}{l}500-1.000 \text { (Chen et } \\
\text { al., 2009), 200-300 } \\
\text { (BU, 2008), } \\
1.200-1.800 \\
\text { (Hadjipaschalis et al., } \\
\text { 2009) }\end{array}$ & $\begin{array}{l}0,058 \\
\text { (Shoenung, 2001) }\end{array}$ \\
\hline $\begin{array}{l}\text { Baterias de Níquel- } \\
\text { Cadmio }\end{array}$ & \begin{tabular}{|l|}
$0,2-0,6 \%$ (Chen et \\
al., 2009), 0,6\% (BU, \\
$2008), 0,03 \%$ \\
(Hadjipaschalis \\
et al., 2009)
\end{tabular} & $\begin{array}{l}\text { 10-20 (Chen et al., 2009), } \\
\text { 15-20 (Hadjipaschalis } \\
\text { et al., 2009) }\end{array}$ & $\begin{array}{l}72 \text { (Barton and Infield, 2004), } \\
60-83 \text { (Hadjipaschalis et al., } \\
\text { 2009) }\end{array}$ & $\begin{array}{l}\text { 2.000-2.500 (Chen et } \\
\text { al., 2009), 1;500 (BU, } \\
\text { 2008), 1.500-3.000 } \\
\text { (Hadjipaschalis et al., } \\
\text { 2009) }\end{array}$ & 0,003 \\
\hline $\begin{array}{l}\text { Baterias de sódio- } \\
\text { enxofre }\end{array}$ & $\begin{array}{l}20 \% \text { (Chen et al., } \\
2009 \text { ) }\end{array}$ & $\begin{array}{l}10-15 \text { (Chen et al., 2009), } \\
15 \text { (Smith et al., 2008; NGK, } \\
2009 c), 5 \text { (Shoenung, 2001), } \\
10 \text { (Schaber et al., 2004) }\end{array}$ & $\begin{array}{l}\text { 75-90 (Chen et al., 2009), } \\
87 \text { (Barton and Infield, 2004), } \\
85 \text { (Arai et al., 2008), 76 } \\
\text { (Shoenung, 2001), 89-92 } \\
\text { (Hadjipaschalis et al., 2009) }\end{array}$ & $\begin{array}{l}2.500 \text { (Chen et al., } \\
2009 ; \\
\text { Schaber et al., 2004), } \\
4.500 \text { (NGK, 2009c) }\end{array}$ & $\begin{array}{l}0,019 \\
\text { (Shoenung, 2001) }\end{array}$ \\
\hline Baterias de lítio & $\begin{array}{l}0,1-0,3 \% \text { (BU, 2008; } \\
\text { Chen et al., 2009), } \\
0,02 \% \\
\text { (Hadjipaschalis } \\
\text { et al., 2009) }\end{array}$ & $\begin{array}{l}\text { 5-15 (Chen et al., 2009), } \\
10 \text { (Schaber et al., 2004) }\end{array}$ & $\begin{array}{l}\text { quase } 100 \text { (Chen et al., 2009), } \\
\text { 90-100 (Hadjipaschalis et al., } \\
\text { 2009), } 85 \text { (Schaber et al., 2004) }\end{array}$ & $\begin{array}{l}1000-10.000+(\text { Chen } \\
\text { et al., 2009), } \\
300-500+(B U, 2008), \\
<1500 \\
\text { (Hadjipaschalis et al., } \\
2009), 800 \text { (Schaber } \\
\text { et al., 2004) }\end{array}$ & 0,03 \\
\hline Célula Combustível & $\begin{array}{l}\text { Quase zero (Chen et } \\
\text { al., } \\
\text { 2009) }\end{array}$ & $\begin{array}{l}5-15 \text { (Chen et al., 2009), } \\
20 \text { (Shoenung, 2001) }\end{array}$ & $\begin{array}{l}20-50 \text { (Chen et al., 2009), } 32 \\
\text { (Barton and Infield, 2004), } \\
59 \text { (Shoenung, 2001), 20-36 } \\
\text { (Faias et al., 2008), 45-66 }\end{array}$ & $\begin{array}{l}\text { 1000+ (Chen et al., } \\
2009 \text { ) }\end{array}$ & $\begin{array}{l}0,003-0,006 \\
\text { (Shoenung, 2001) }\end{array}$ \\
\hline $\begin{array}{l}\text { Bateria redox de } \\
\text { vanádio }\end{array}$ & $\begin{array}{l}\text { Poucas (Chen et al., } \\
\text { 2009) }\end{array}$ & $\begin{array}{l}\text { 5-10 (Chen et al., 2009), } \\
30 \text { (Schaber et al., 2004) }\end{array}$ & $\begin{array}{l}85 \text { (Chen et al., 2009), } \\
75 \text { (Barton and Infield, 2004), } \\
80 \text { (Arai et al., 2008; Schaber } \\
\text { et al., 2004) }\end{array}$ & $\begin{array}{l}\text { 12.000+ (Chen et al., } \\
2009)\end{array}$ & 0,04 \\
\hline Bateria de zinco-bromo & $\begin{array}{l}\text { Poucas (Chen et al., } \\
\text { 2009) }\end{array}$ & $\begin{array}{l}\text { 5-10 (Chen et al., 2009), } \\
\text { 30+ anos (PP, 2009; Schaber } \\
\text { et al., 2004) }\end{array}$ & $\begin{array}{l}75 \text { (Chen et al., 2009), } 70 \\
\text { (Barton and Infield, 2004), } \\
80 \text { (Arai et al., 2008), } 66 \\
\text { (Shoenung, 2001) }\end{array}$ & $\begin{array}{l}\text { 2000+ (Chen et al., } \\
\text { 2009; Lipman et al., } \\
\text { 2005) }\end{array}$ & $\begin{array}{l}6-26 \\
\text { citepdoe2001 }\end{array}$ \\
\hline SMES & \begin{tabular}{|l|} 
10-15\% (Chen et al., \\
$2009)$
\end{tabular} & $\begin{array}{l}20+\text { (Chen et al., 2009), } \\
30 \text { (Shoenung, 2001) }\end{array}$ & $\begin{array}{l}\text { 97+ (Chen et al., 2009), } 21 \\
\text { (Barton and Infield, 2004), } \\
\text { 95-98 (Smith et al., 2008), } \\
95 \text { (Faias et al., 2008; Ribeiro } \\
\text { et al., 2001; Shoenung, 2001) }\end{array}$ & $\begin{array}{l}100.000+\text { (Chen et } \\
\text { al., 2009; Faias et al., } \\
\text { 2008) 20.000+ }\end{array}$ & $\begin{array}{l}\text { 6-26 (Shoenung, } \\
2001)\end{array}$ \\
\hline Volante de inércia & $\begin{array}{l}\text { 100\% (Chen et al., } \\
2009 ; \text { Hadjipaschalis } \\
\text { et al., 2009) }\end{array}$ & $\begin{array}{l}15 \text { (Chen et al., 2009; Anderson } \\
\text { and Leach, 2004), } 20 \text { (Smith } \\
\text { et al., 2008; Shoenung, 2001; } \\
\text { Hadjipaschalis et al., 2009) }\end{array}$ & $\begin{array}{l}\text { 90-95 (Chen et al., 2009), } \\
89 \text { (Barton and Infield, 2004), } \\
80-85 \text { (Smith et al., 2008), } \\
92 \text { (Anderson and Leach, } \\
2004), \\
90-93 \text { (Shoenung, 2001), } \\
90 \text { (Faias et al., 2008; } \\
\text { Hadjipaschalis et al., 2009) } \\
\end{array}$ & $\begin{array}{l}\text { 20.000+ (Chen et al., } \\
2009 \text { ), 100.000 (Faias } \\
\text { et al., 2008) }\end{array}$ & $\begin{array}{l}0,03-0,06 \\
\text { (Shoenung, 2001) }\end{array}$ \\
\hline Capacitores & $\begin{array}{l}40 \% \text { (Chen et al., } \\
2009 \text { ) }\end{array}$ & 5 (Chen et al., 2009) & $60-70$ & $\begin{array}{l}\text { 50.000+ (Chen et al., } \\
2009), 100.000+\end{array}$ & \\
\hline Supercapacitores & $\begin{array}{l}20-40 \% \text { (Chen et al., } \\
2009 \text { ), } 0.5 \% \\
\text { (Hadjipaschalis et } \\
\text { al., 2009), 5\% } \\
\text { (lbrahim et al., } \\
2008 \text { ) }\end{array}$ & $\begin{array}{l}\text { 8-20+ (Chen et al., 2009), } \\
10-12 \text { (Smith et al., 2008), } \\
12 \text { (Hadjipaschalis et al., 2009), } \\
\text { 8-10 (Ibrahim et al., 2008) }\end{array}$ & $\begin{array}{l}\text { 84-95 (Smith et al., 2008), } 86 \\
\text { (Barton and Infield, 2004), } 95 \\
\text { (Shoenung, 2001; lbrahim et al., } \\
\text { 2008), } 90 \text { (Faias et al., 2008), } \\
\text { 85-98 (Hadjipaschalis et al., } \\
\text { 2009) }\end{array}$ & $\begin{array}{l}100.000+(\text { Chen et } \\
\text { al., 2009; Faias et al., } \\
2008), 10.000 \\
\text { (Shoenung, 2001), } \\
500.000 \\
\text { (Hadjipaschalis et al., } \\
2009)\end{array}$ & $\begin{array}{l}0,04 \\
\text { (Shoenung, 2001) }\end{array}$ \\
\hline
\end{tabular}




\subsubsection{Aplicações dos sistemas de armazenamento de energia (SAE)}

O papel dos sistemas de armazenamento de energia para incrementar a estabilidade das redes de distribuição está crescendo dia a dia. Um dos benefícios mais importantes que os SAEs trazem é dar suporte à rede de energia no propósito de satisfazer a demanda da carga constantemente. No caso dos SAEs e as energias renováveis, os SAES cumprem um importante papel nas redes onde se tem um crescimento considerável na penetração destas fontes de geração, sendo capazes de ajudar a controlar as variações de frequência, aumentar a capacidade das linhas de transmissão de energia, mitigando as flutuações de tensão e aprimorando a qualidade e confiabilidade do sistema como tal. Na Figura 7, mostram-se a magnitude da potência e o tempo requerido para cada uma das aplicações anteriormente mencionadas, mostra-se também quem pode ser a parte mais interessada nessas aplicações, as concessionárias de energia ou os usuários finais.

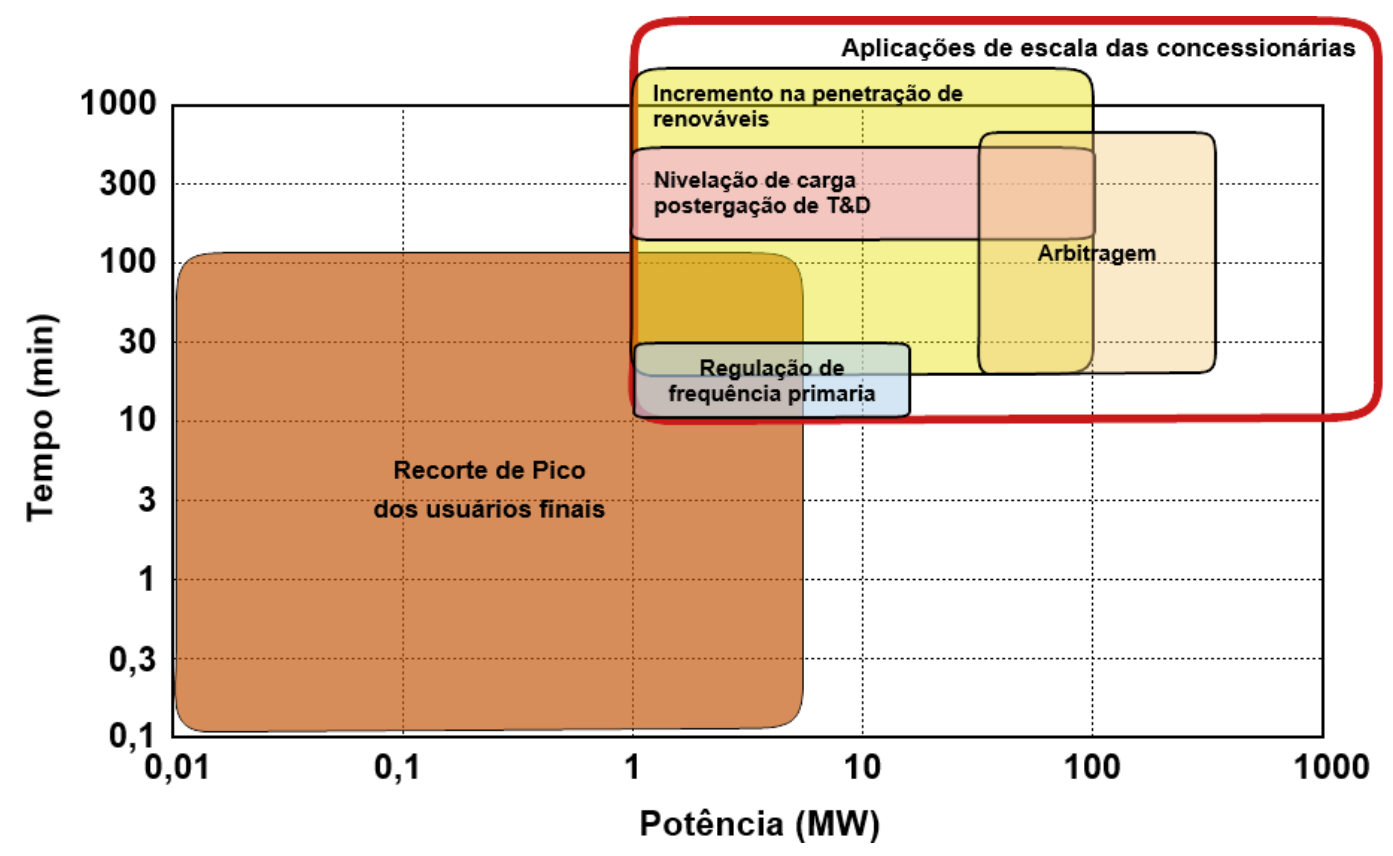

Figura 7: Aplicações dos SAE por beneficiário do uso. Fonte: adaptado de Koohi-Kamali et al., 2013 
As aplicações para os SAE podem variar em seus requisitos de capacidade de energia, tempo de reação e disponibilidade do recurso, bem como a quantidade de potência que podem entregar para sistema. Na Figura 8, mostram-se as aplicações que diferentes tipos de SAEs podem proporcionar por tempo de descarga e potência nominal do sistema de armazenamento.

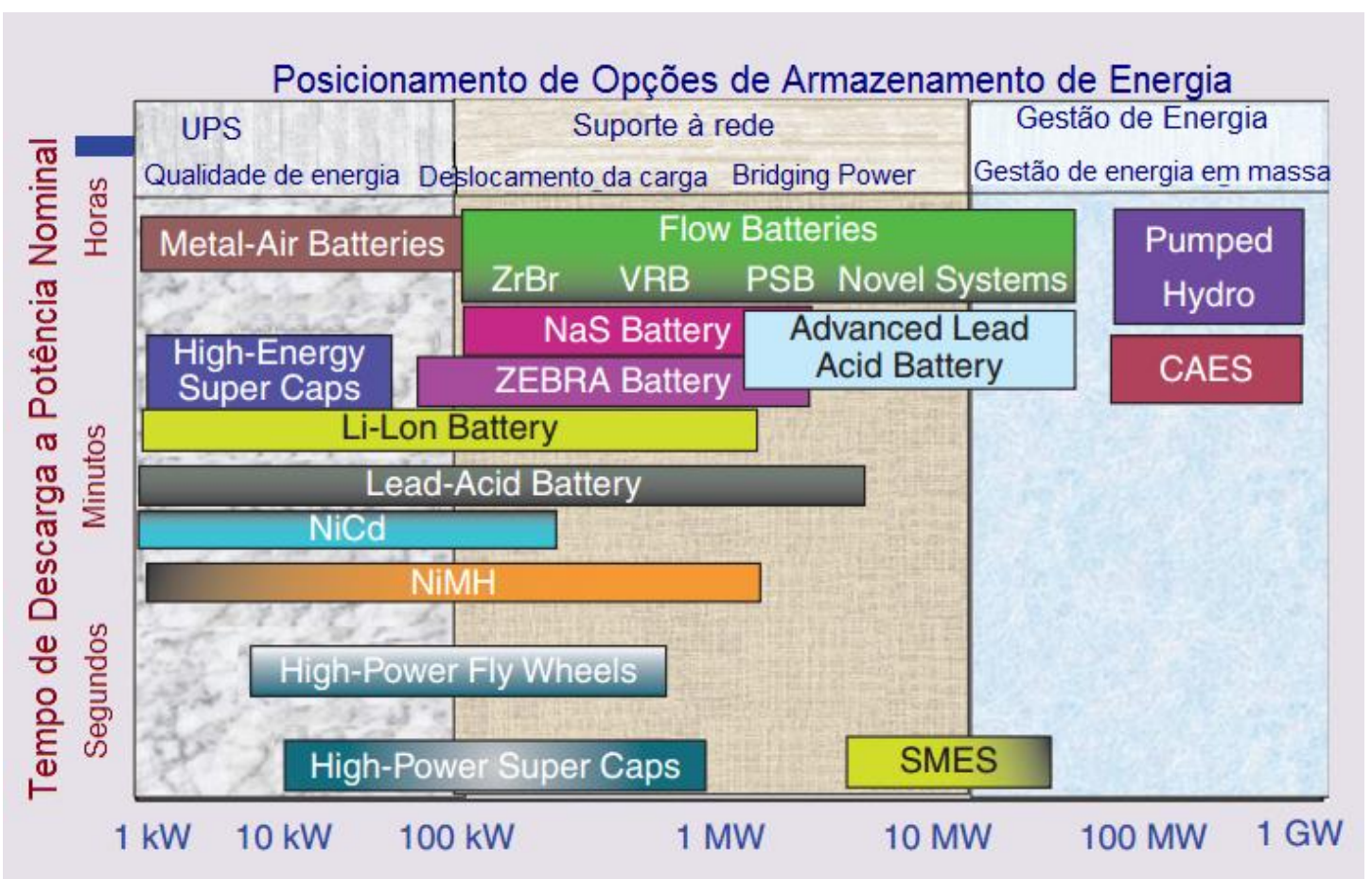

Figura 8: Aplicações dos SAEs por tipo de benefício brindado e tempo de duração. Fonte: adapto de EPRI.

A implementação dos SAEs no sistema elétrico pode facilitar as seguintes aplicações:

\section{Incrementar a penetração das fontes renováveis de energia}

Ainda quando as fontes renováveis de energia são ambientalmente amigáveis, a natureza intermitente de alguns destes tipos de geração de energia, como no caso, por exemplo, da energia fotovoltaica e eólica, podem resultar em oscilações da tensão e frequência na rede (Koohi-Kamali et al., 2013). Essas oscilações, bem como a variação na produção de energia destas fontes devido à não concordância 
entre a produção esperada e produção real, podem incrementar o uso de fontes emergênciais que possuem um tempo de reação rápido (como é caso das usinas que utilizam gás natural) para compensar essas variações.

Para resolver o problema da intermitência característica de algumas fontes de energia renovável, apresenta-se a necessidade de respaldar essas unidades de geração com a presença de outras usinas convencionais no sistema. Estima-se que a cada $10 \%$ de energia eólica inserida no sistema deve existir aproximadamente um 2 - 4\% da capacidade instalada de energia eólica de energia produzida por outras fontes, com o propósito de criar um equilíbrio de energia e assim o sistema possa manter sua estabilidade. O uso de usinas convencionais para esse propósito faz o sistema mais complexo do que aqueles que fazem uso de SAEs (Koohi-Kamali et al., 2013), além de que o uso de SAEs em lugar de usinas convencionais pode significar uma redução na geração de gases de efeito estufa.

\section{Cortar picos da demanda}

O recorte do pico da demanda pode referir-se à política de operação aplicada aos dispositivos de armazenamento, para que armazenem eletricidade no período que o preço é baixo (fora de pico) com o propósito de vender a energia armazenada à rede nos momentos de alta demanda ou pico. Os dispositivos de armazenamento desejáveis para esta aplicação são baterias, baterias de fluxo, sistemas de armazenamento de energia por ar comprimido (CAESS pelas suas siglas em inglês) e hidroelétricas com bombeamento.

Pesquisas tecno-econômicas vêm sendo realizadas e mostram a viabilidade de armazenar energia em horas de pouca demanda e vendê-la em períodos de picos de demanda. Em Kapsali M, Kaldellis JK, 2010, apresenta-se a pesquisa técnicoeconômica para estudar a viabilidade dos sistemas eólicos-hídricos para prover energia em períodos de baixa demanda. Os resultados mostram um excelente rendimento técnico e econômico. Pode-se concluir desta pesquisa que a integração de plantas eólicas, no caso de estudo, pode ser incrementada em $9 \%$, permitindo um nível de penetração de $20 \%$. 


\section{Regulação de frequência e amortecimento de oscilações}

A frequência do sistema é um importante parâmetro a ser mantido dentro de uma faixa permitida para a manutenção da estabilidade do sistema elétrico. Se os GDs não são utilizados em conjunto com SAEs durante os momentos de transição, um câmbio no estado do sistema pode resultar em oscilações incontroláveis levando o sistema a um estado de instabilidade. Para ajustar a frequência da rede dinamicamente durante as transições, os SAEs podem ter um papel chave para manter a estabilidade do sistema (Koohi-Kamali et al., 2013).

Devido ao fato de que os ajustes de frequência dependem grandemente da injeção e absorção de potência ativa em uma curta duração de tempo (1-2 s), dispositivos de armazenamento de energia de mediano e pequeno porte podem ser utilizados para estabilizar a frequência angular. Essa aplicação pode contribuir, por exemplo, para estabilizar a frequência em concessionárias de energia isoladas com uma alta porcentagem de geração eólica, ver Rabiee et al., 2013. As baterias de fluxo e SAEs de curta duração como supercapacitores, volantes de inércia e sistemas de supercondutores são muito indicados para este tipo de aplicações.

\section{Reserva operacional}

Numa rede de energia, a reserva operacional refere-se à capacidade de geração que se encontra disponível e pode ser injetada ao sistema pela decisão do operador num curto período de tempo. Espera-se que a reserva operacional atenda a carga em caso de perda do principal fornecedor de energia ou qualquer outra razão que possam resultar em que o intercâmbio de potência seja diferente de zero (KoohiKamali et al., 2013). A maior parte dos sistemas de potência estão projetados de tal forma que em condições normais a reserva operacional é sempre igual à menor capacidade da maior usina mais uma fração do pico de carga. A reserva operacional consiste em spinning reserve, bem como na reserva não suplementar ou nãospinning.

Em Rabiee et al., 2013, spinning reserve é definida como a capacidade de geração não usada que pode ser ativada por decisão do operador do sistema, e a qual é fornecida sincronizando dispositivos capazes de afetar a potência ativa do sistema 
com a rede. A reserva não spinning ou suplementar refere-se a capacidade extra de geração que não se encontra conectada ao sistema no momento, mas pode ser colocada em linha depois de uma pequena demora. Em sistemas isolados de energia, tipicamente equivale à energia disponível dos geradores de resposta rápida. No entanto, em sistemas interligados de energia pode incluir a energia disponível com pouca antecedência, importando energia desde outros sistemas ou retirando a energia que já tinha sido injetado no sistema.

As reservas secundária e terciária podem ser consideradas como spinning reserve, porqueelas também podem ser ativadas por decisão do operador. Segundo Rabiee et al., 2013, existem várias tecnologias de armazenamento as quais são apropriadas para estas aplicações como: o volante de inércia, SMES, baterias, baterias de fluxo, HESS, CAES ou PHS. VBRs também são candidatos apropriados para esse tipo de aplicações, já que eles podem responder rapidamente a qualquer mudança na demanda de energia da rede, assim como também possuem a capacidade de trabalhar em sobrecarga.

\section{Capacidade de suportar (ride-through) baixa de tensão (LVRT)}

LVRT é um problema que se apresenta quando uma falha nas proximidades da rede causa uma redução na tensão da rede no ponto onde a usina é conectada com a rede. Isso limita a energia que pode ser extraída do dispositivo. Se existe uma grande entrada de energia sem controle, o desequilíbrio leva a um incremento desregulado da velocidade da turbina, ou o bus da tensão DC dos conversores back to back. Os SAEs podem prevenir o excesso de velocidade nas turbinas, estabilizar o bus de tensão DC, e por conseguinte satisfazer os requisitos da rede.

\section{Aprimoramento da qualidade de energia}

Beaudin et al., 2010, sugere que nas redes grandes os problemas de qualidade de energia relacionados às flutuações das fontes variáveis de energia renovável precisam ser tratados quando a tensão varia mais de $10 \%$ do valor nominal, e mais do $5 \%$ do tempo, ou se ocorre uma queda de tensão maior que $15 \%$ do valor nominal.

Na norma IEEE 1547.2, 2008, estabelece-se que a tensão deve ser mantida dentro de uma faixa de $\pm 5 \%$ da tensão nominal e, assim, para gerar energia de alta 
qualidade, é obrigatório controlar cuidadosamente o fluxo de potência reativa na rede. O uso de SAEs podem ajudar a aprimorar o comportamento dinâmico das unidades de geração às quais se encontram ligadas, tais como geradores eólicos os quais supõem-se serão operados como unidades compensadoras de tensão (KoohiKamali et al., 2013). Devido ao fato de que uma rampa com uma taxa elevada é necessária para responder às variações na demanda de energia, as baterias e dispositivos de armazenamento de curta duração tempo tais como: supercapacitores, volantes de inércia e SMES, podem ser soluções desejáveis para esta aplicação.

O uso de inversores, os quais são necessários para sistemas fotovoltaicos e alguns geradores eólicos, introduzem vários harmônicos indesejáveis que podem afetar negativamente os equipamentos eletrônicos. Aliás, os sistemas fotovoltaicos são susceptíveis a picos de energia, bem como a ausência de geração - passagem de nuvens ou objetos sobre os painéis. As tecnologias de armazenamento de energia que podem tratar esses problemas de qualidade de energia requerem uma boa disponibilidade de ciclos de uso e um tempo de resposta rápido como, por exemplo, a resposta de subciclo a preço razoável pode ser fornecida por volantes de inércia, capacitores e baterias. Supercapacitores e SMES, os quais têm um excelente ciclo de vida, podem ter potencial nestas aplicações, mas ainda não são tecnologias o suficientemente maduras para serem considerados numa aplicação em uma concessionária (Beaudin et al, 2010). Sem embargo, as tecnologias antes mencionadas estão emergindo e aprimorando seu funcionamento rapidamente, o que pode fazer com que substituam a dominante bateria chumbo ácida.

\subsubsection{Tecnologias de comunicação da informação}

Um requisito importante para a implementação das VPP são as tecnologias e infraestrutura de comunicação. Os diferentes requisitos e necessidades foram classificados dentro de três categorias principais, que refletem o grau de importância das diversas necessidades de comunicação, ver o Quadro 6. 
Quadro 6: Classificação das necessidades e requisitos de comunicação das VPP. Fonte: ADHI, E. 2007.

\begin{tabular}{|c|c|c|}
\hline $\begin{array}{l}\text { Comunicação do estado } \\
\text { operacional em tempo real }\end{array}$ & $\begin{array}{c}\text { Comunicação } \\
\text { operacional }\end{array}$ & $\begin{array}{l}\text { Comunicação } \\
\text { administrativa }\end{array}$ \\
\hline $\begin{array}{l}\text { Comunicação de dados } \\
\text { operacionais em tempo real: } \\
\text { Teleproteção }\end{array}$ & $\begin{array}{l}\text { Registro de eventos e } \\
\text { distúrbios }\end{array}$ & Telefones \\
\hline $\begin{array}{l}\text { Sistemas de Controle de } \\
\text { potência }\end{array}$ & $\begin{array}{l}\text { Controle de ativos e } \\
\text { gestão de informação de } \\
\text { contratos de venda }\end{array}$ & Fax \\
\hline Comunicação de voz: telefonia & Subestações & E-mail \\
\hline
\end{tabular}

Diferentes meios podem ser considerados para realizar os projetos de comunicação entre os sistemas de gestão de energia (SGE) /SCADA e o centro de despacho de distribuição de energia (Marihart, D. 2001). As tecnologias de comunicação mais apropriadas para realizar o intercâmbio de informação que se encontram disponíveis atualmente são consideradas por ordem de prioridade da seguinte maneira:

- Cabos de fibra ótica desde o sistema do centro de controle mestre a cada uma das áreas do centro de despacho de distribuição (se aplicável) e às subestações na rota do cabo de fibra ótica.

- Comunicação por micro-onda ou DMA desde as áreas dos centros de distribuição de despacho à subestação selecionada.

- Sistemas de rádio multidirecionais (MARS pelas suas siglas em inglês) e radio UH P-T-P nas bandas $450 / 900 \mathrm{MHz}$ para o controle remoto dos comutadores das subestações e das linhas.

- Comunicação por satélite desde o sistema do centro de controle mestre a cada uma das ADDCs (se poder ser aplicado).

- Cabo metálico (Coaxial ou trançado) para aplicações locais.

De acordo com a topologia de controle, pode-se dividir as usinas virtuais nas seguintes categorias:

- Usina Virtual centralizada: nesta categoria as unidades de geração distribuída são controladas por um centro de coordenação de controle (CCC) que está localizada bem no centro das unidades de geração distribuída. Os sinais das cargas são transmitidos para o CCC e processados por meio de um algoritmo 
lógico,depois os sinais são despachados para cada controlador de geração distribuída (CGD), e logo a potência ativa que precisa ser entregue é produzida de acordo com os sinais do CCC (ver Figura 9). O CCC é capaz de realizar funções tanto técnicas como econômicas com o propósito de obter a maior quantidade de benefícios da agregação da geração distribuída.

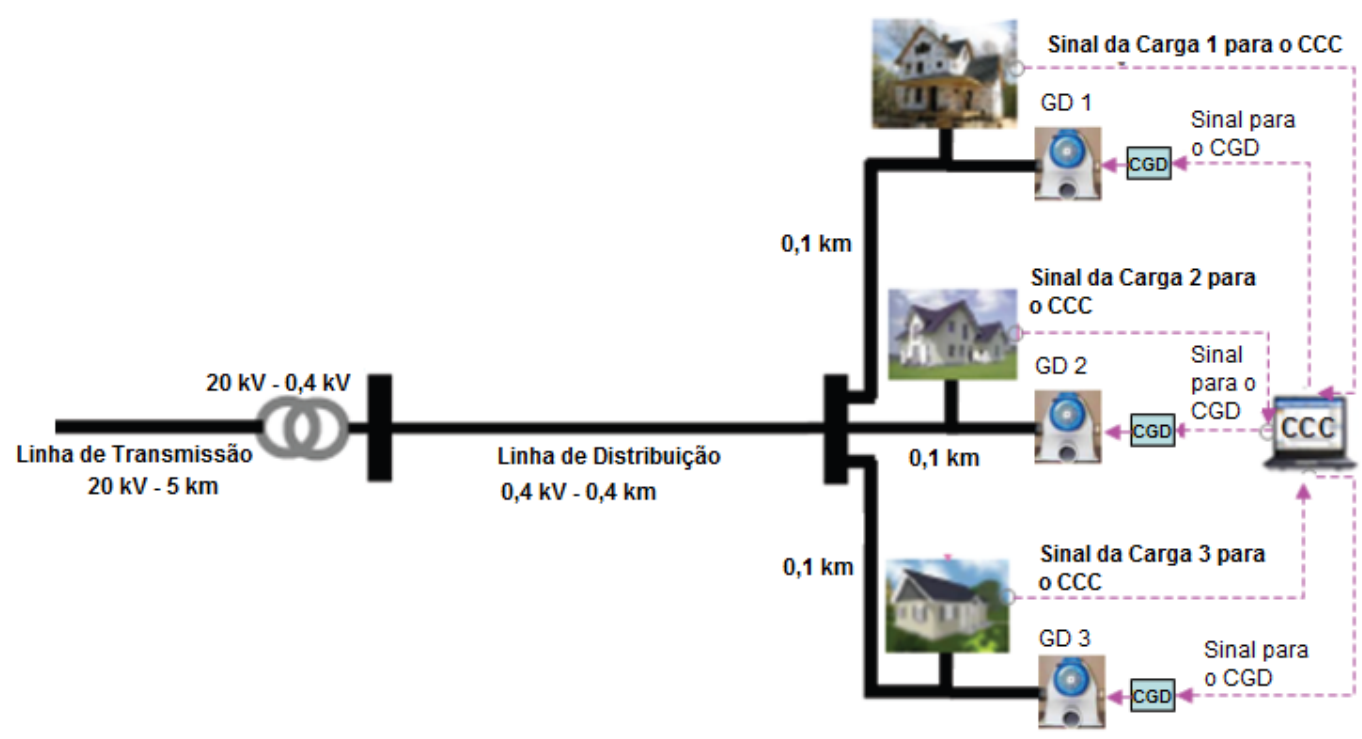

Figura 9: Usina Virtual Centralizada. Fonte: adaptado de ADHI, E. 2007.

- Usina Virtual Descentralizada: na topologia do sistema descentralizado, cada unidade de geração distribuída é controlada por um controlador local (CL). Primeiro a energia ativa que é produzida é controlada pelo controlador de geração distribuída (CGD) e o CGD é controlado pelo CL o qual, por sua vez, é controlado por meio de algoritmos lógicos. Para atuar como um sistema integrado, os controladores locais são conectados/ligados entre eles, formando assim uma rede de comunicação em estrutura de anel para permitir o intercâmbio coordenado de sinais conseguindo de esta forma ser tratado como um centro de controle único (Ver Figura 10). 


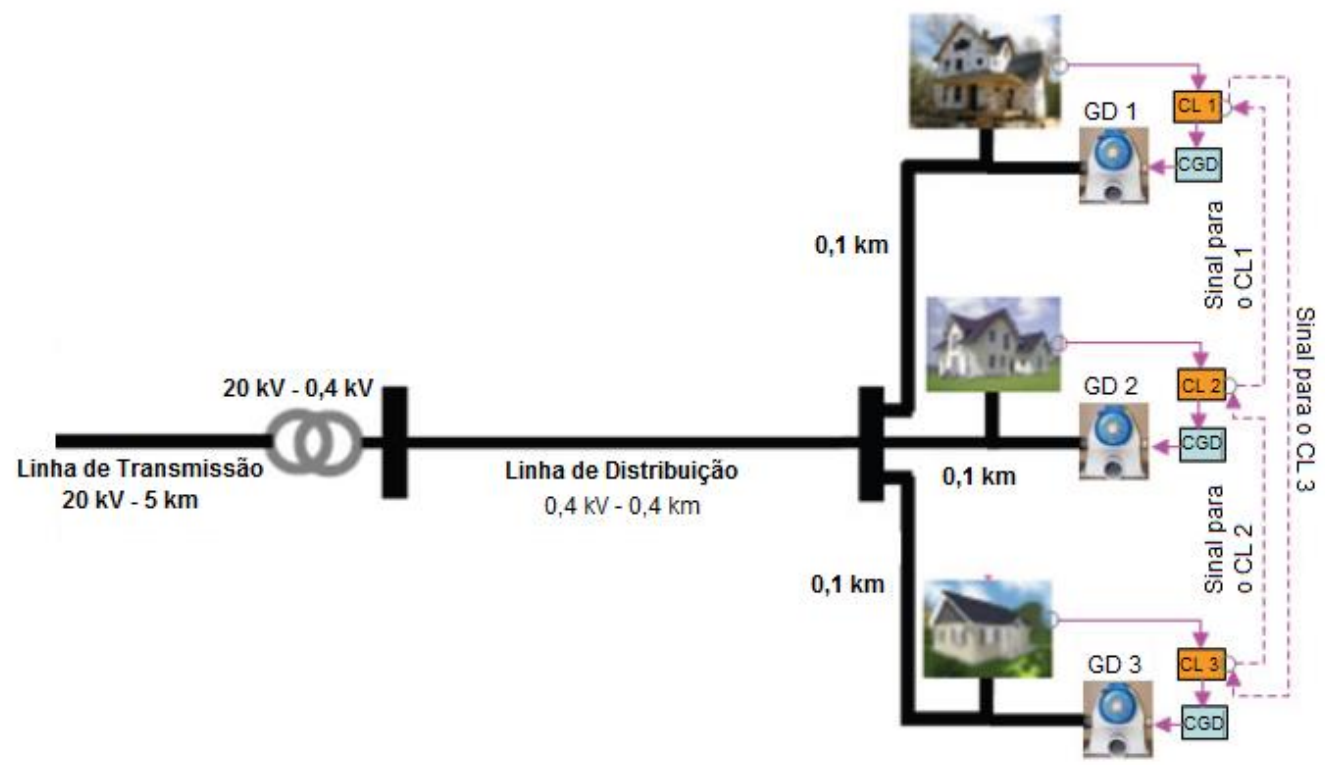

Figura 10: Usina Virtual Descentralizado. Fonte: adaptado de ADHI, E. 2007.

Como meio de facilitar a arquitetura de comunicação adequada para a controle dos DER encontra-se a norma de comunicação IEC 61850, esta norma foi originalmente desenvolvida para a automatização de subestações proporcionando um protocolo único de intercâmbio de informação entre vários equipamentos de controle. Esta norma foi estendida para usinas eólicas (IEC 61400-25-2), usinas hidroelétricas (IEC 61850-7-410) e para DERs (IEC 61850-7-420). Em cada nova extensão introduzemse novos modelos informáticos consistentes com a norma original, IEC 61850.

\subsection{Tipos de Usinas virtuais}

As usinas virtuais podem ser usadas para facilitar o acesso de uma ampla variedade de DERs no mercado de energia, sendo capaz assim de prestar serviços de apoio à gestão do sistema - por exemplo: regulação de frequência, tensão e fator de potência. Neste sentido, as usinas virtuais podem se classificar da seguinte forma: 


\subsubsection{Usina Virtual Técnica (UVT)}

A usina virtual técnica é conformada por DERs da mesma locação geográfica. A UVT representa-se por meio de um perfil agregado o qual inclui a influência da rede local em tempo real na energia entregue pelo conjunto de DERs conectados à rede e representa também, o custo e características de operação do portfólio. Dentre os serviços prestados e funções prestadas por uma UVT incluem-se: gestão do sistema local para o operador do sistema de distribuição, assim como dar ao operador do sistema de transmissão serviços auxiliares e de balanço do sistema. O operador de uma UVT requer informação detalhada da rede local, devido a isso tipicamente a operação da UVT está em mãos do operador do sistema de distribuição.

A usina virtual técnica permite:

- A visibilidade das unidades DER ante o operador do sistema

- Contribuição das DER na gestão do sistema

- Uso ótimo da capacidade das DER para fornecer serviços auxiliares incorporando as limitações da rede local

A visibilidade ante o operador de sistema e o mercado de energia, permite a pequenas unidades de geração fornecer serviços auxiliares e reduzir os riscos de indisponibilidade do serviço ao diversificar o portfólio de fontes de geração e aumentar a capacidade se comparado com as unidades DER independentes. Uma revisão mais extensa da possibilidade de que os DER forneçam serviços auxiliares pode ser encontrada em FENIX, 2009. E El Bakari, K. 2010. O potencial tecnológico é investigado mediante aplicações de um novo método de avaliação que considera o conversor de acoplamento com a rede por separado em relação com as suas capacidades individuais, com o que um enorme potencial tecnológico é identificado.

O operador do sistema que use o conceito de UVT pode também ser considerado como operador de uma rede ativa de distribuição (RAD). Um operador de RAD pode usar os serviços auxiliares ofertados pelas unidades DER para aperfeiçoar a operação da sua rede. Por outro lado, um operador de RAD pode também prestar serviços a outros operadores do sistema. Podendo assim existir uma 
estrutura hierárquica ou paralela de RADs, em que o conceito de UVT é aplicado, por exemplo, de acordo com os níveis de tensão ou diferentes regiões da rede.

Algumas das funções que deverão ser realizadas numa UVT são:

- Monitoramento contínuo das condições da rede, recuperação do histórico dos equipamentos.

- Gestão de ativos, respaldada por dados estatísticos.

- Autodescrição/identificação dos componentes do sistema

- Manutenção das instalações

- Análise estatística e otimização do planejamento do portfólio de DERs.

Deve notar-se que como as propriedades do sistema das usinas virtuais também são baseadas nos serviços requeridos pelo operador da usina virtual, o operador do sistema de distribuição e os proprietários dos DERs contratados, o controle do sistema envolve uma grande quantidade de transferências de dados entre os medidores inteligentes, agentes de participação e o computador de controle central, com o propósito de administrar os DER disponíveis e entregar os serviços e energia contratados.

\subsubsection{Usina Virtual Comercial (UVC)}

Uma usina virtual comercial é caracterizada por um perfil agregado de DERs e por uma potência de saída a qual representa o custo e as características operativas de um conjunto de DERs. A influência da usina virtual na rede de distribuição não é considerada neste perfil agregado.

As funções de uma usina virtual comercial incluem: a comercialização no mercado atacadista de energia, equilíbrio das negociações dos DERs que conformam o portfólio e a prestação de serviços que não são especificamente designados ao operador do sistema. O operador da UVC pode ser qualquer um, por exemplo, um terceiro ou a parte responsável pelo equilíbrio com o acesso ao mercado de energia, tal como um fornecedor de energia.

A usina virtual comercial é uma representação do portfólio de DERs que podem ser utilizados para participar no mercado atacado de energia na mesma forma que as usinas conectadas ao sistema de transmissão. Para os DERs do portfólio esse 
enfoque reduz os riscos de desequilíbrio associados com a participação individual no mercado e proporciona os benefícios da diversificação de recursos e aumento da capacidade de geração através da agregação. Mediante o UVC os DERs podem obter os benefícios da economia de escala e da inteligência do mercado para maximizar suas oportunidades de ingressos.

Nos sistemas em que é permitido o acesso ilimitado ao mercado atacado de energia, as usinas virtuais comerciais podem representar DERs de qualquer locação geográfica no sistema. No entanto, em mercados em que a localização geográfica é crítica - devido às limitações da rede, por exemplo - o portfólio agregado deverá ser restringido a incluir só DER da mesma localização - por exemplo, a uma área correspondente à rede de distribuição ou um nodo determinado da rede de transmissão. Ainda nestes casos a UVC pode representar DERs de locações diferentes, mas a agregação dos recursos deverá ocorrer por locação resultando num conjunto de portfólios de DERs definidos por suas respectivas locações geográficas.

Todos os DERs inclusos no portfólio da usina virtual comercial enviam informação de seus parâmetros de operação, características de seus custos marginais, entre outros. Essas informações são acumuladas para criar um perfil que represente a capacidade combinada de todos os DERs inclusos no portfólio. Com a adição da inteligência do mercado o UVC otimizará o potencial de renda dos DERs no seu portfólio ao fazer contratos de intercâmbio de energia e contratos a prazo. Quando a atividade no mercado atacado de energia completa-se, a UVC fornecerá a informação dos contratos de funcionamento dos DERs individuais e seus leilões correspondentes e oferecerá ajustar os horários de funcionamento para a UVT.

As funções básicas de uma UVT serão: a otimização e atualização da produção da energia, baseando-se na previsão da demanda e potencial de geração. Quando as necessidades reais diferem do previsto, introduzem-se os recursos de resposta à demanda para poder completar a diferença entre o consumo e produção real.

Em geral, as funções da UVC também devem incluir:

- Características de manutenção e funcionamento dos DERs

- Previsão de produção e consumo 
- Gestão da interrupção na demanda

- Criar licitações de DERs

- Participação em licitações no mercado

- Otimização e programação da geração diária

- Venda da energia produzida pelos DERs no mercado

\subsection{Algumas experiências de aplicação das usinas virtuais na Europa}

\subsubsection{O projeto FENIX, demonstração de Usinas virtuais.}

O projeto Flexible Electricity Network to Integrate the eXpected energy evolution (FENIX) é um projeto de pesquisa e desenvolvimento fundado parcialmente pela Comissão Europeia - dentro do sexto programa-quadro de pesquisa - em conjunto com universidades, centros de pesquisa e concessionárias de distribuição e transmissão de energia elétrica.

O objetivo de FENIX é demonstrar o valor e confiabilidade do conceito da agregação da geração distribuída por meio das usinas virtuais. FENIX visa facilitar a inserção dos DERs maximizando sua contribuição no sistema elétrico, agregando usinas virtuais de grande porte e a gestão descentralizadae, desta forma, facilitar à comercialização de serviços que podem ser prestados pelos DERs, maximizando seus efeitos positivos na operação da rede (O. Abarratégui, J. Marti, A. González, 2009).

Uma das redes selecionadas para a implementação e demonstração do projeto FENIX encontra-se localizada na província de Álava no norte de Espanha, a qual é operada por Iberdrola distribuição. A rede de lberdrola, é uma rede de distribuição operada radialmente com limites bem estabelecidos com a rede de transmissão. Encontra-se subdividida nos seguintes níveis de tensão: 30 kV e 13 kV. 
As fontes mais significativas de geração encontram-se na rede de $30 \mathrm{kV}$, e quase todas estão representadas por: usinas fotovoltaicas, mini hidroelétricas, eólicas, plantas de cogeração e usinas de biomassa. Como se mostra na Figura 11, conta-se com quatro subestações de distribuição com uma Potência instalada de 480 MVA que alimentam a rede que possui uma demanda pico de $253 \mathrm{MW}$ e a capacidade instalada dos DERs é de aproximadamente 170 MVA.

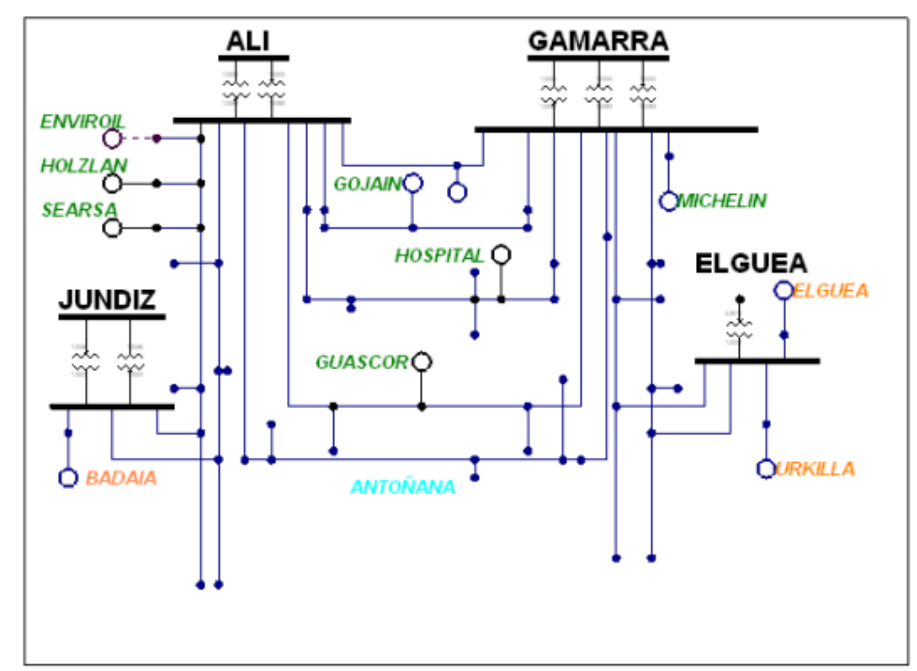

Figura 11: Rede de distribuição de Álava, Espanha. Fonte: O. Abarratégui, J. Marti, A. González, 2009.

Dos DERs presentes na rede de distribuição de Álava, os que formam parte ativa da demonstração são: Usina Eólica Urkilla, Usina de biomassa Guascor, Planta de cogeração Energy Works Vitvall Michelin, usina de cogeração Salinera de Añana e a mini hidroelétrica Antoñana.

Neste caso, serão abordados os seguintes aspectos da demonstração:

- Oferta de serviços terciários de reserva auxiliar

- A contribuição para manter a qualidade de serviço

Para esse propósito, foram preparados diferentes avanços tecnológicos:

$\checkmark$ Um sistema de controle paralelo (sistema de controle FENIX) que funciona para a empresa de distribuição para a qual foi criada com propósitos demonstrativos. Este sistema contém todos os elementos de relevância para 
a rede de Álava. O sistema de dados FENIX é atualizado por meio de um enlace ICCP com o sistema SCADA funcionando em tempo real.

$\checkmark$ Foi necessário desenvolver um sistema de gestão de energia distribuída ou Distributed Energy Management System (DEMS), e adaptá-lo às necessidades do cenário com o objetivo de ter as funções de agregador/desagregador comercial. O DEMS comunica-se com o sistema de controle por um enlace ICCP e também com todos os DERs em tempo real por meio de um enlace GPRS.

$\checkmark$ A unidade de comunicação que é capaz de intercambiar informação com o DEMS e interoperar com os controles das unidades de geração, a qual é chamada FENIX Box (FB). Algumas unidades DERs têm dispositivos de comunicação e controle próprios que devem ser adaptados para os fines de comunicação com o DEMS, no caso de que não os possuam então é usada uma FB padrão. O link de comunicação pode variar - PLC, GPRS- mas, neste cenário foi usado um link GPRS para realizar a comunicação entre o DEMSUVC e cada DER. A FB também pode ser usada para visualizar os DERs e seus níveis atuais de potência ativa e reativa para fins de faturamento, controle, dentre outros. Na Figura 12 mostra-se a arquitetura do sistema da usina virtual em demonstração.

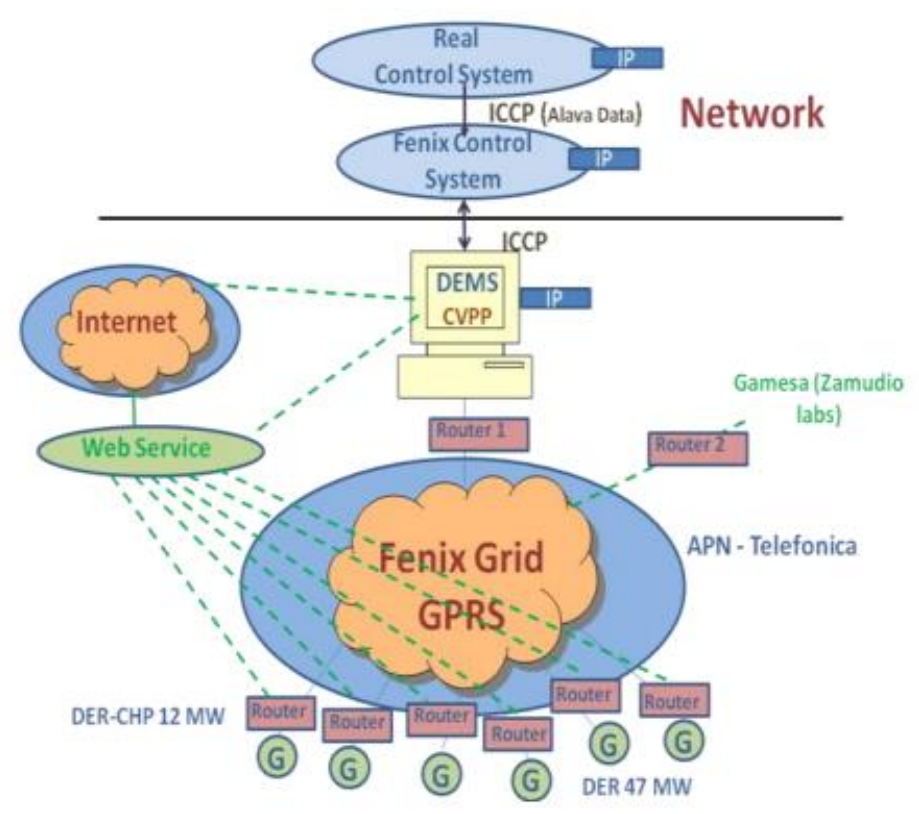

Figura 12: Arquitetura da Usina Virtual em demonstração em Álava (O. Abarratégui, J. Marti, A. González, 2009). 
Alguns dos serviços prestados pela Usina Virtual de Àlava São:

\section{Reserva Terciária}

A reserva terciária é um serviço auxiliar para a correção dos desvios e variações de demanda. As usinas participantes no projeto devem ser capazes de entregar ou deixar entregar certa quantidade de potência ativa num intervalo de 5 minutos e também de manter a nova quantidade de energia exigida por duas horas. Para lograr esse objetivo deve existir um intercâmbio de informação em tempo real entre o DEMS e a FB com os DERS por meio de um link GPRS.

Se o serviço de reserva terciária for requerido, o UVC recebe uma notificação e envia o requisito de potência ativa correspondente ao DER que se encontra configurado para fornecer o serviço, isso através do link de comunicações.

\section{Controle de tensão}

A visibilidade e controle dos DERs podem contribuir também ao controle da qualidade do serviço nos nós da rede de distribuição, administrando a quantidade de potência reativa que cada um dos DERs é capaz de fornecer. Além disso, os DER podem ajudar a manter o nível de tensão desejado nas barras de alta tensão das subestações, dito nível de tensão é predeterminado pelo operador do sistema de transmissão.

Para esse propósito foi desenvolvido a ferramenta de controle de distribuição ou Distribution Management Tool (DMT), chamada Volt VAR Control (VVC). O VVC é um algoritmo baseado em fluxo ótimo de potência, que ajuda a determinar que ações devam ser tomadas para manter os níveis de tensão. Existem três possíveis ações a serem tomadas: alterar a potência reativa produzida pelo DER, alterar os taps dos transformadores ou conectar um banco de capacitores. Assim o VVC é quem determina a potência reativa necessitada de cada DER, o requisito da potência reativa é encaminhado a cada um dos DERs via GPRS. 


\subsubsection{Usina virtual de RWE Energy e Siemens na Alemanha}

Em 2007, RWE Energy associou-se com o departamento de transmissão e distribuição de energia da Siemens para desenvolver e testar modelos de negócios e conceitos técnicos para a criação de uma usina virtual ou VPP. Siemens participou como fornecedor de tecnologia e também como administrador central do sistema de TI a ser implementado durante o piloto.

O projeto da usina virtual de RWE procurou agregar usinas descentralizadas como centrais de cogeração, usinas de biomassa ou eólicas para formar uma usina virtual controlada por um sistema de controle centralizado. Para o projeto, o departamento de negociação faz o papel de agregador, enquanto que a Siemens gerencia de forma centralizada o sistema de TI.

Em 2008, a primeira usina virtual de RWE começou a funcionar. Na primeira fase nove hidroelétricas operadas por Lister- und Lennekraftwerke em Sauerland, North Rhine-Westphalia, foram integradas à usina virtual. A capacidade destas plantas de geração distribuída variou de $150 \mathrm{~kW}$ a $1100 \mathrm{~kW}$, a capacidade total de todas as plantas hidroelétricas alcançou aproximadamente 8.6 MW.

A característica principal desta usina virtual é o DEMS da Siemens, o qual é combinado com os controladores dos DERs. A capacidade de manter a comunicação entre os equipamentos tem um papel fundamental na gestão das usinas virtuais. Com o propósito de integrar completamente as unidades de geração ao sistema de controle central e entre elas, cada unidade é monitorada via GPRS. Os sinais GPRS entregam a informação relevante ao DEMS.

RWE Energy vende a energia elétrica gerada pelas unidades distribuídas, usando seu sistema de TI de comercialização, de duas formas: como eletricidade no European Energy Exchange (EEX) ou como capacidade de reserva através dos leilões por internet.

\section{Descobertas}

Os resultados iniciais mostram que é economicamente viável integrar unidades de geração com uma capacidade de pelo menos $500 \mathrm{~kW}$. As unidades de menor capacidade têm custos muito elevados relativos ao hardware que deve ser instalado, 
bem como com os custos operacionais dos serviços de comunicação para gerar um lucro.

A usina virtual além de mostrar a importância de um bom sistema de comunicação para fornecer os serviços ofertados, tem provado ser muito bem sucedida, tanto que a próxima expansão está prevista para 30-40 MW.

\subsection{Benefícios das Usinas Virtuais}

Desde que a função principal das usinas virtuais é incrementar o valor e quantidade da energia elétrica produzida por um conjunto de geradores distribuídos de pequeno porte, mostra-se a continuação quais são os benefícios de adotar essa abordagem:

- Ótimo uso das unidades DER para fornecer serviços à rede de distribuição

- Redução das perdas de distribuição e transmissão

- Localização de falhas, integrando automaticamente o gerenciamento de falhas.

- Incremento da diversificação das fontes de geração de energia

- Contribuição à regulação de tensão e frequência do sistema

- Melhores benefícios econômicos para os proprietários de DERs

- Incentivo do uso de recursos renováveis, e, portanto, a diminuição da produção de gases de efeito estufa relacionados com a geração de energia.

- Facilita aos DER acesso ao mercado atacado de energia

\subsection{Desvantagens das usinas virtuais}

- Dependência intertemporal dos recursos de geração

- Devem ser criados marcos regulatório para promover a contribuição dos DERs ao sistema

- Incerteza da resposta dinâmica do sistema

- As características da rede elétrica com as quais os DERs se encontram conectados também influenciam as características gerais das usinas virtuais

- Necessidade de uma rede de tecnologia e informação

- O custo da energia para o usuário final pode refletir um incremento 


\subsection{Considerações sobre a utilização das usinas virtuais}

As usinas virtuais propõem fazer um melhor uso dos DERs e as características próprias de cada tipo de geração. Ao fazer com que trabalhem conjuntamente, complementando assim as características de cada DER e conseguir que funcionem como uma única usina de grande porte -quando comparado com as capacidades dos DERs que a compõem-, incrementando desta forma a quantidade de energia firme disponível no sistema. Devido a essa característica deve ser realizada uma cuidadosa seleção dos tipos de geração que podem ser capazes de trazer um serviço confiável e, assim, evitar penalidades financeiras.

$>$ É necessário criar as bases de regulação técnicas e comerciais que permitam realizar a inclusão dos DER no sistema através das usinas virtuais com sucesso.

$>$ A implementação de uma usina virtual requer a participação de muita tecnologia de comunicação e informação, além de uma maior quantidade de pessoas envolvidas no processo de geração e comercialização de energia. Uma análise econômica deve ser realizada para verificar que os custos adicionais sejam compensados ao participar em contratos de energia que comprem a melhores preços

$>$ Ao incluir e incrementar a participação dos DERs no mercado atacadista de energia é possível fazer um melhor uso dos recursos que estão sendo subutilizados e diversificar a matriz energética das regiões

As usinas virtuais aumentam a segurança do fornecimento de energia, especialmente em regiões onde as linhas de transmissão estão próximas a atingir o ponto de congestionamento ou nos sistemas de transmissão com altas porcentagens de perdas. 


\section{Histórico e projeções da operação do subsistema Sudeste/Centro Oeste (SE/CO)}

Nesse capitulo é apresentado o histórico de operação do subsistema Sudeste/Centro Oeste (SE/CO), o seu histórico de consumo e de geração por fonte, ressaltando importância que esse subsistema possui no Sistema Interligado Nacional (SIN), tanto na porcentagem de geração quanto na porcentagem de consumo. Também são apresentados o histórico de intercâmbios de energia entre os subsistemas, necessários para uma otimização de uso dos recursos disponíveis no SIN, e as projeções das condições de atendimento do subsistema SE/CO. Continuando com a apresentação da informação que caracteriza o atendimento do Estado de São Paulo, tanto o seu histórico quanto as suas projeções de operação.

\subsection{Histórico de operação do sistema elétrico do subsistema SE/CO}

O sistema elétrico da região Sudeste é constituído por uma rede básica com mais de $35.000 \mathrm{~km}$ de linhas nas tensões de 750, 500, 440, 345 e $230 \mathrm{kV}$ e um sistema em 138, 88 e 69 kV referente às Demais Instalações de Transmissão (DIT). A região, constituída pelos estados de São Paulo, Minas Gerais, Rio de Janeiro e Espírito Santo, Goiás, Mato Grosso e do Distrito Federal e considerando, a partir de 2009, os estados do Acre e Rondônia (PDE 2023), tem a maior malha interligada do País, atendendo cerca de 62\% da carga do SIN no ano 2013 (ONS). Os maiores centros de consumo estão localizados nas áreas metropolitanas de São Paulo, Rio de Janeiro e Minas Gerais, afastados das principais fontes de geração, resultando na necessidade de uma extensa rede de transmissão em alta tensão para o seu atendimento. Nesse sentido, o subsistema SE/CO é o mais extenso do Brasil e o mais importante tanto em consumo, quanto na geração, sendo responsável de aproximadamente $60 \%$ da geração de energia do SIN que, no ano 2013, foi realizada no subsistema SE/CO (ONS).

Devido ao fato de que os grandes projetos de geração que completam o atendimento desta região estão localizados longe dos grandes centros de carga, 
são exigidos extensos sistemas de transmissão para o transporte de grandes blocos de energia nas estações chuvosas e pequenos montantes durante as estações secas, aumentando assim, a complexidade operativa do SIN em termos de segurança eletroenergética.

No Gráfico 1 pode ser observada a evolução da demanda de energia do subsistema SE/CO desde janeiro de 2009 até dezembro de 2014. Observa-se que, como mencionado anteriormente, o SE/CO é responsável pelo maior consumo de energia do Brasil e que os meses de maior demanda de energia são os meses correspondentes ao verão em especial fevereiro, bem como que tem uma taxa de crescimento anual quase constante. Percebe-se assim que as mudanças e variações nas tendências de consumo do SE/CO afetam o comportamento de todo o SIN.

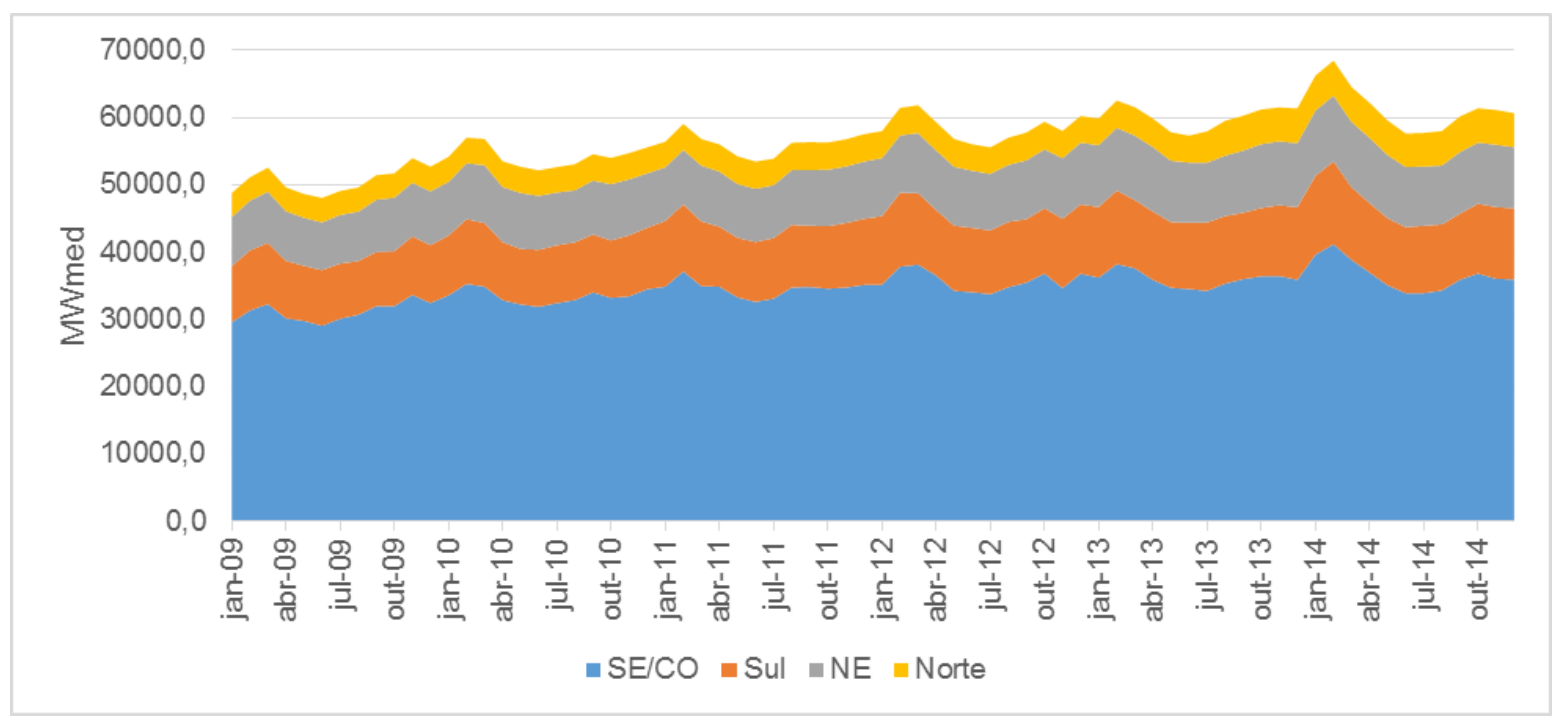

Gráfico 1: Evolução da carga de energia do SIN por subsistemas. Fonte: Elaboração própria com dados da ONS.

No Gráfico 2 mostra-se a evolução da geração de energia no SIN por tipo de geração, assim como também a participação do subsistema SE/CO na geração do SIN incluindo a energia gerada por Itaipu no subsistema SE/CO. A maior porcentagem da energia gerada no subsistema SE/CO é gerada a partir de hidroeletricidade e energia térmica nuclear, mas também possui a maior capacidade instalada de usinas termoelétricas do SIN. Pode observar-se que a participação do 
SE/CO diminuiu desde julio 2013, visto que o Brasil atravessa por uma fase climatológica desfavorável, e como consequência, dentre outras, a disponivilidade de geração das hidroelétricas diminuiu.

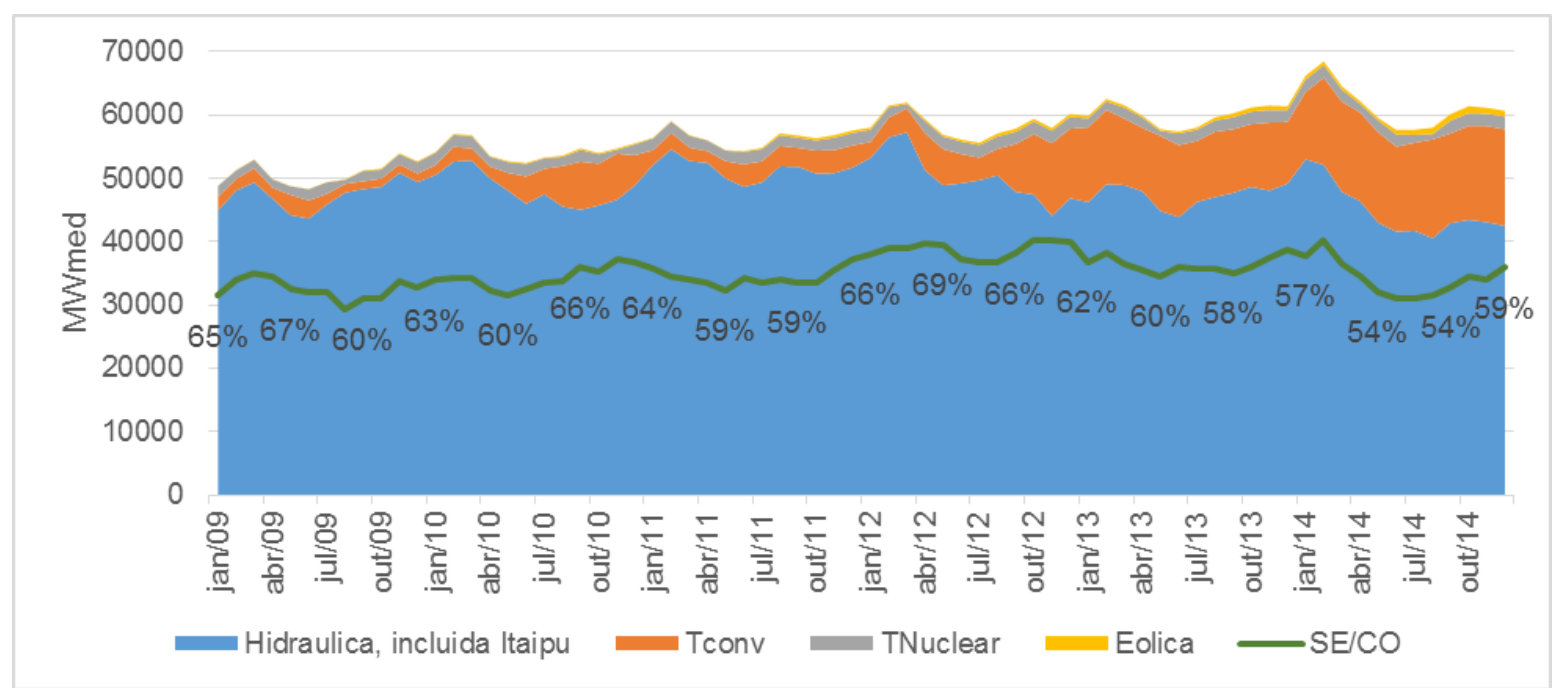

Gráfico 2: Evolução da geração de eletricidade por tipo de geração e participação do SE/CO na geração do SIN. Fonte: Elaboração própria com dados da ONS.

No Gráfico 2 é possível apreciar a grande participação da hidroeletricidade no SIN, e a sua variação ao decorrer das estações do ano, ou mesmo nos anos. É possível observar que quando existe menor disponibilidade de hidroelétricas é preciso uma maior ativação das termoelétricas convencionais para completar o atendimento, 0 que encarece o atendimento do sistema e incrementa as emissões de $\mathrm{CO}_{2}$ relacionadas à geração de eletricidade. Um importante aumento na produção de termoelétricas convencionais pode ser claramente observado no período de março 2012 até dezembro 2014, colocadas em operação para garantir a segurança do sistema por meio da manutenção dos níveis dos reservatórios das hidrelétricas. Essa medida elevou o custo da energia. A evidente necessidade da ativação das termoelétricas nos anos com reduções consideráveis do recurso hídrico mostra a necessidade da inclusão de outras fontes de geração da matriz elétrica do Brasil, que podem aumentar a segurança do SIN, além de acompanhar o crescimento da carga de energia. 
No gráfico 3 apresenta-se a geração de energia por fonte no subsistema SE/CO incluindo a energia gerada por Itapu - a parcela correspondente ao Brasil e a importada da parcela do Paraguai. Observa-se a sazonalidade da geração das hidroelétricas e a necessidade de complementar a demanda de energia no subsistema com geração local de usinas térmicas convencionais ou importações desde outros subsistemas.

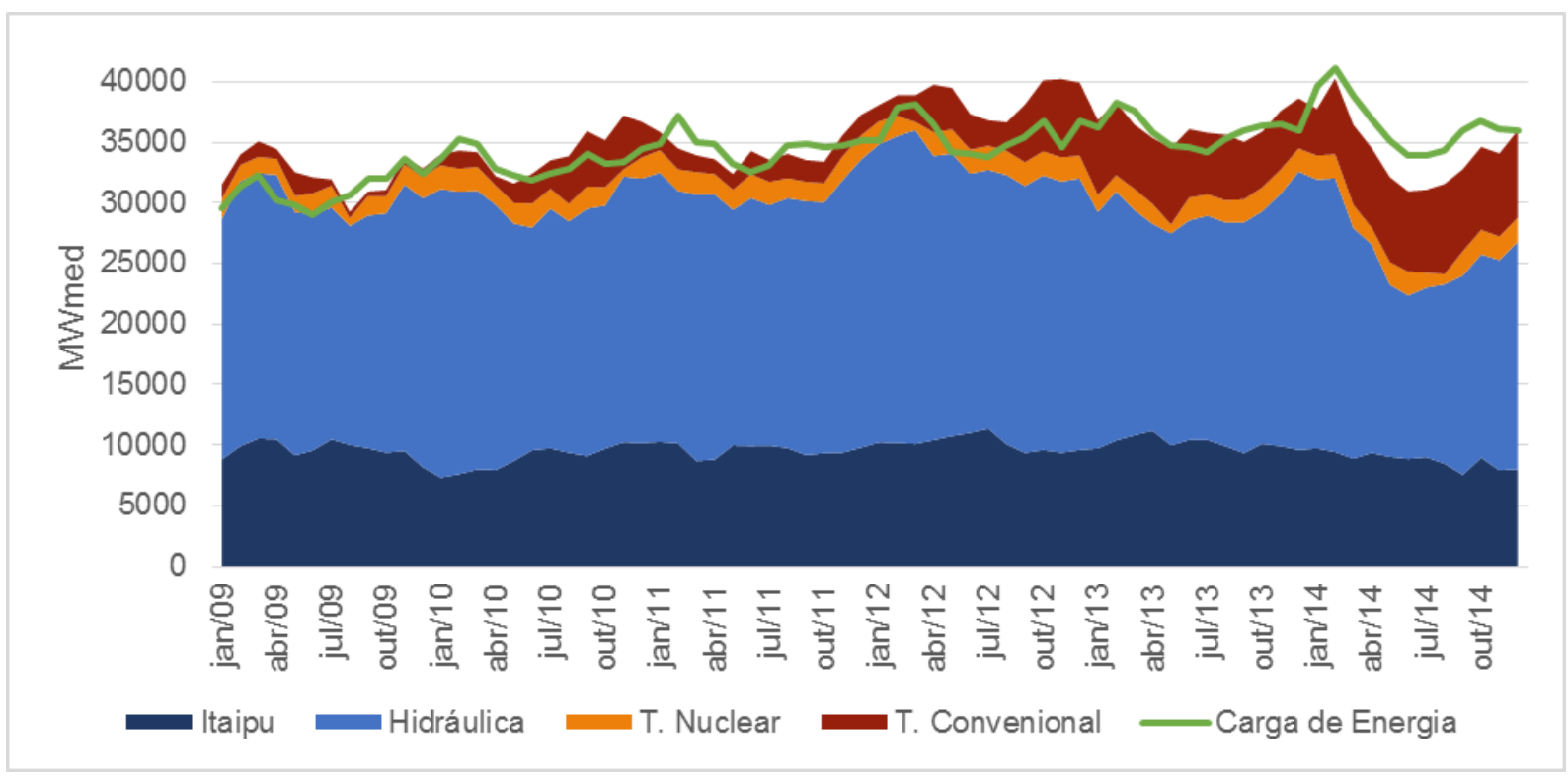

Gráfico 3: Carga de energia e Geração de energia no SE/CO 2009 -2014. Fonte: Elaboração própria com dados do ONS.

As importações de energia para completar o atendimento da carga do SE/CO em geral são feitas das hidroelétricas do norte que se encontram a grande distância dos grandes centros de consumo e possuem uma acentuada sazonalidade, o que faz com que na época de chuva se transmitam grandes blocos de energia e, na época seca, em pequenas quantidades. Isso contribui a aumentar as perdas na rede básica e aumenta a necessidade de expansões nas interligações entre os subsistemas.

No Gráfico 4 pode ser observado o balanço de intercâmbio de energia entre os subsistemas. É possível apreciar a notável sazonalidade dos intercâmbios do subsistema norte e a crescente necessidade de importação do subsistema SE/CO a qual é acentuada nos anos em que a hidroeletricidade é pouco favorável como o foram 2013 e 2014. É possível observar que nos meses de maior disponibilidade de 
energia no $\mathrm{N}$ os subsistemas SE/CO e Sul tendem a incrementar as importações aproveitando a disponibilidade dos recursos e preservando os reservatórios locais. O NE continua caracterizando-se como um importador.

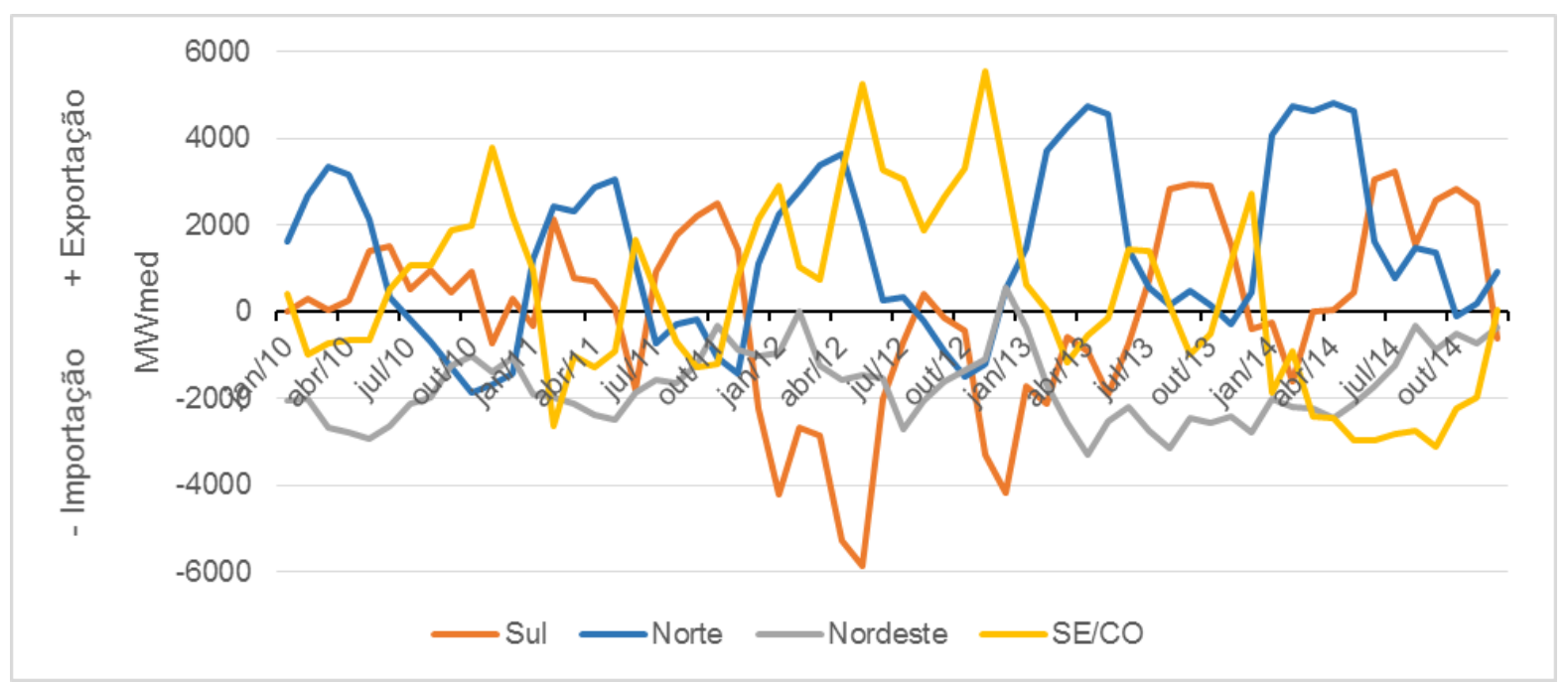

Gráfico 4: Balanço de intercâmbio de energia nos subsistemas. Fonte: Elaboração própria com dados da ONS.

Ao comparar os Gráficos 3 e 4, observa-se que no 2012 a oferta de energia hidroelétrica do norte foi baixa mas os subsistemas Sul e NE precisaram de importações, as quais foram atendidas pelo SE/CO, que teve uma grande geração com termelétricas convencionais, nessas mesmas datas. Observa-se também que em 2014, apesar da grande quantidade de energia importada pelo SE/CO foi ampla a necessidade de acionar as térmicas convencionais, evidenciando assim a necessidade da implementação de outras fontes de geração e a vantagem que podem representar os aproveitamentos locais que sejam completares à produção hidroelétrica. 


\subsection{Perdas na rede básica}

Em 2012, a rede básica de energia teve uma porcentagem de perdas média de 4,54\% o que representou quase 20 TWh de perdas no ano 2012 (CCEE, 2012). Usando a técnica de cálculo de perdas pro-rata, as perdas totais da rede básica são obtidas da medição direta da energia bruta gerada nas usinas e a energia bruta consumida da rede básica, alocando $50 \%$ de perdas para consumo e 50\% para a geração. Os montantes de energia participantes no rateio de perdas não são os mesmos que os montantes brutos, já que em redes nas quais existe geração e consumo de energia próprios, apenas participarão no rateio de perdas no caso em que precisem absorver ou jogar energia na rede e essa participação será proporcional à quantidade de energia na transação e referenciada à rede básica. As fórmulas utilizadas para calcular as perdas de geração e consumo utilizadas em CCEE, 2012 são apresentadas a seguir:

$$
\% P G_{i}=\left(1-\frac{T O T_{-} G P_{i}-T O T_{-} P_{i} / 2}{T O T_{-} G P_{i}}\right) * 100
$$

Em que:

\%PGi é a porcentagem de perdas referentes a geração de energia no período de tempo i

TOT_GPi, é a energia gerada participante do rateio de perdas no período i, e TOT_Pi, é a quantidade de perdas totais na rede básica no período i.

e,

$$
\% P C_{i}=\left(1-\frac{T O T_{-} C P_{i}-T O T_{-} P_{i} / 2}{T O T_{-} C P_{i}}\right) * 100
$$

Em que: 
\% $\mathrm{PC}$ i é a porcentagem de perdas referentes ao consumo de energia no período de tempo i

TOT_CPi, é a energia consumida participante do rateio de perdas no período i, e TOT_P $\mathrm{P}$, é a quantidade de perdas totais na rede básica no período i.

No Erro! Fonte de referência não encontrada. são apresentadas as porcentagens de perdas totais na rede básica de energia do SIN e a porcentagem correspondente a geração e ao consumo participante no rateio das perdas no SIN.

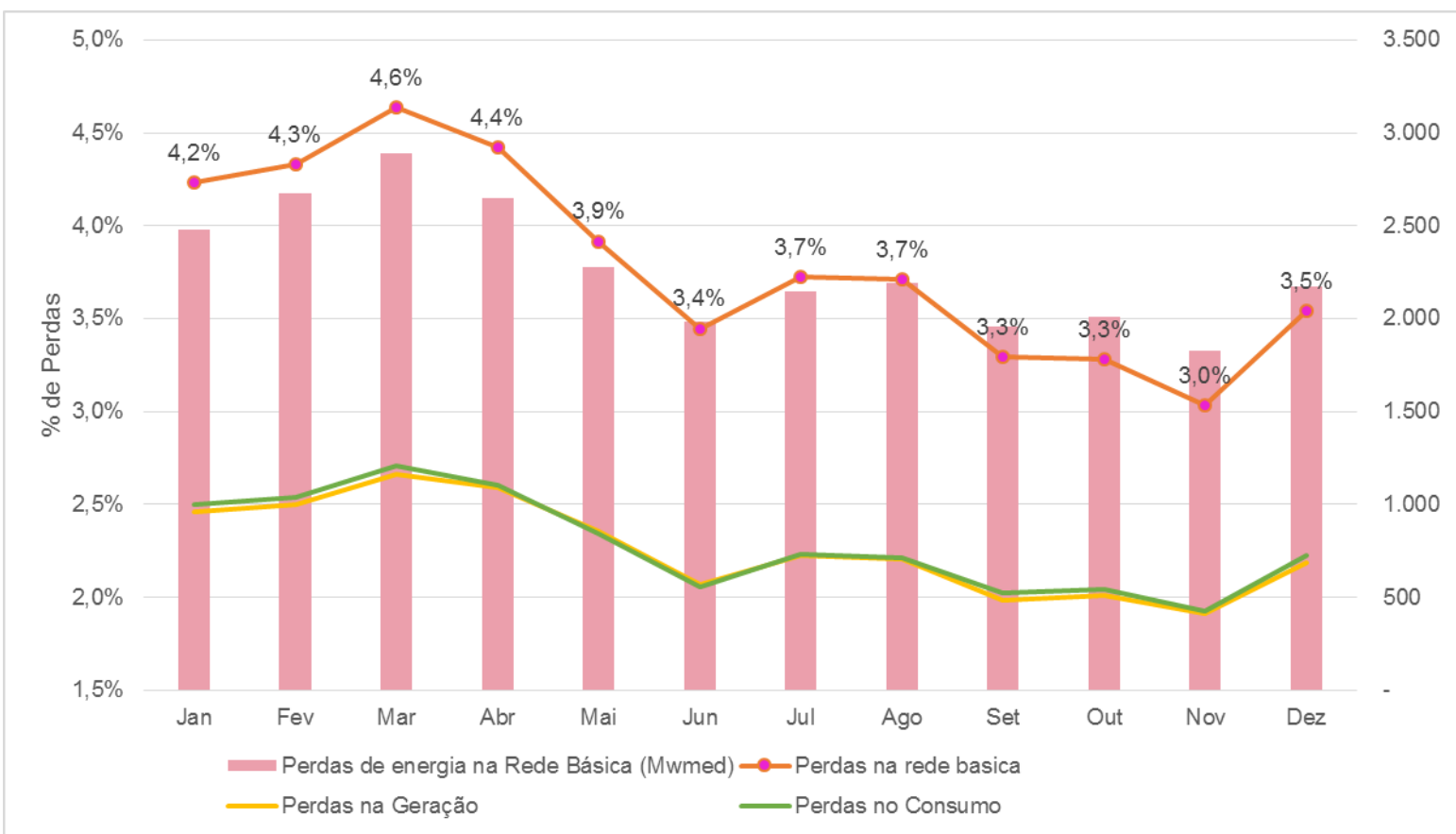

Gráfico 5: Porcentagem de perdas na rede básica de energia no ano 2012. Fonte: Elaboração própria dados CCEE.

Observa-se que são perdidos aproximadamente 2000 MWmed por mês na entrega de energia das usinas até as concessionárias de distribuição, porcentagem que poderia diminuir com uma maior inserção de geração próxima ao ponto de carga. Ressalta-se que os fatores de perdas são apurados em cada patamar de carga por semana, sendo que os valores médios mensais apresentados são meramente ilustrativos quanto à evolução dos fatores de perda elétrica no ano ao qual se refere. 
Para o cálculo das perdas por subsistema, foi assumido que as perdas de geração são distribuídas equitativamente em todos os subsistemas, dado que essas perdas são "levadas" ao centro de gravidade do sistema. Portanto, as perdas de geração que foram alocadas equitativamente em cada um dos 4 subsistemas são \%PGi/4, já que para dar um adequado atendimento às suas cargas locais, os subsistemas intercambiam energia. Mas as perdas correspondentes ao consumo foram calculadas como diretamente proporcionais ao consumo de cada subsistema. No Gráfico 6, mostra-se a porcentagem de perdas totais da rede básica dividas por subsistema, ressaltando a participação do subsistema SE/CO na participação dessas perdas devido ao fato de que é o maior consumidor do país.

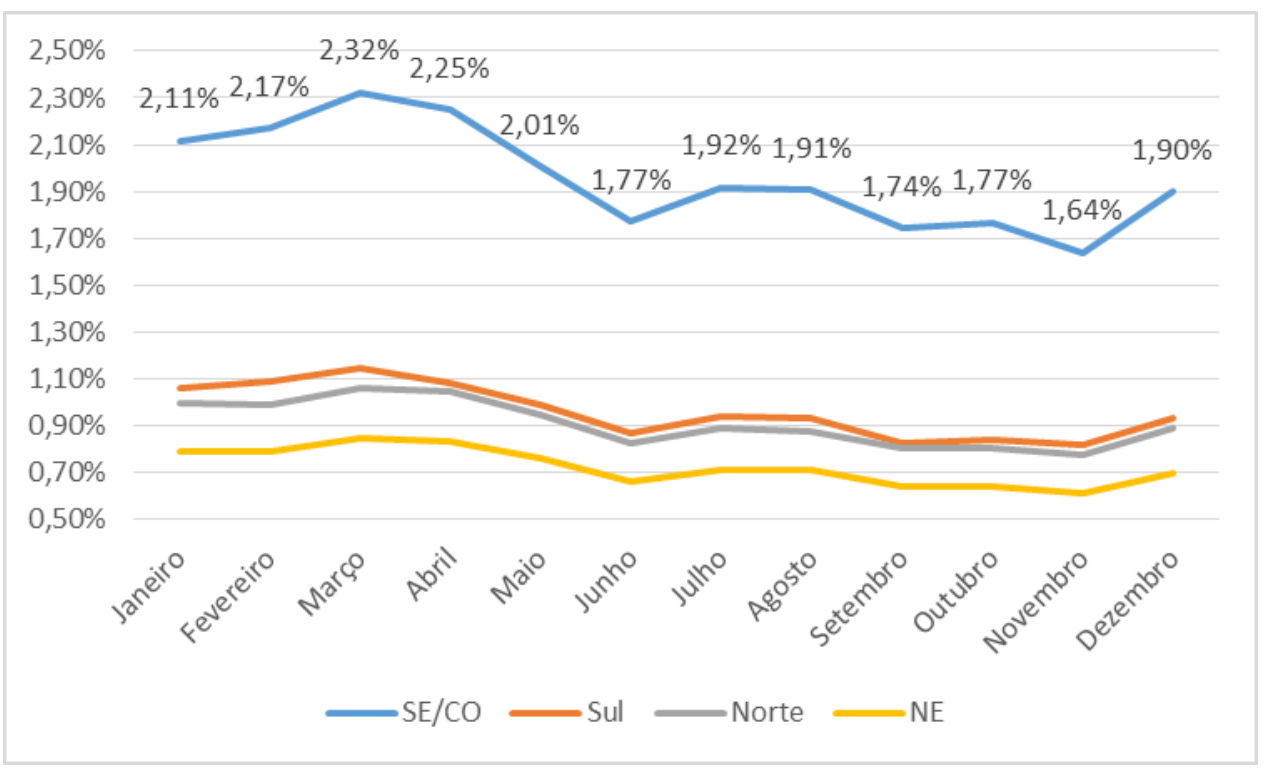

Gráfico 6: Porcentagem de perdas na rede básica por subsistemas ano 2012: Fonte: elaboração própria com dados do CCEE.

Essa porcentagem de perdas é calculada por patamar de carga (leve, média ou pesada) por semana de consumo. No Gráfico 7, mostra-se a evolução das perdas da rede básica referentes ao subsistema SE/CO e a sua evolução por patamar de carga e por semana no ano 2012. Neste gráfico pode ser observado uma diferença notória da média mensal obtida pelos montantes de consumo e da geração ao final do mês. 


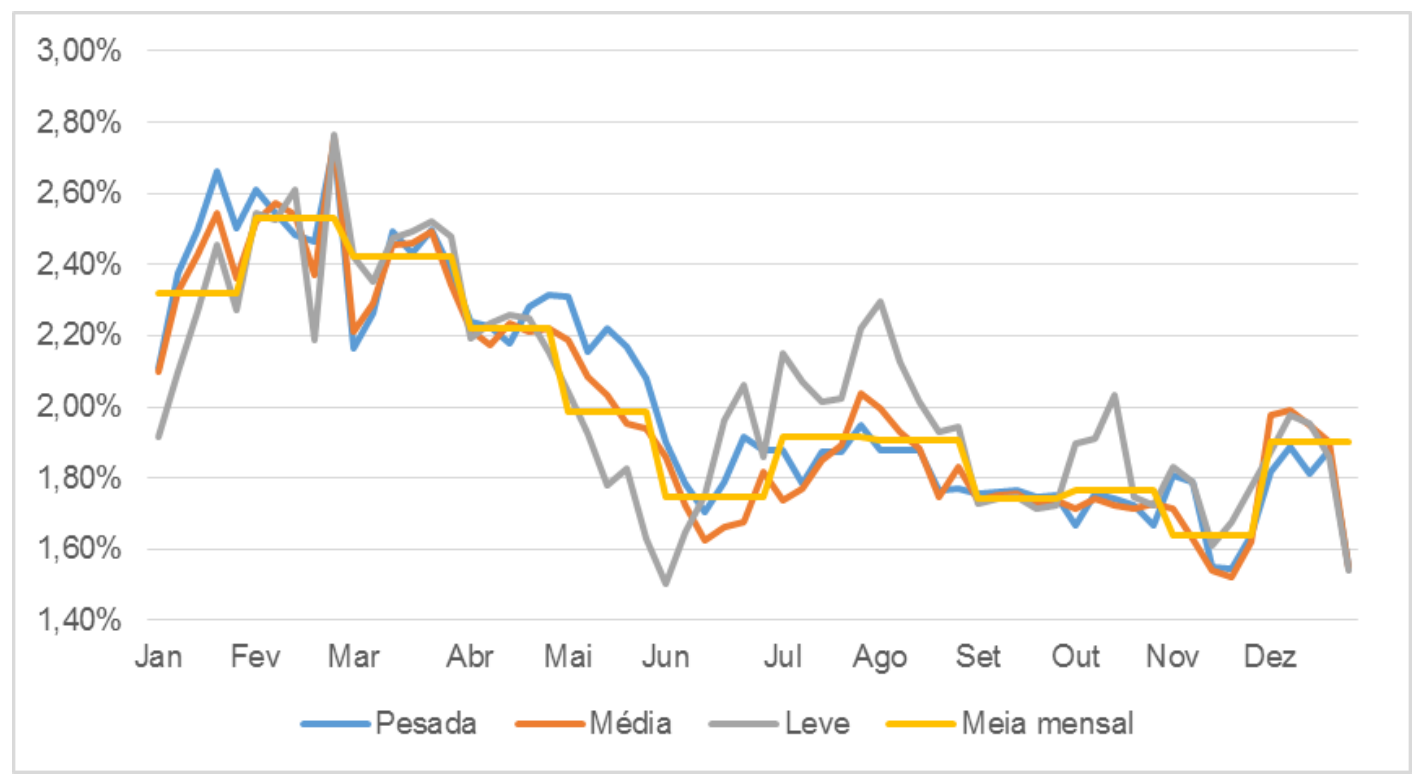

Gráfico 7: Porcentagem de perdas na rede básica de energia do subsistema SE/CO por patamar de carga no ano 2012. Fonte: Elaboração própria com dados da CEEE.

Os pontos de medição de energia bruta, consumo e geração, são referenciados aos barramentos da rede básica. Nesse sentido, as perdas associadas às diferenças dos montantes brutos de energia gerada e consumida são inteiramente atribuídas à transmissão da energia na rede básica.

\subsection{Projeções do atendimento do subsistema SE/CO}

A tendência do SE/CO de importar energia aumentará no decorrer dos próximos anos segundo o PDE 2023, exigindo cada vez mais intercâmbios de energia. Essa tendência pode ser observada no Gráfico 8, no qual se mostra o balanço estático de garantia física para o subsistema SE/CO, considerando a disponibilidade de Itaipu a parcela correspondente à geração brasileira acrescida da estimativa importada da parcela do Paraguai -, não considera a energia proveniente de Acre/Rondônia. Observa-se que a previsão de crescimento da carga da região não é acompanhada pelo crescimento da oferta local previsto, com o que se incrementará cada vez mais a necessidade de importação de energia de outros subsistemas, isto ainda incluindo a geração local feita com usinas termoelétricas acionadas por combustíveis fósseis. 


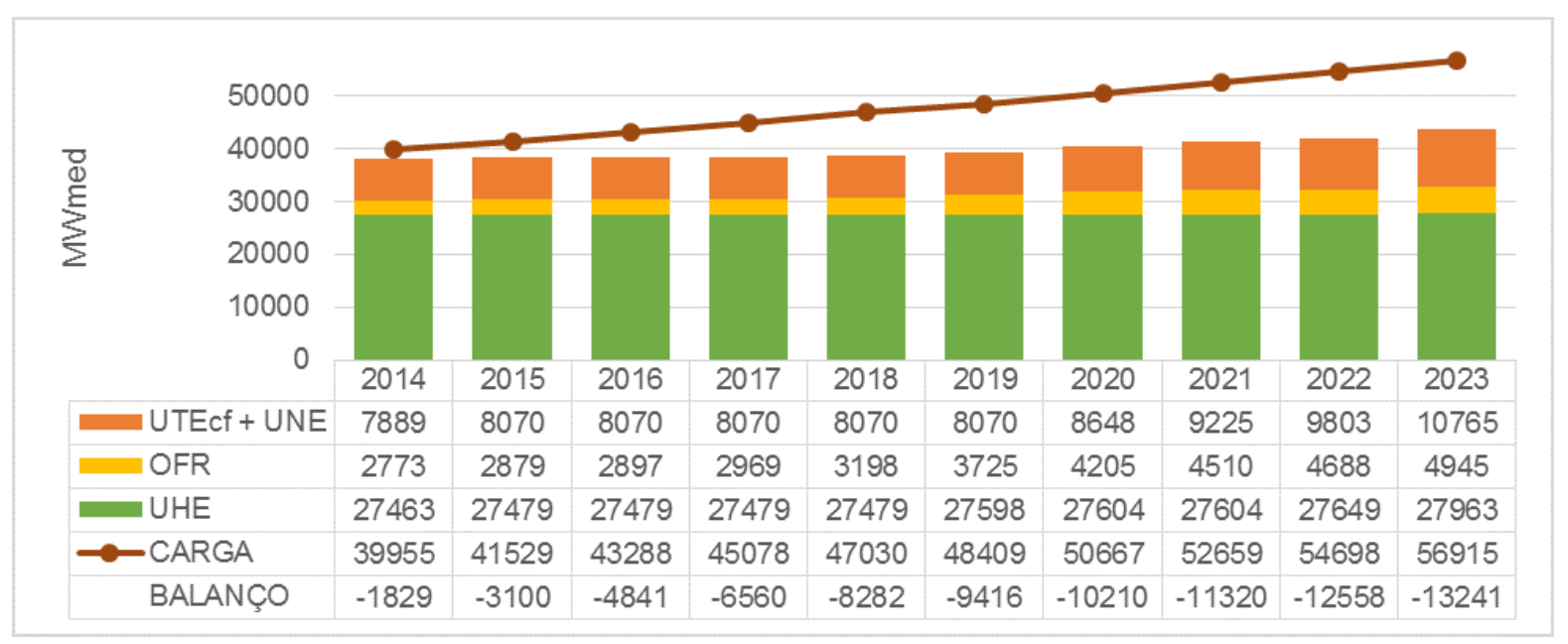

Gráfico 8: Balanço de garantia física SE/CO + Itaipu. Fonte: Adaptado do PDE 2023.

UHE-usinas hidrelétricas. OFR-outras fontes renováveis. UNE-usinas nucleares. UTEcf -usinas termelétricas comb. Fósseis.

Neste gráfico não são considerados os intercâmbios de energia com outros subsistemas, inclusive com a ligação com Acre/Roraima e Teles Pires da qual se espera que o subsistema SE/CO receba uma considerável quantidade de energia. Cabe observar que a disposição geográfica dos novos empreendimentos, que em sua maioria se encontram distantes dos maiores centros de carga, indica a necessidade de uma avaliação criteriosa da concretização da expansão da oferta, tanto de geração quanto das interligações, permitindo assim o escoamento da energia de forma segura.

O Gráfico 9 mostra o balanço de garantia física do subsistema SE/CO considerando a disponibilidade de energia para importação desde Acre/Rondônia + Teles Pires + Tapajós. É importante assinalar que de acordo com o PDE 2023 as interligações entre os sistemas permitirão o escoamento da energia excedente desde $\mathrm{AC} / \mathrm{RO}+\mathrm{T}$. Pires + Tapajós para SE/CO, graças às expansões das capacidades nas interligações planejadas para AC/RO $\rightarrow$ SE/CO e T. Pires + Tapajós $\rightarrow$ SE/CO. Pode ser observado que o acréscimo da energia aportada por Acre/ Rondônia diminui significativamente as necessidades de importações de energia proveniente do N/NE, mas ainda assim será preciso importar energia do N/NE. Dependendo da real disponibilidade dos recursos e da configuração adotada para o melhor funcionamento do sistema e maior aproveitamento de recursos renováveis, as importações de energia podem ser maiores que as apresentadas nesse gráfico. 


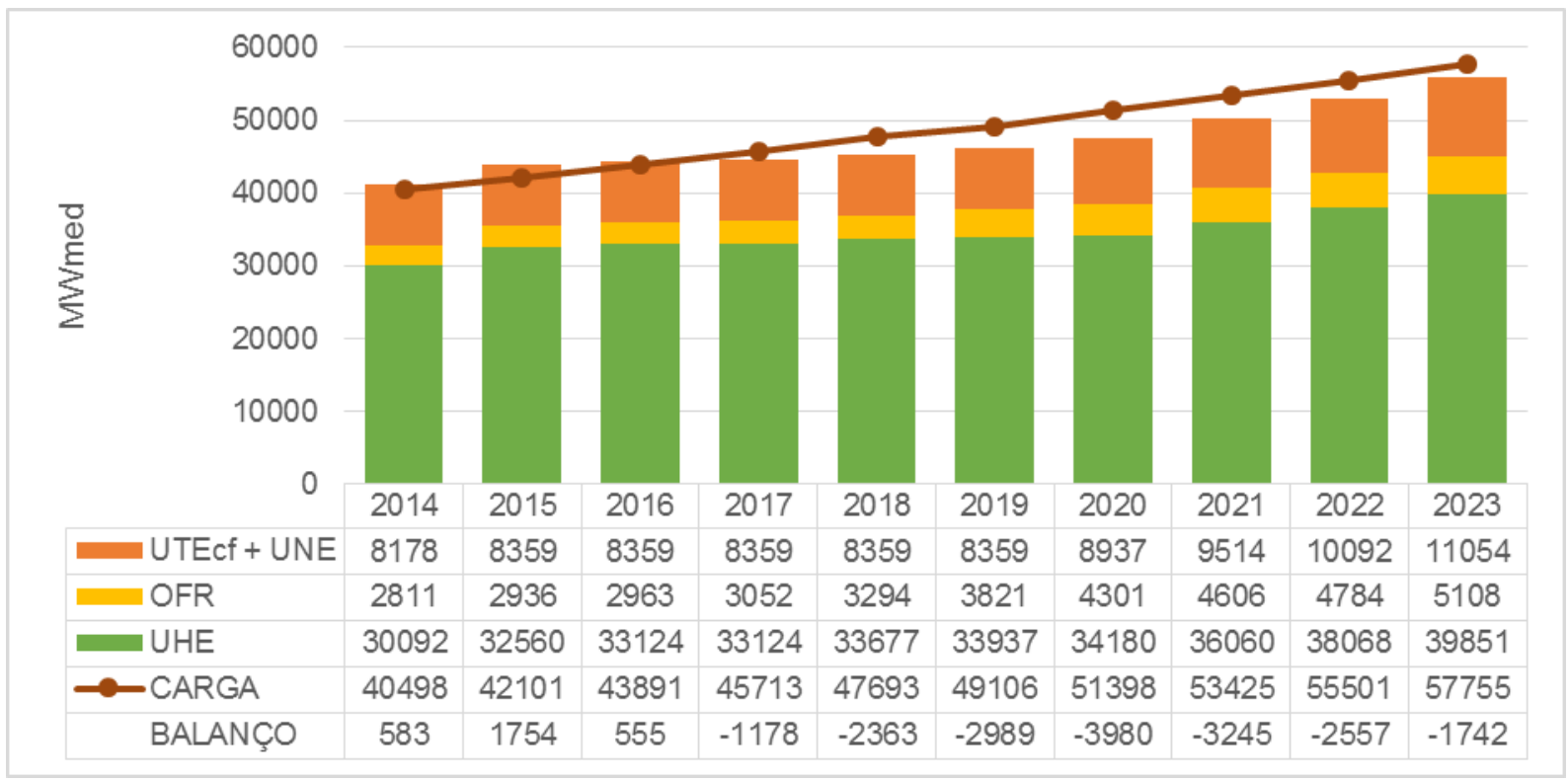

Gráfico 9: Balanço de garantia física de SE/CO + Itaipu+ AC/RO + T. Pires + Tapajós. Fonte: Adaptado do PDE 2023.

UHE-usinas hidrelétricas. OFR-outras fontes renováveis. UNE-usinas nucleares. UTEcf -usinas termelétricas comb. Fósseis.

O sistema de transmissão permite a troca de energia entre as diversas regiões, viabilizando a otimização dos recursos eletroenergéticos disponíveis no SIN para o atendimento da carga de energia elétrica, conforme mostram os seguintes gráficos. Podem ser observados os valores de fluxo, em 2.000 cenários hidrológicos simulados, para os doze meses dos anos 2016 e 2022, ordenados (PDE 2022). No Gráfico 10, pode-se observar que no ano $2016 \mathrm{em}$ aproximadamente 40\% dos cenários a interligação Imperatriz $\rightarrow$ SE/CO se encontra no limite de transmissão de energia nos patamares de carga média e leve, com uma possibilidade muito menor de acontecer no ano de 2022 devido às ampliações que se têm planejadas nessa interligação, nos anos 2016, 2018 e 2019, para conseguir escoar a energia dos subsistemas norte e nordeste com o propósito de aumentar o uso ótimo dos recursos renováveis e diminuir o risco de blackouts devido a falhas na transmissão e nas interligações entre os subsistemas no SIN. 

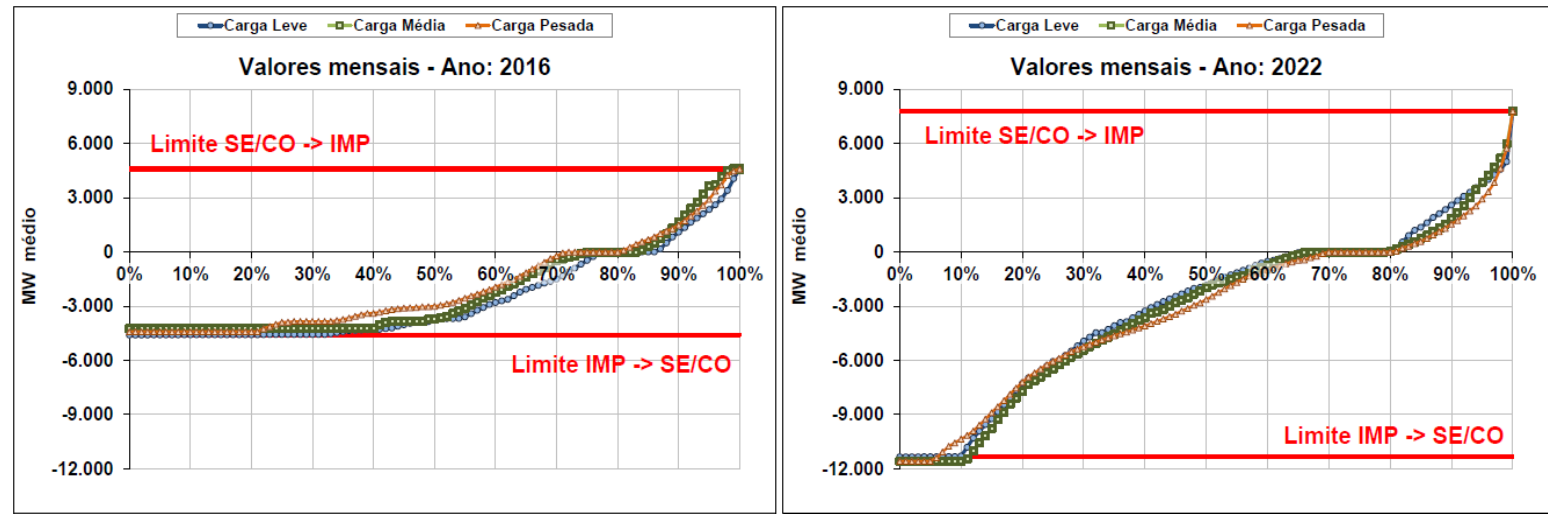

Gráfico 10: Distribuição dos fluxos de energia na interligação Imperatriz $\rightarrow$ SE/CO (MWmed) curvas de permanência. Fonte: Adaptado de PDE 2022.

No Gráfico 11, mostra-se que até o ano 2016 a interligação $\operatorname{Imp} \rightarrow$ SE/CO no patamar de carga leve permanecerá no seu limite em aproximadamente $45 \%$ dos cenários simulados, sem importar se se encontra no período úmido ou no período seco. Já no ano 2022, a possibilidade de a interligação atingir o seu limite acontece em $20 \%$ dos cenários e somente para o período úmido, deixando uma folga considerável na interconexão no período seco e demonstrando assim ainda mais a marcada sazonalidade dos subsistemas N/NE. Esse alto índice de uso da interligação demonstra a importância que a disponibilidade de energia nos subsistemas N/NE tem para os subsistemas SE/CO/S, sendo também possível perceber riscos de sobrecarga das interligações para conseguir atender à demanda de energia dos SE/CO/S o que poderia comprometer a qualidade do atendimento a todo o SIN. 


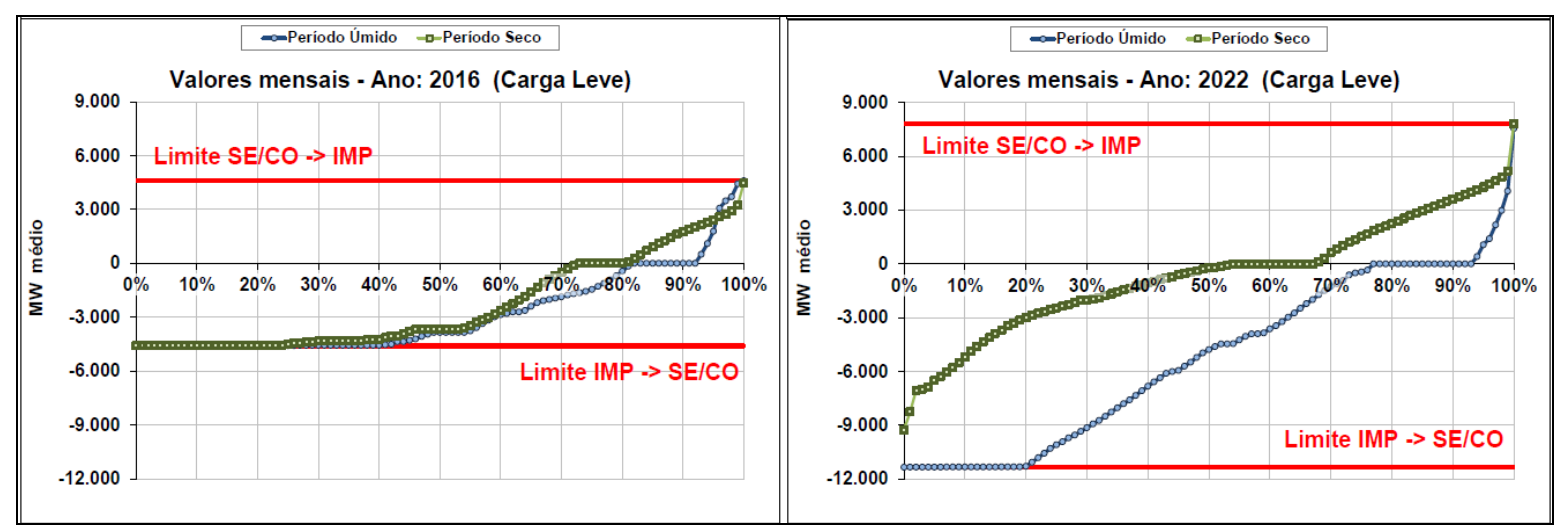

Gráfico 11: Intercambio da interligação Imperatriz- SE/CO para os períodos úmido e seco. Fonte: PDE2022.

A necessidade de uso dos intercâmbios no horário de ponta para o atendimento da demanda de potência é mostrada nos gráficos seguintes, os quais foram apresentados no PDE 2022 para cuja elaboração não foram consideradas a otimização dos recursos energéticos nem representa uma operação de mínimo custo na ponta, nem agrupamentos de intercâmbios. Assim, a utilização das interligações pode ser maior do que os valores apresentados se isso conduzir a uma operação de menor custo. É possível observar no Gráfico 12 que no ano 2017 em $45 \%$ dos cenários, aproximadamente, a interligação Imperatriz- SE -pela qual é escoada a energia do $\mathrm{N} / \mathrm{NE}$ às regiões $\mathrm{SE} / \mathrm{CO} / \mathrm{S}$ - estará no limite da sua capacidade, possibilidade que diminui a partir do 2018 devido às ampliações dessa interligação. É possível observar também que o limite de intercâmbio entre o SE e o Sul mantém uma folga considerável ao longo do período chegando a um máximo de 55\% do limite de transferência em 2019. 
Intercâmbio Imperatriz - SE

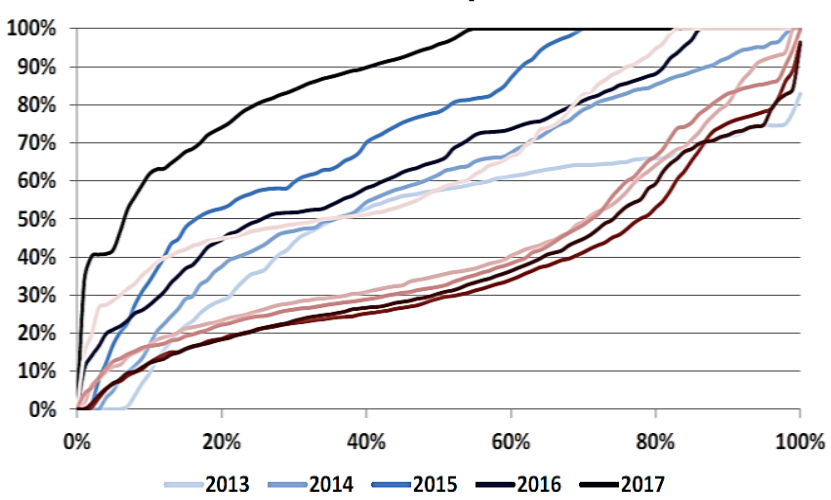

Intercâmbio SE-S

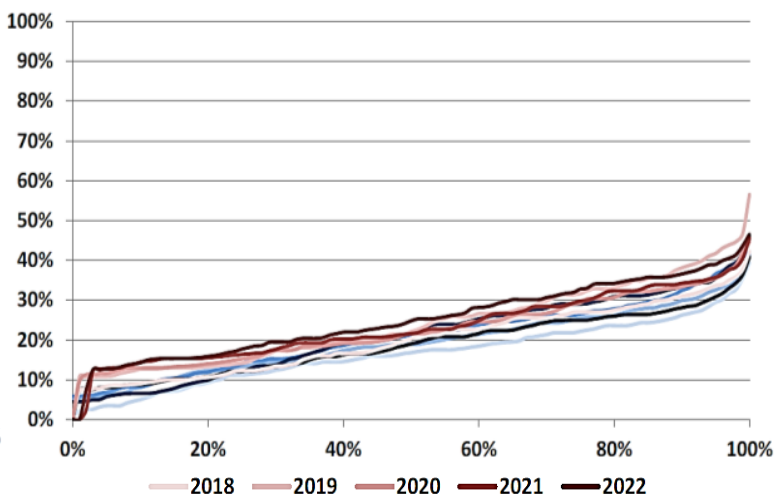

Gráfico 12: Necessidades de uso das interligações no horário de ponta. Fonte: Adaptado de PDE 2022

Deve se ressaltar que devido ao fato de que nos mesmos cenários em que a interligação encontra-se no seu limite de intercâmbio também se apresentam sobras de potência no sul, o que pode indicar que o uso dessa interligação permitirá o atendimento da carga de demanda da região SE/CO. O Gráfico 13, mostra mais claramente esse fato, e observa-se que em 2017 as faltas de potência no sul coincidem com o uso ao limite da interligação Imperatriz - SE/CO, mas nos anos decorrentes continuam se apresentando possibilidades de insuficiências de potência no Sul, mesmo tendo folga nas interligações do N/NE com o SE/CO e na SE/CO-S (o que pode ser visto no Gráfico 12). Portanto, é possível assumir que essas faltas de potência devam-se à insuficiência na oferta de energia para o atendimento do horário de ponta, o que ilustra ainda mais a importância da implementação de novas usinas na região SE/CO/S em uma linha temporal que acompanhe o incremento esperado na carga de energia e na demanda de potência desses subsistemas. 


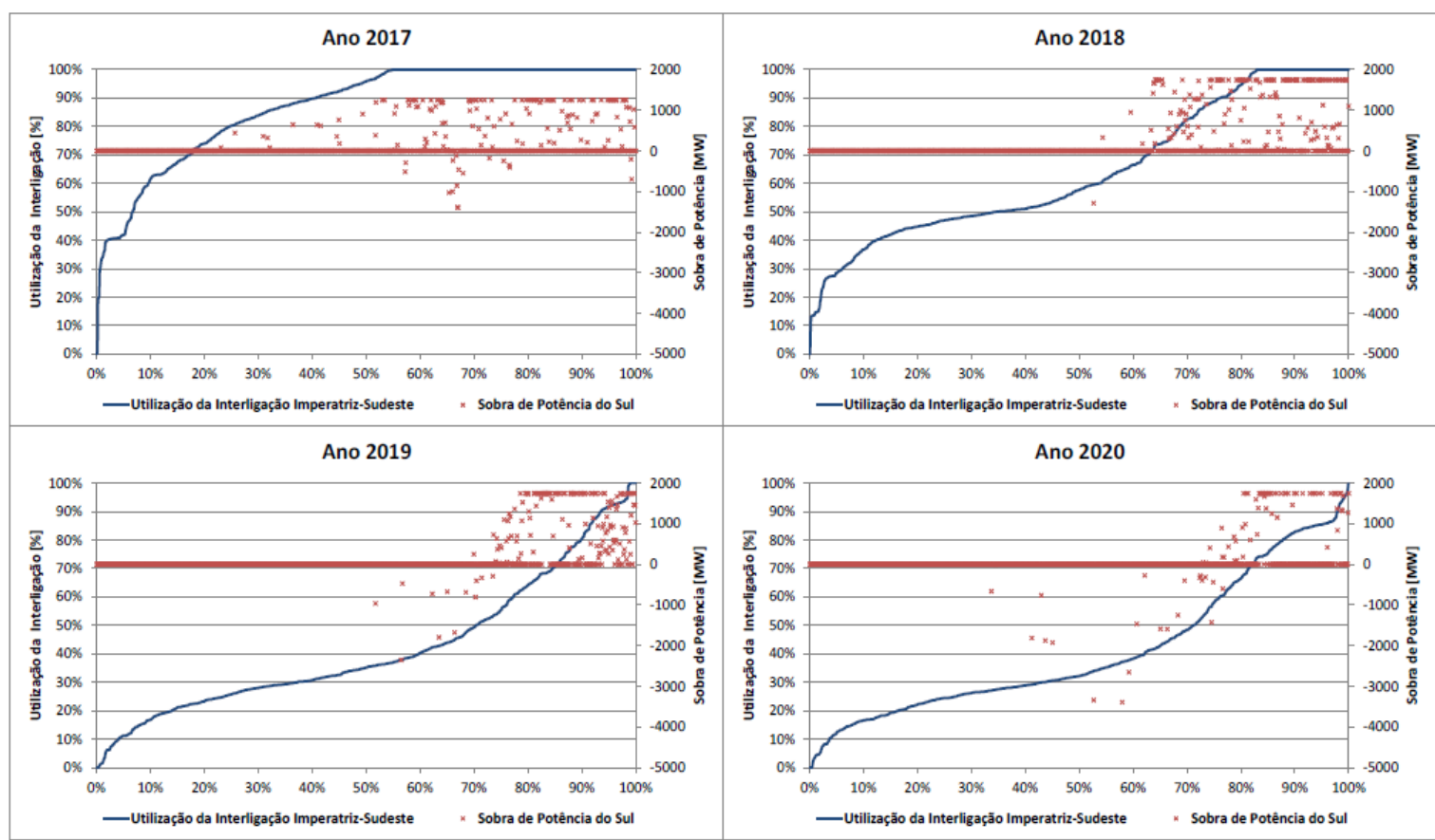

Gráfico 13: Uso da interligação Imperatriz - SE/CO versus os excedentes de potência no SUL. Fonte: PDE 2022.

\subsection{Sistema Elétrico do Estado de São Paulo}

Apesar da segurança no fornecimento de energia ser um dos pilares do modelo institucional do setor elétrico brasileiro aprovado no ano de 2004, a própria posição geográfica de São Paulo dentro do Sistema Interligado Nacional (SIN), relativamente longe dos principais centros de geração - especialmente em relação às novas expansões na Bacia Amazônica-, torna-o mais vulnerável a eventuais falhas de transmissão (SEE, 2011). Isso torna os aproveitamentos dos recursos de geração disponível localmente mais importantes, não só para propósitos de exploração de recursos, senão também, para ter uma maior segurança no fornecimento e diminuição de perdas na transmissão da energia. 


\subsubsection{Histórico de operação do sistema do Estado de São Paulo}

O consumo de eletricidade do estado de São Paulo representou $29 \%$ do consumo de energia elétrica no Brasil no ano 2013, (BEESP, 2014 e BEN, 2014) e na última década $50 \%$ da carga do SE/CO. No Gráfico 14 pode ser observada a evolução da origem da energia disponível para o consumo da última década no estado de São Paulo, onde os dados de geração referem-se unicamente à energia gerada pelas centrais elétricas de serviço público, e a energia que é gerada -na sua maioria com biomassa- e consumida pelos autoprodutores não é considerada neste gráfico. A energia gerada pelas usinas de serviço público é de origem hidráulica e, embora no estado exista geração térmica, esta não foi acionada nesse tempo. É possível observar que na década o aumento no consumo no ESP foi de $20 \%$ em relação ao de 2004, também nota-se uma dependência considerável de importações de energia, sendo de $53 \%$ em 2013 , na sua maioria proveniente de Itaipu.

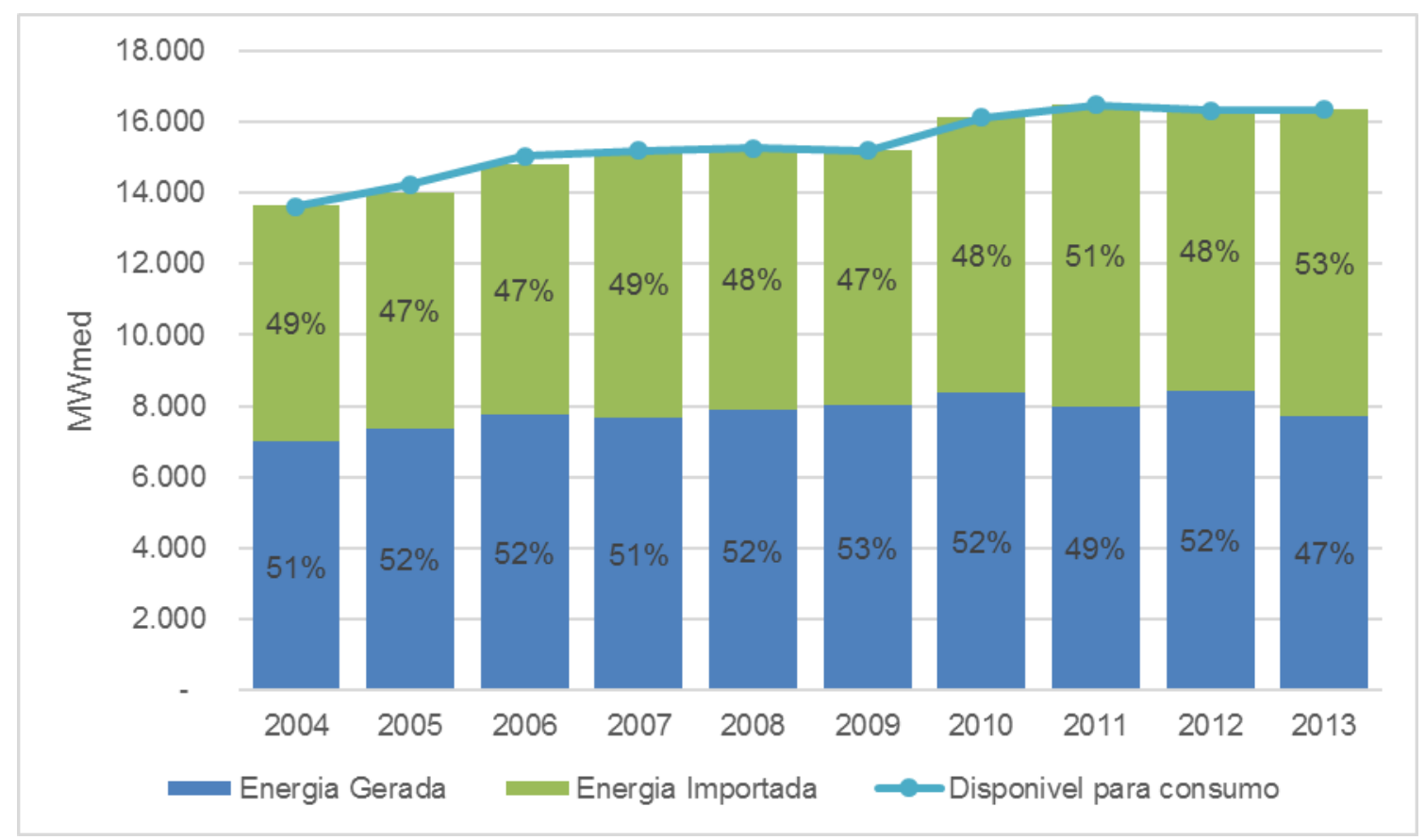

Gráfico 14: Energia elétrica disponível para consumo no estado de São Paulo. Fonte: Adaptado do BEESP, 2014.

No Gráfico 15, apresenta-se a evolução mensal do consumo e geração de energia elétrica em São Paulo 2012-2014, na qual é possível se observar que o maior 
consumo de eletricidade ocorre nos meses correspondentes às estações de primavera e verão. Estações nas quais aumentam as temperaturas e o uso de aparelhos de ar condicionado. Também é possível observar a sazonalidade da hidroeletricidade, principal fonte de geração do ESP, e a decorrente variação nas importações que dependerão tanto da variação na demanda quanto da variação na disponibilidade de hidroeletricidade local.

Nota-se um aumento importante nas importações quando se comparam as importações de eletricidade dos anos 2012 e 2013, devido principalmente à menor produção local pelas condições desfavoráveis da produção com hidroelétricas, o que afetou a todo o SIN. Mas essa notável diminuição da oferta local de energia, pelo fato de que a matriz do ESP não é muito diversificada, deixa claro que deve considerar-se seriamente a implementação de novas fontes de geração local. 

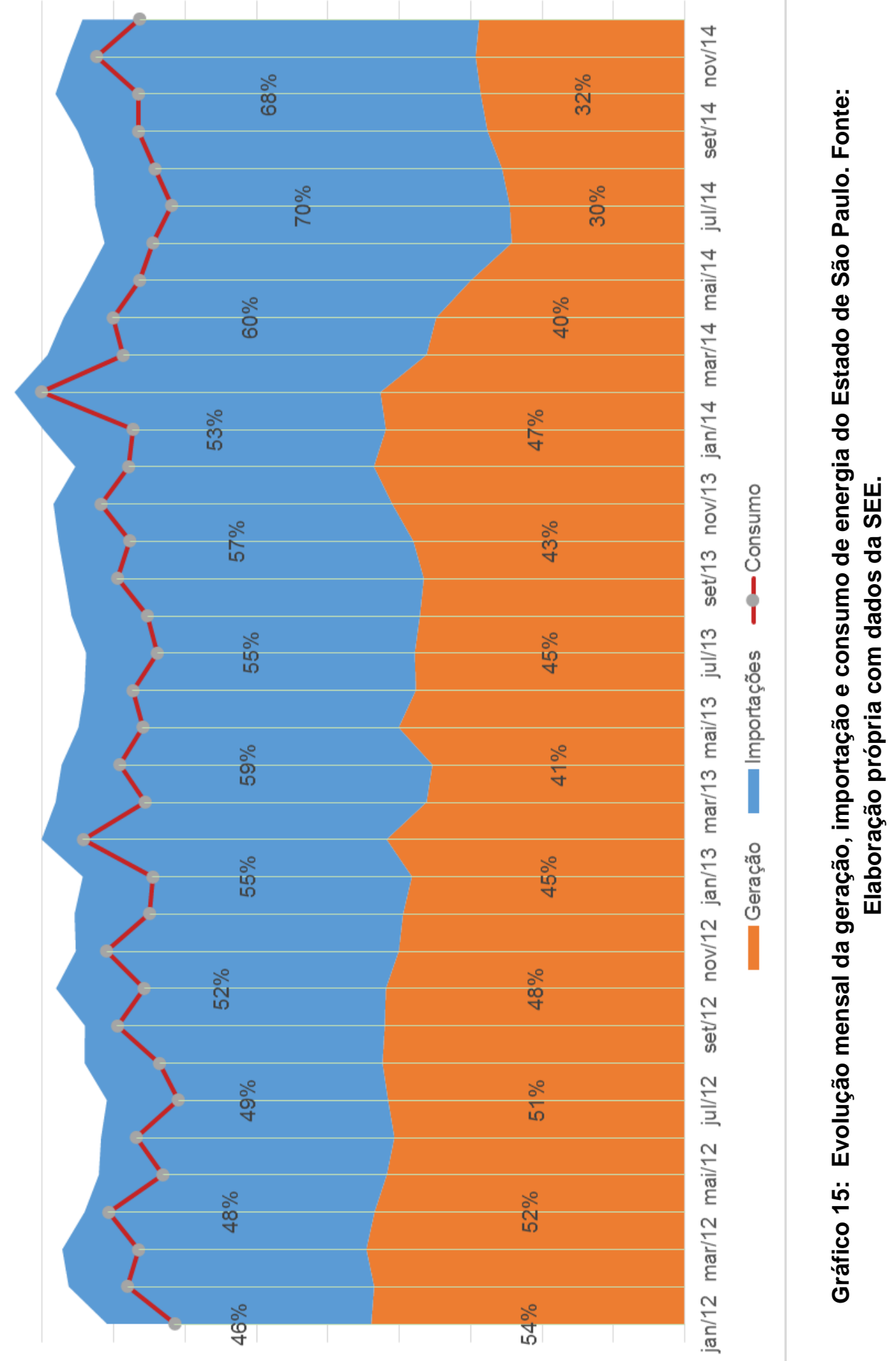

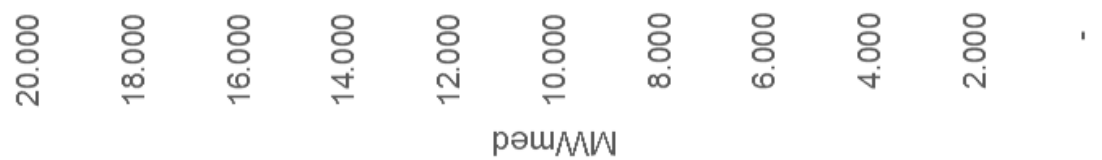




\subsubsection{Projeção do mercado de energia elétrica no ESP}

As projeções aqui apresentadas foram obtidas do PPE 2020, para a sua elaboração a principal diretriz foi a priorização da participação das fontes renováveis de energia, para o atendimento do crescimento do consumo de energia elétrica até 2020, considerando os efeitos ambientais e a segurança energética. Para as simulações energéticas necessárias ao ajuste do plano de oferta de energia e ampliações nas interligações, foi utilizado o modelo Newave, com a simulação de 2 mil cenários hidrológicos (PDE 2020).

Para destacar o ESP, usou-se uma modelagem semelhante à empregada no PDE 2020, porém, segmentando o sistema SE/CO em dois subsistemas: Subsistema São Paulo e Subsistema com demais estados do SE/CO. Considerou-se que as interligações de transmissão do ESP serão com a usina Itaipu, o subsistema Acre/Rondônia, o subsistema Sul e a energia proveniente dos subsistemas N/NE e o resto do SE/CO será agrupada num mesmo conjunto. Esta modelagem permitiu a elaboração do balanço da oferta e demanda de eletricidade do ESP, determinando a produção interna e os intercâmbios de energia necessárias para o bom atendimento do setor. Com isto, foi possível determinar a evolução do grau de dependência do estado com relação à energia importada, bem como o impacto de programas alternativos da expansão da oferta interna.

O cenário adotado e considerado como mais provável pelo PPE 2020, nas projeções de aumento da oferta de energéticos, considera tendências de evolução atuais e seus comportamentos históricos. Considerando:

- análise da oferta de eletricidade proveniente de hidroelétricas com potência maior a $30 \mathrm{MW}$, centrais termoelétricas (combustível fóssil) e centrais nucleares;

- fontes renováveis como biomassa, $\mathrm{PCH}$, eólica, solar fotovoltaica, etc. A expansão da geração da biomassa considerando a tendência atual; e aumento tendencial da oferta no estado de São Paulo, referente à adição de usinas a biomassa; 
- carga do estado de São Paulo, considerando tendência de participação de São Paulo no Sudeste (de 50\% em 2010 para 47,5\% em 2020);

- revisão da projeção de demanda de energia elétrica, a partir de estudos da EPE para o plano 2012-2013;

- PCHs existentes e as que estão em implantação;

- aumento da oferta no estado de São Paulo referente à adição de usinas térmicas(UTEs) acionadas por gás natural.

- aumento da oferta de energia elétrica através da cogeração de energia e climatização a gás natural.

Para a projeção do consumo e da carga foi utilizado o trabalho intitulado "NOTA TÉCNICA EPE/DEA 16/11 - Projeção da demanda de energia elétrica para os próximos 10 anos (2012-2021)"; ou seja, foram adotadas as mesmas hipóteses do cenário de referência para configuração do consumo e da carga do estado de São Paulo.

\section{i. Projeção de consumo e geração do ESP até 2020}

De acordo com o PPE 2020, tem-se programada a inserção de duas usinas térmicas, com potência nominal conjunta de $829 \mathrm{MW}$, ao parque de geração de usinas de serviço público do ESP, as usinas de Pederneiras e Canas. As quais se encontram em processo de viabilização pelas empresas (Duke e AES), inclusive buscando a garantia de suprimento de gás natural, com início de operação no ano de 2017. Estima-se que mesmo com a entrada em funcionamento dessas usinas continue a tendência de importar.

Nessa projeção considerou-se também o programa de fomento de cogeração com gás natural, que resultaria no aumento da oferta de energia elétrica na forma de geração distribuída. Nesse trabalho o acréscimo desse tipo de geração foi considerado na oferta para destacar sua importância. Os valores utilizados obtidos são apresentados no Gráfico 16. 


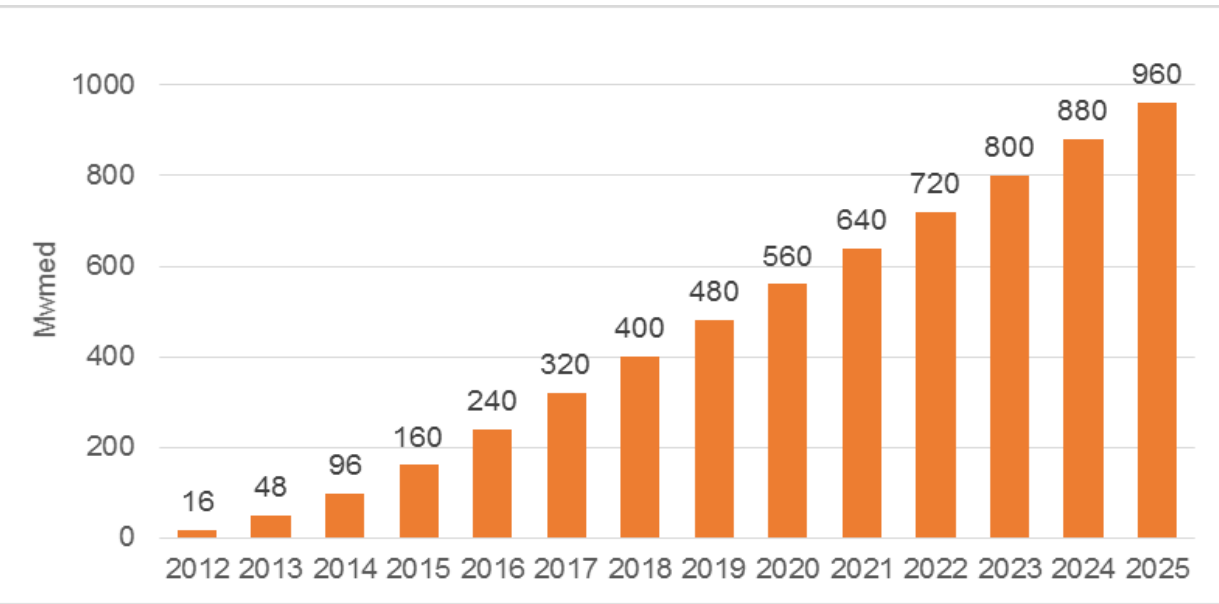

Gráfico 16: Evolução da participação da cogeração com gás natural no ESP. Fonte: Adaptado de PPE 2020.

No Gráfico 17 mostra-se a projeção do balanço energético do Estado de São Paulo no cenário provável de acordo com o PPE 2020. Pode-se observar que a tendência de importar continua aumentando a cada ano durante o escopo do estudo, o que se deve ao fato de que a projeção da inserção de novas usinas não consegue acompanhar o crescimento esperado na carga local. Nota-se também uma grande variação sazonal dos recursos locais, hídrico e biomassa, e que as expectativas de geração quando comparadas com o Gráfico 15 foram optimistas, já que a geração 2012-2014 ficou muito abaixo das expectativas.

Cabe ressaltar que nessas projeções não se reflete a produção de energia eólica nem fotovoltaica, recursos com potencialidades importantes no ESP. 


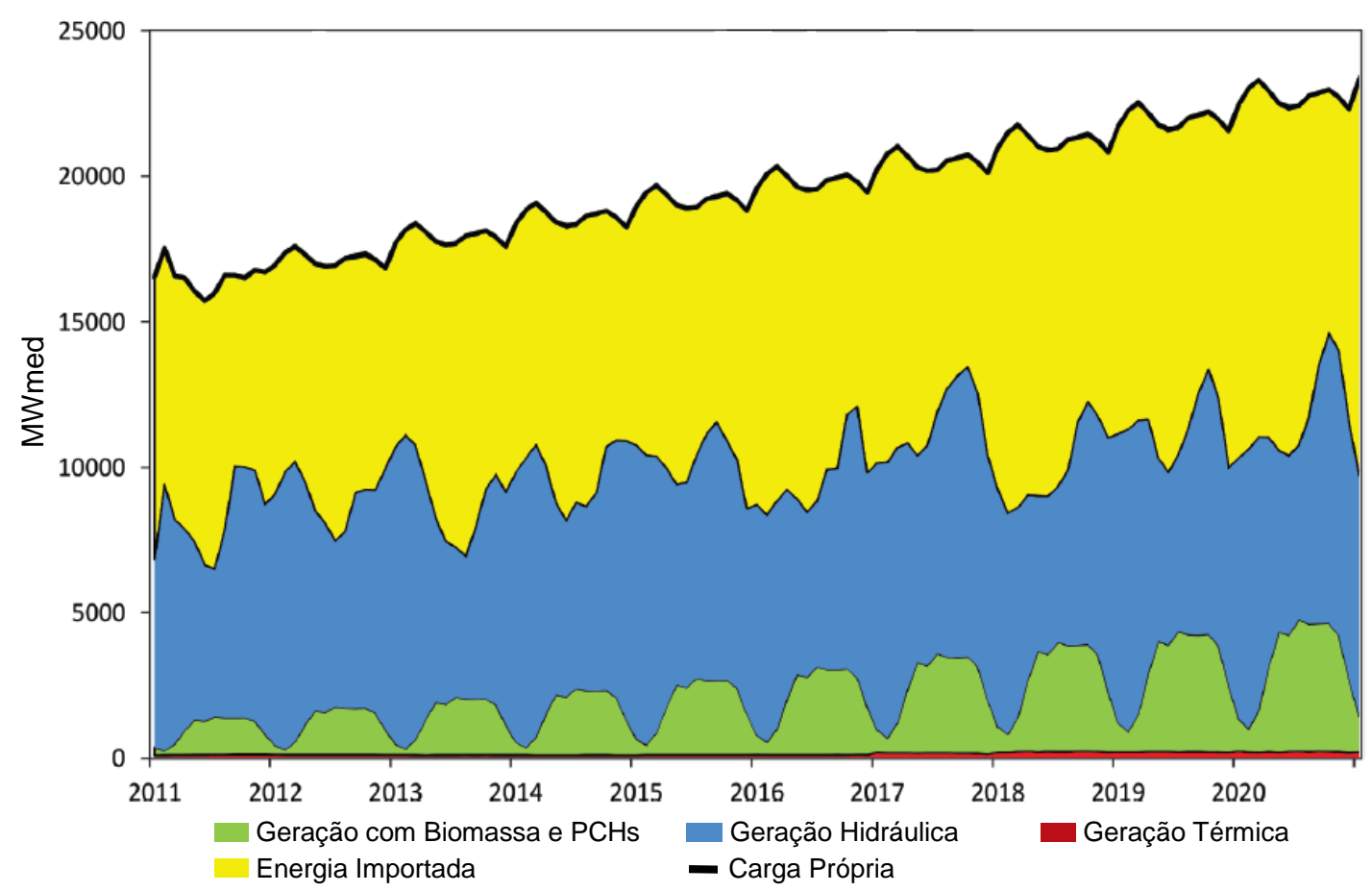

Gráfico 17: Projeção do balanço energético do ESP de acordo ao cenário provável. Adaptado de PPE 2020.

No Gráfico 18 se apresenta a projeção da evolução da carga do ESP por patamares de carga e a porcentagem de duração dos patamares de carga no SIN, observa-se que é esperado que o sistema do ESP permaneça em mais de $60 \%$ do tempo no requerimento de energia correspondente aos patamares médio ou pesado que têm valores muito próximos.

$\mathrm{Na}$ projeção mostrada no Gráfico 18 , observa-se que dada a importância da participação do consumo do ESP no consumo do SE/CO e do SIN, tem-se previsto um crescimento no consumo de $25 \%$ no patamar de carga leve e de $28 \%$ nos patamares de carga pesada e média, espera-se que no 2023 o ESP seja o resposável de 47\% da carga média do SE/CO. Espera-se então que a carga média do ESP em 2023 seja de 26750 MWmed (ver Gráfico 8). Mas o crescimento na capacidade de geração das centrais de serviço público é de $5,6 \%$, do que pode se assumir que uma porcentagem importante das necessidades de importação previstas para o SE/CO será para o atendimento do ESP (ver Gráfico 9). 


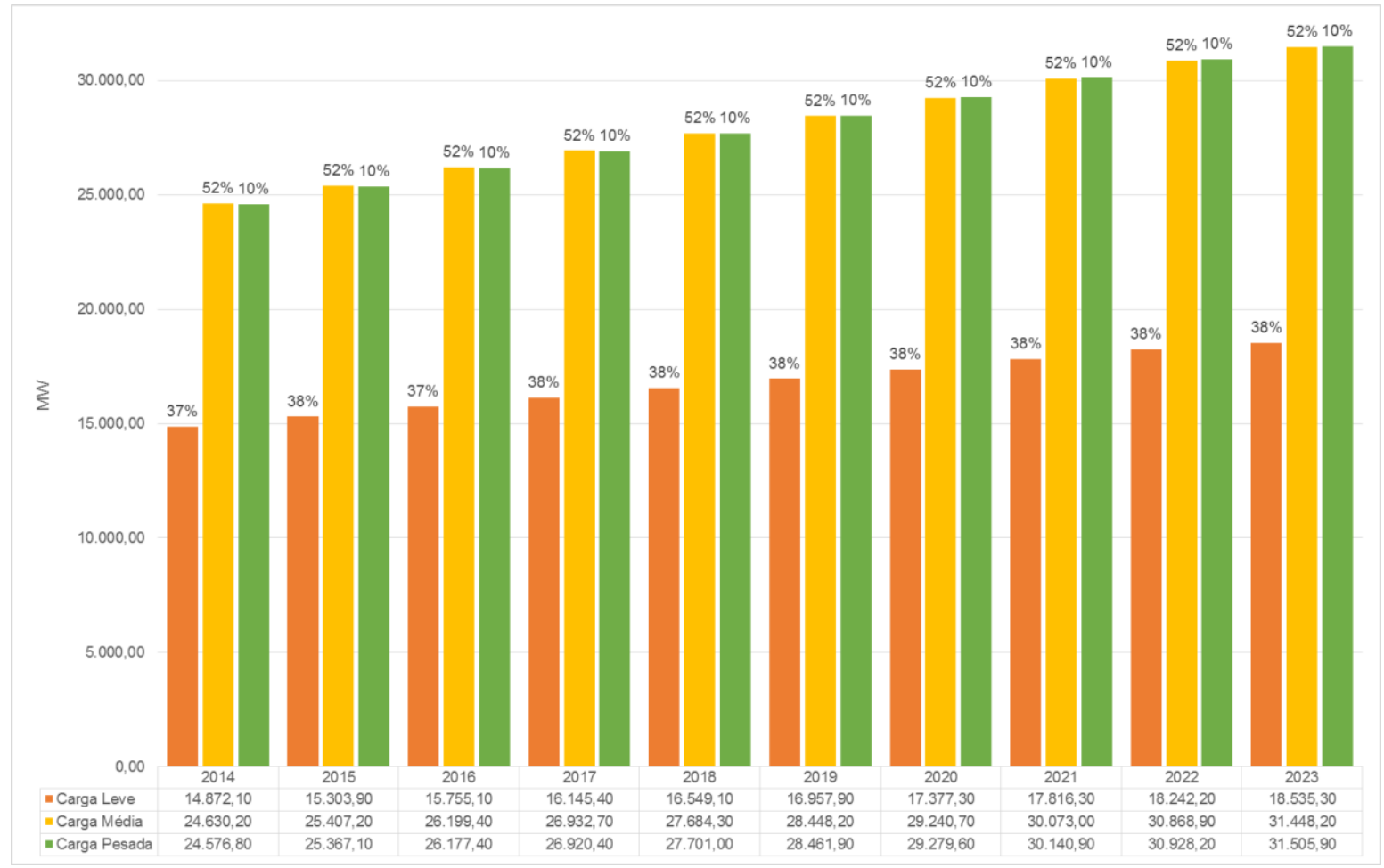

Gráfico 18: Projeção da evolução da carga por patamar no ESP. Fonte: Adaptado de PDE 2023 com dados da EPE.

Deve-se considerar que em 2014, a capacidade nominal instalada nas centrais elétricas de serviço público no ESP totalizava 14.537,1 MW - sendo 13.629,1 MW em hidroelétricas e 908,0 em termoelétricas - e que até 2020 só se tem planejada a inserção de $829 \mathrm{MW}$ através de duas termelétricas de serviço público com as que se totalizariam 15.366,10 MW de capacidade nominal instalada. Tendo em conta também os dados apresentados no Gráfico 14, no qual é possível observar o histórico de geração da última década do ESP, observa-se que a maior geração média das hidroelétricas foi de 8400 MWmed em 2010 e que a geração máxima que poderia ser obtida por termoelétricas seria de $1650 \mathrm{MWmed}$, obtendo-se assim, uma geração local das centrais de serviço público de $10.050 \mathrm{MWmed}$, isso esperando uma hidroeletricidade favorável, além do uso contínuo das termoelétricas. Ao comparar essa disponibilidade com os 26750 MWmed da projeção do consumo do ESP é possível perceber que a disponibilidade local não será suficiente nem para o atendimento da potência requerida no patamar de carga leve, fazendo com que sejam necessárias as importações de grandes blocos de energia do resto do subsistema SE/CO ou mesmo do SIN, causando uma carga constante no sistema 
de transmissão para conseguir atender os requerimentos de carga de todos os patamares.

Cabe ressaltar que pelo SE/CO e AC/RO terem uma grande dependência hídrica, nos meses de menor disponibilidade desse recurso deverá ser necessária a geração termoelétrica muito acima da inflexibilidade, no caso de não haver a inserção de outras fontes para o atendimento da carga.

No ESP ainda existem potencialidades de geração a serem exploradas, com o que se aumentaria a segurança do $\mathrm{SIN}$, e se reduziria as perdas associadas à transmissão de grandes blocos de energia desde grandes distâncias para um dos principais centros de carga, além do aumento da diversificação na matriz energética que ajudará a incrementar a proteção contra reduções drásticas de energia disponível, ao depender em grande medida de poucas fontes de geração.

\section{ii. Projeção de intercâmbios de energia do Estado de São Paulo}

No Gráfico 19, mostra-se a projeção da origem da energia a ser importada pelo ESP até 2020, na qual é possível observar que espera-se que o principal fornecedor da energia importada será a usina Itaipu, já que o ESP é o ponto principal de chegada da energia gerada pela Itaipu. Estima-se que o sistema $\mathrm{AC} / \mathrm{RO}$ fornecerá a segunda maior porcentagem de energia, sendo o restante fornecido por N/NE e o resto pelo SE/CO, deixando uma menor participação ao subsistema Sul cuja contribuição diminuirá no transcurso dos anos.

O início de operação do primeiro Bipolo da interligação em corrente contínua que permite a conexão das usinas conectadas do subsistema Acre/Rondônia (AC/RO) com o SIN via a Subestação Araraquara localizada no estado de São Paulo, entrou em operação em 29 de novembro de 2013, o que permitiu a injeção de 700 MW diretamente no SE/CO (ONS, 2014). Essa interligação ocorreu quase 2 anos após a previsão.

Deve-se destacar que, Itaipu e as usinas de AC/RO são consideradas como a fio d'água, isto é, não possuem reservatórios para armazenamento de água. Portanto, seu perfil de geração será semelhante ao perfil sazonal de suas afluências. No caso 
das hidroelétricas ligados ao $\mathrm{AC} / \mathrm{RO}$, apresentam oferta hidroelétrica abundante na estação chuvosa, podendo produzir sua capacidade máxima de geração, e reduzida na estação seca, podendo gerar, em média, 2.000 MWmed (ONS, 2014).

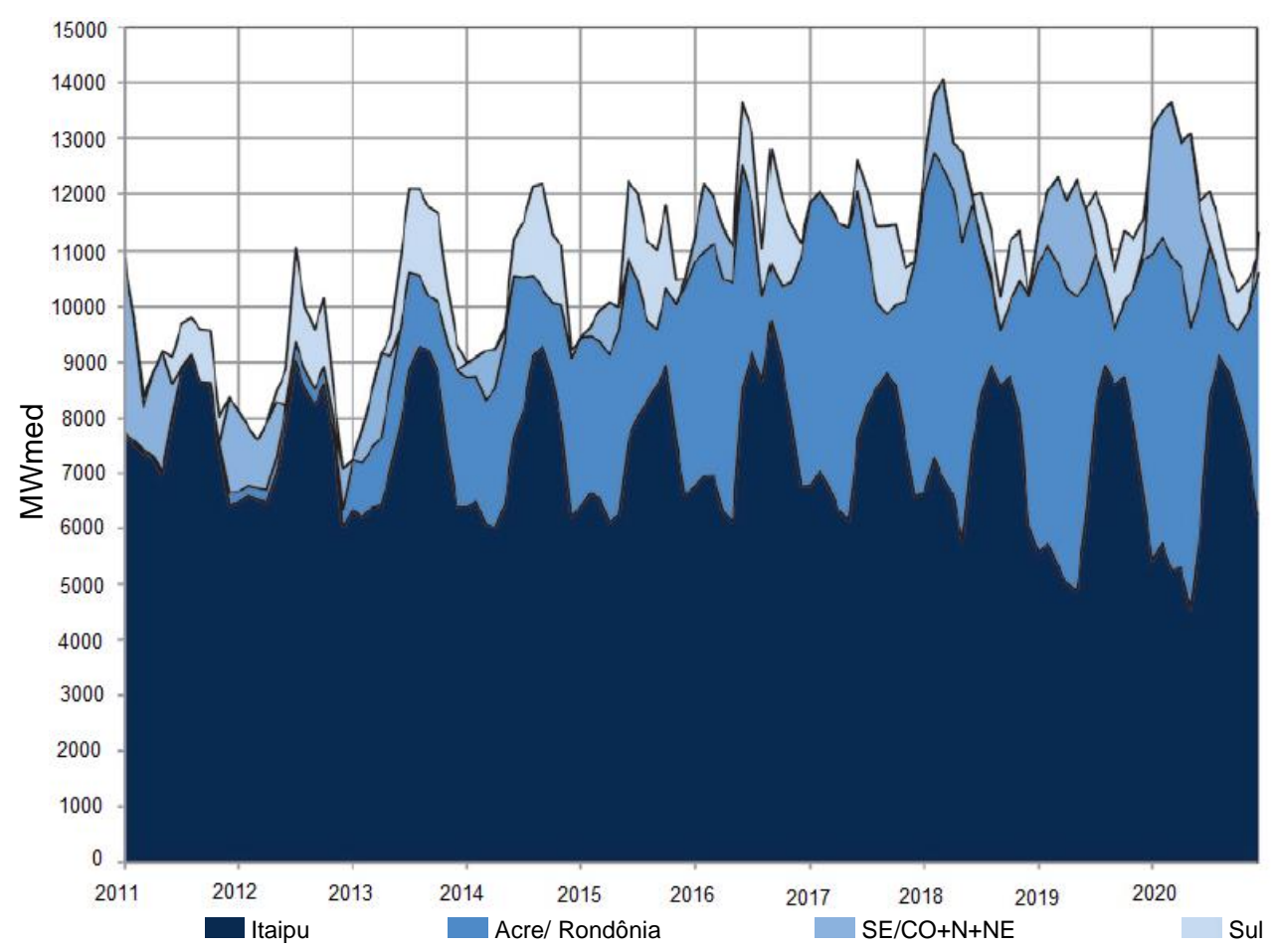

Gráfico 19: Projeção da origem da energia importada pelo Estado de São Paulo. Fonte: Adaptado de PPE 2020.

A existência de outras fontes de geração local no ESP contribuirá para manter a segurança do sistema ao preservar os reservatórios e provavelmente adiar investimentos em fontes de geração localizadas mais distantes do centro de carga, além de colaborar com a manutenção de uma matriz energética limpa no Brasil e preparar o sistema do ESP para o incremento esperado na sua demanda de eletricidade.

No cenário provável, também foram projetadas as previsões das exportações a serem feitas pelo ESP e o destino dessa energia. Esses intercâmbios ocorrem com o subsistema sul e com outro conjunto no qual se agruparam o resto do subsistema $\mathrm{SE} / \mathrm{CO}+\mathrm{N} / \mathrm{NE}$. Nota-se no Gráfico 20 que a exportação será com maior frequência 
e quantidade com o conjunto de resto de $\mathrm{SE} / \mathrm{CO}+\mathrm{N} / \mathrm{NE}$, e serão menos significativas com o subsistema Sul.

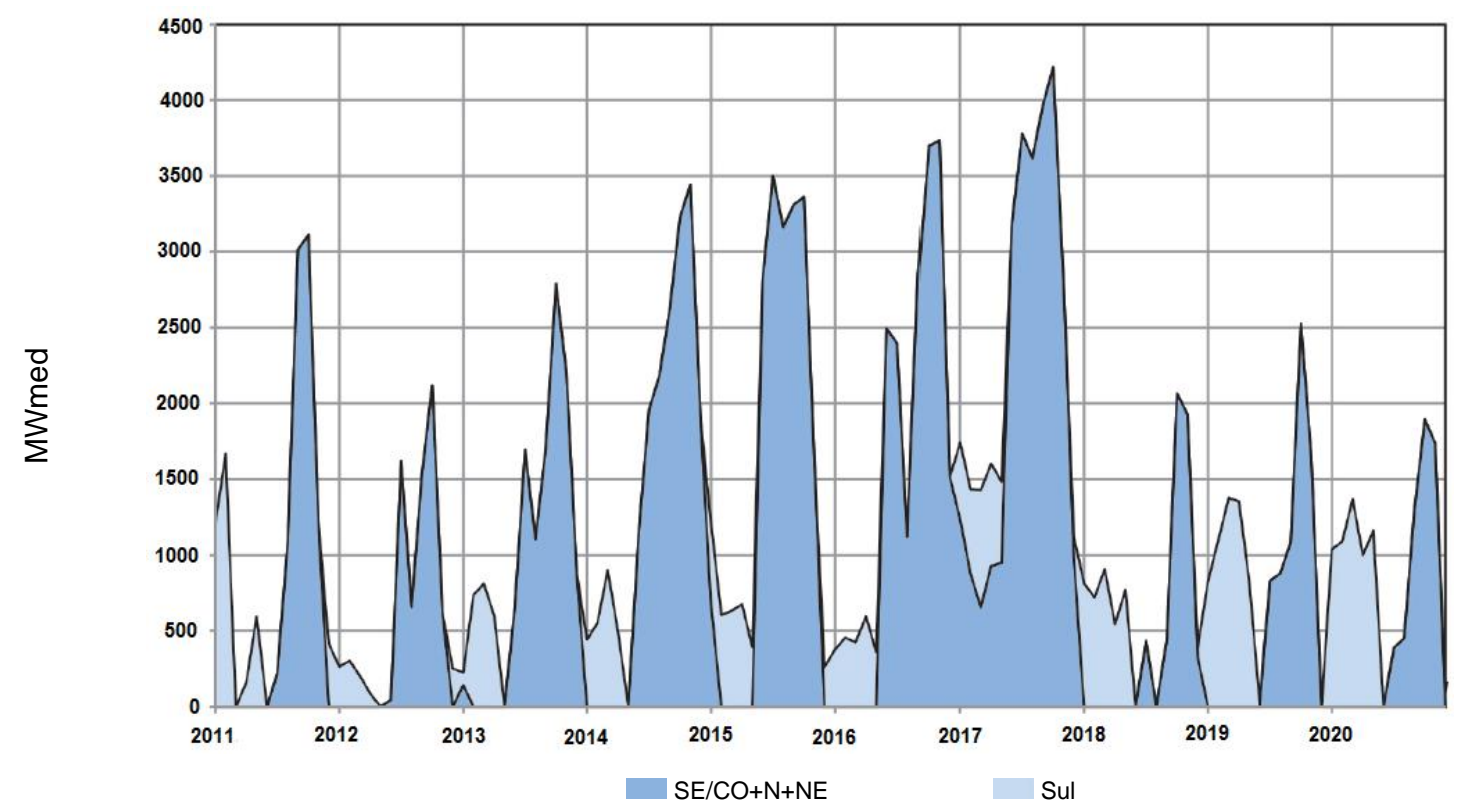

Gráfico 20: Projeção do destino das exportações de energia do ESP. Fonte: adaptado de PPE 2020.

Pode-se notar que a partir de 2018 se prevê uma redução significativa nas exportações do ESP, e também que quando são considerados os dados apresentados nos Gráfico 11, 12 e 20, as possibilidades de déficits de potência previstas para o subsistema Sul poderiam ser reduzidas com a inserção de novas fontes de geração no ESP, já que também se prevê folga nas transferências com a interligação com o subsistema sul.

Do anteriormente mencionado, se observa que dado que a maior porcentagem da energia que se prevê será importada pelo ESP vem de hidroelétricas a fio d'água, denota-se a importância de fazer uso de outros tipos de geração, preferivelmente com fontes renováveis para ajudar a manter a matriz energética limpa no intuito de permitir que as hidroelétricas com reservatórios armazenem energia para o período de menor disponibilidade de recursos renováveis, adiando ou diminuindo, desta forma, o uso das termoelétricas e mitigando os efeitos das condições hidrológicas desfavoráveis que poderão modificar muito 0 resultado real da projeção apresentada. 
O incremento na geração local, além de aumentar a segurança energética do sistema elétrico do ESP, ajudará a incrementar a eficiência e o bom funcionamento global do SIN, permitindo maior disponibilidade de energia para outros subsistemas que são importadores. Se a geração local for injetada diretamente na rede de distribuição, isso reduziria ainda mais as perdas no sistema, já que seriam evitadas as perdas de transformação e transporte pela rede básica, além de que o consumo estaria muito próximo da geração, de modo que as novas usinas a serem implementadas poderiam se considerar mais como uma diminuição na carga. 


\section{Estimativas dos potenciais de geração por fontes renováveis pouco convencionais no Estado de São Paulo}

Os altos custos, econômicos, sociais e ambientais envolvidos na construção de novas centrais elétricas e linhas de transmissão e distribuição cuja implementação é necessária para suprir as necessidades energéticas do Estado de São Paulo, associados ao esgotamento da capacidade de geração local e ao aumento da carga de energia, motiva a buscar novas fontes de geração que possibilitem o adequado atendimento do sistema elétrico. Ainda mais, em termos de evolução da matriz de energia elétrica e de segurança do SIN, ao se manter a atual tendência da expansão da hidroeletricidade com baixa ou nenhuma regularização, faz-se necessário a consideração da inserção de fontes alternativas de geração que complementem a variação na geração desses empreendimentos e que contribuam, deste modo, a manter uma matriz de energia limpa e a segurança de fornecimento e qualidade de energia.

Neste capítulo, faz-se uma revisão dos recursos renováveis, dos quais ainda não se está utilizando o seu potencial de geração de energia no ESP, mais especificamente energia eólica, fotovoltaica, incineração de resíduos sólidos urbanos (RSU) e o uso energético da vinhaça. Tomou-se somente esses quatro tipos de geração devido à disponibilidade da informação e porque o objetivo da análisedar é oferecer uma amostra, grosso modo, do potencial que não é aproveitado atualmente e que poderia ajudar a melhorar a segurança energética do estado.

A seguir se apresenta um resumo de alguns recursos disponíveis no ESP e os seus potenciais de geração.

\subsection{Potencial de geração eólica}

Os dados do potencial de geração de energia eólica foram obtidos do Atlas Eólicos do Estado de São Paulo, publicado no ano 2012 pela Secretaria de Energia. As medições anemométricas mostraram que em todos os locais de bom potencial eólico o regime de ventos fortes é noturno, isto é, existe um ciclo diário bem definido 
em que a velocidade do vento é marcadamente alta durante a noite e diminui durante as horas em que a Terra recebe a luz do sol. O maior potencial se detecta nos meses de junho e novembro, no norte e no resto do estado respectivamente, apresentando maiores velocidades no oeste do estado no inverno e no centro, leste e sul na primavera; no verão, enfim, entre dezembro e fevereiro, o potencial eólico é bem reduzido em todo o estado.

No contexto atual, os potenciais eólicos com velocidades anuais médias maiores do que $6,5 \mathrm{~m} / \mathrm{s}$ são considerados interessantes para projetos de parques eólicos, já que a partir dessa velocidade se apresenta um fator de capacidade maior do que $30 \%$ com certos aero geradores, o que facilita a sua participação em leilões de energia. Mas, por se pretender quantificar potencialidades de geração que podem formar parte de uma usina virtual, contabilizaram-se os potenciais de geração existentes com velocidades anuais médias a partir de $6 \mathrm{~m} / \mathrm{s}$.

Considerar-se-á o potencial de geração com velocidades médias anuais maiores a 6 $\mathrm{m} / \mathrm{s}$ a uma altura de $100 \mathrm{~m}$, tendo em vista as restrições de distância convenientes a cada caso nas áreas onde existam reservatórios e rios, rodovias e ferrovias, linhas de transmissão, usinas hidroelétricas e termoelétricas, zonas urbanas e áreas de floresta e conservação integral.

Observa-se na Tabela 1 que o potencial mais interessante para a implementação de parques eólicos se encontra nos locais com velocidades médias anuais maiores a $6,5 \mathrm{~m} / \mathrm{s}$, já que com essas velocidades é possível obter um fator de capacidade maior a 30\%, o que facilita sua participação em leilões de energia.

Tabela 1: Potencial de geração de energia eólica a $100 \mathrm{~m}$ de altura por faixa de velocidade. Fonte: SEE, 2012.

\begin{tabular}{|c|c|c|c|c|}
\hline $\begin{array}{c}\text { Faixa de } \\
\text { velocidade } \\
(\mathbf{m} / \mathbf{s})\end{array}$ & $\begin{array}{c}\text { Área } \\
\left.\mathbf{( k m}^{2}\right)\end{array}$ & $\begin{array}{c}\text { Potência } \\
\text { Instalável } \\
(\mathbf{M W})\end{array}$ & $\begin{array}{c}\text { Energia } \\
\text { Anual } \\
(\mathbf{G W h})\end{array}$ & $\begin{array}{c}\text { Fator de } \\
\text { Capacidade } \\
(\%)\end{array}$ \\
\hline $6 \leq \mathrm{V}<6,5$ & 6.286 & 26.157 & 58.918 & 25,7 \\
$6,5 \leq \mathrm{V}<7,0$ & 1.000 & 4.170 & 11.247 & 30,8 \\
$7,0 \leq \mathrm{V}<7,5$ & 129 & 543 & 1.679 & 35,3 \\
$\mathrm{~V}>7,5$ & 5 & 21 & 74 & 40,0 \\
\hline
\end{tabular}


Observa-se que o potencial aproveitável em parques eólicos é de $13 \mathrm{TWh} / \mathrm{ano}$ numa área de $1.134 \mathrm{~km}^{2}$, que representa $0,46 \%$ da área do ESP. Embora exista esse potencial que pode ser aproveitado em parques eólicos, é interessante considerar também o potencial de geração disponível com as velocidades maiores a $6 \mathrm{~m} / \mathrm{s}$ e menores a $6,5 \mathrm{~m} / \mathrm{s}$ que poderiam ser parte de uma usina virtual o que facilitaria o aproveitamento de até $59 \mathrm{TWh} / \mathrm{ano}$, ocupando 3\% da área do ESP.

Mesmo que as projeções de geração em SEE, 2012, tenham sido idealizadas para a criação de parques eólicos, dado a que as usinas virtuais podem ter teoricamente quase qualquer potência que quiser participar nela, foram inclusas na estimativa de aproveitamento por meio de usina virtual, pois dessa forma os parques eólicos poderão proporcionar uma maior estabilidade no seu funcionamento e estarão menos expostos a penalizações por incumprimentos nos contratos de venda de energia ou serviços para a rede.

Vale mencionar que a existência de uma área extensa, espalhada em quase todo o estado, com presença de velocidades médias anuais maiores do que $5 \mathrm{~m} / \mathrm{s}$ que podem ser exploradas com turbinas eólicas de pequeno porte em projetos de geração distribuída ou para complementar a eletrificação das áreas rurais. Nas Figura 13 - Figura 16 mostra-se a variação sazonal das velocidades médias do vento no ESP.

\subsection{Potencial de energia fotovoltaica}

Os dados apresentados foram obtidos do levantamento de potencial de energia solar Paulista (SEE, 2013). O potencial que se considera nesta estimativa corresponde à radiação solar anual incidente de $5,61-5,70 \mathrm{kWh} /\left(\mathrm{m}^{2}\right.$.dia $)$ já que é nesta faixa que os projetos têm viabilidade técnica-econômica para sua implementação. Com essa incidência anual seria possível inserir na rede elétrica um total de 12 TWh/ano, utilizando uma área total de $732 \mathrm{~km}^{2}$, que corresponde a 0,3\% da área do estado.

O maior potencial se detecta nos meses correspondentes à primavera e verão, baixando aproximadamente 30\% nos meses de outono e inverno. Essa caraterística de disponibilidade do recurso cria uma complementariedade de energia entre a 
geração eólica e solar, já que a velocidade dos ventos aumenta noite, e existe também uma compensação sazonal, uma vez que a maior geração de energia eólica se espera no mês de junho e nos meses de inverno e a segunda melhor temporada é na primavera no mês de novembro.

No ano 2012 observou-se que nos meses de maior disponibilidade de energia eólica e fotovoltaica, o SIN fez maior uso das usinas termoelétricas (ONS); o que faz mais evidente os benefícios do aproveitamento dos recursos disponíveis no estado, tanto para aumentar a eficiência no sistema elétrico nacional como para dar prioridade as fontes de geração renováveis. Nas Figura 13 - Figura 16, mostra-se a comparação da variação sazonal do potencial eólica e solar. 


\section{Verão}

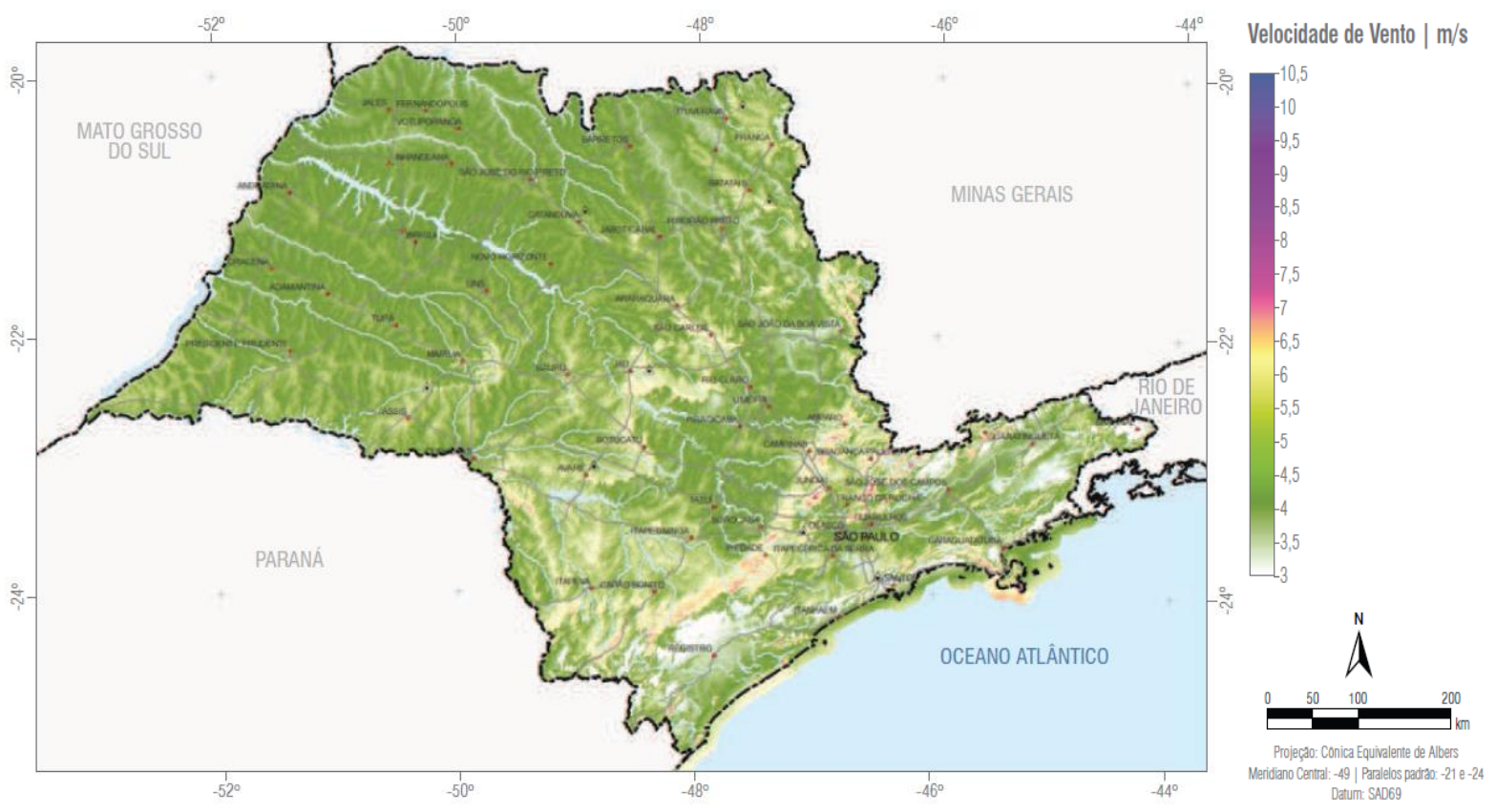

Fonte: Consórcio Bioventos

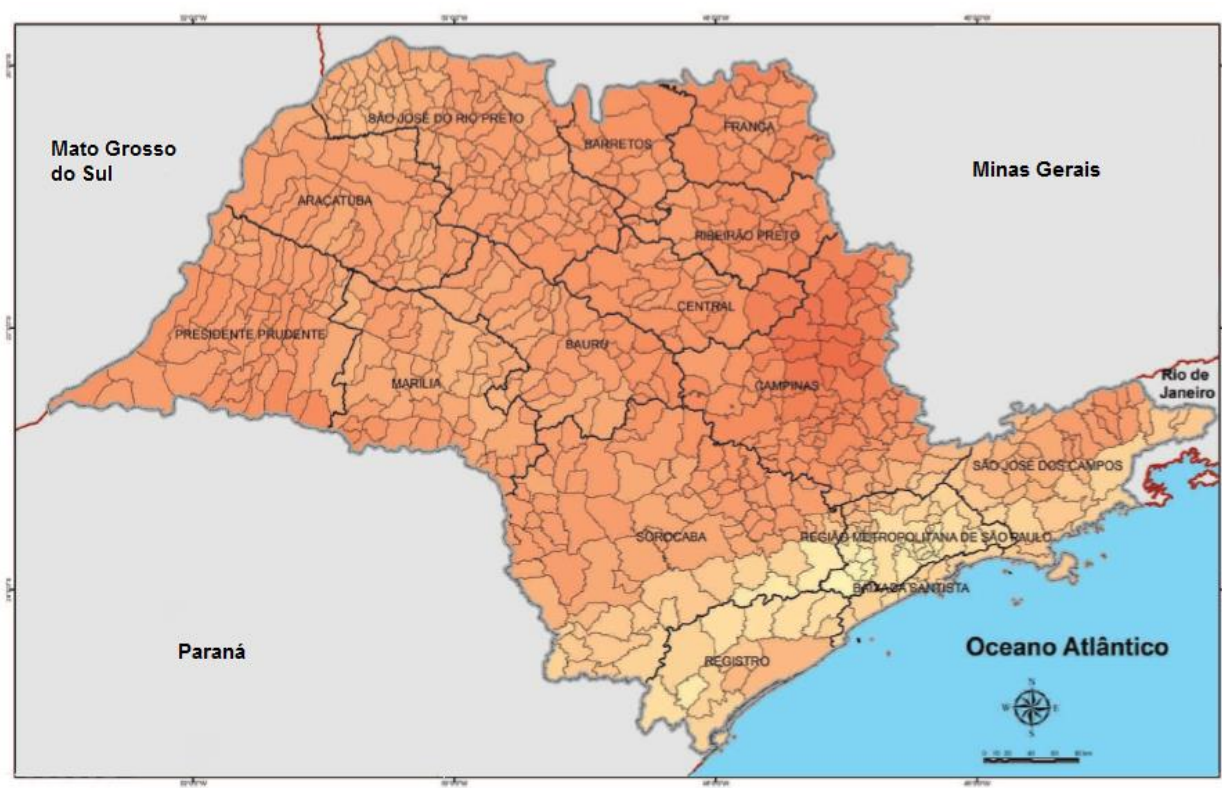

$\square^{5,3}$

$\square^{5,6}$

$\square^{5,7}$

5,8

$\square_{6,0}^{5,9}$

$\square^{6,0}$

$\square^{6,1}$

6,3

6,6

Limite do Estado

Estado De São Paulo Regiôes Administrativas Oceano Atlántico

Figura 13: Incidência Solar global média por municípios e Velocidade média do vento no Verão a 100 m no Estado de São Paulo. Fonte: Adaptação de SEE, 2011 e SEE, 2012. 


\section{Outono}

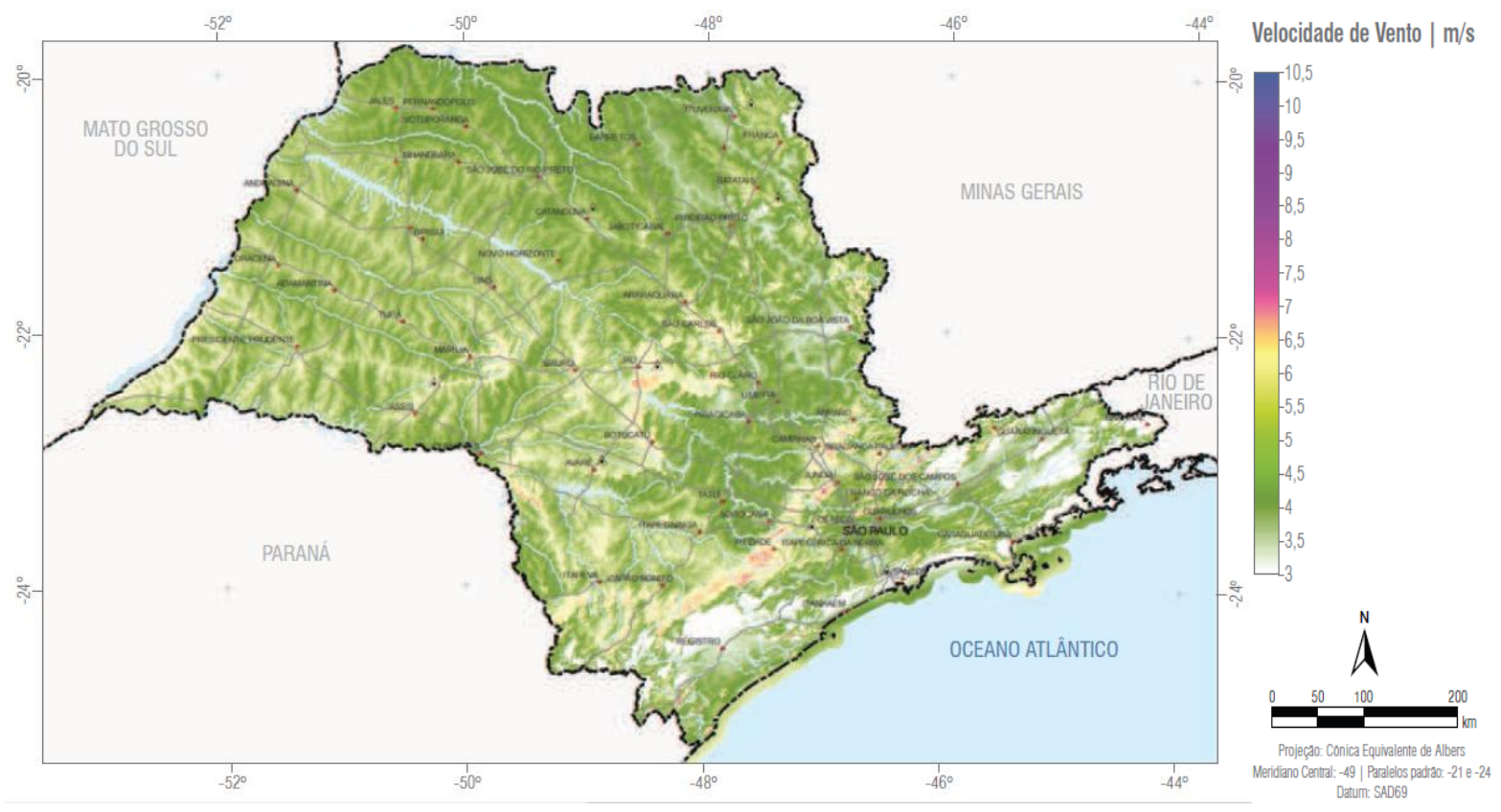

Fonte: Consórcio Bioventos

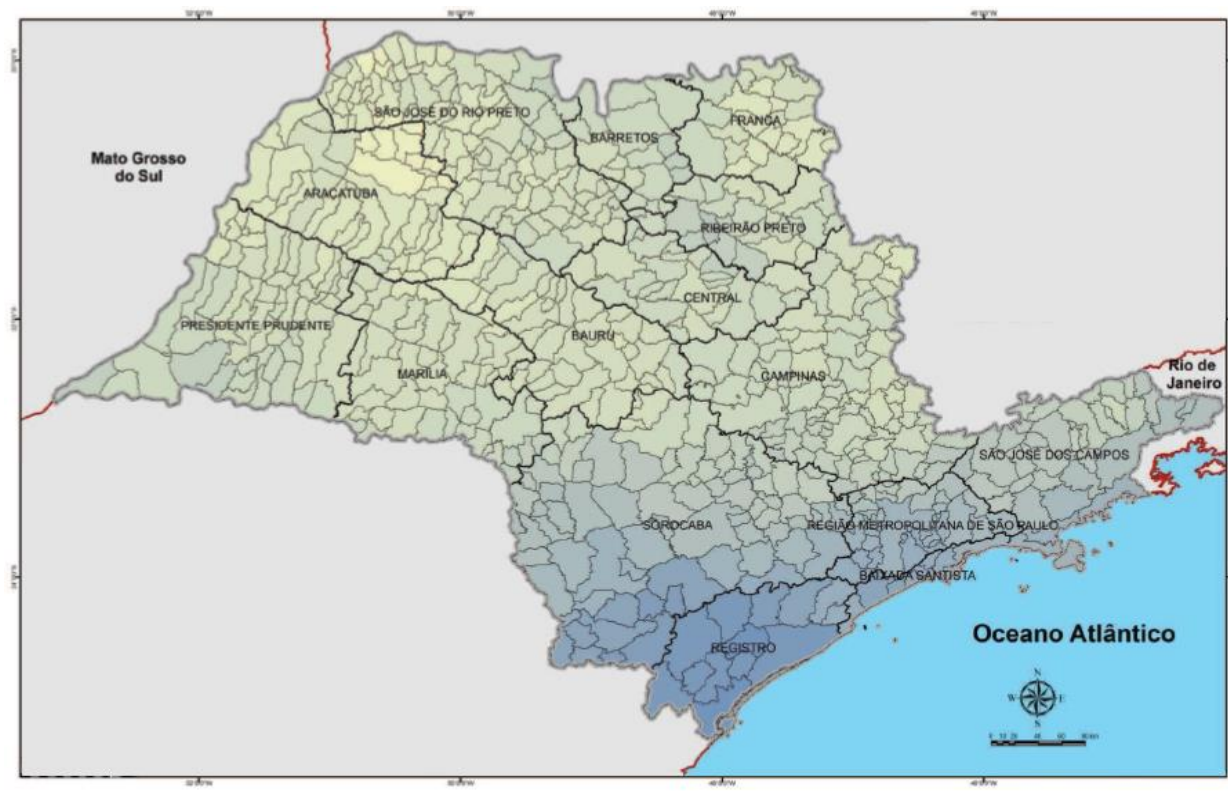

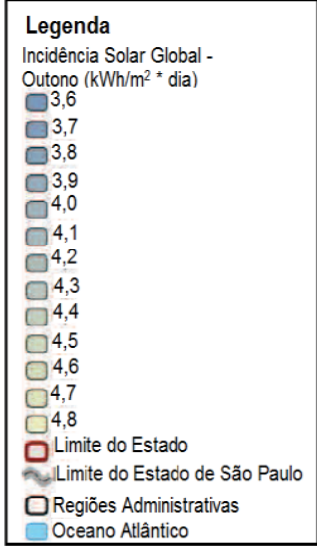

Figura 14: Incidência Solar global média por municípios e Velocidade média do vento no Outono a 100 m no Estado de São Paulo. Fonte: Adaptação de SEE, 2011 e SEE, 2012. 


\section{Inverno}
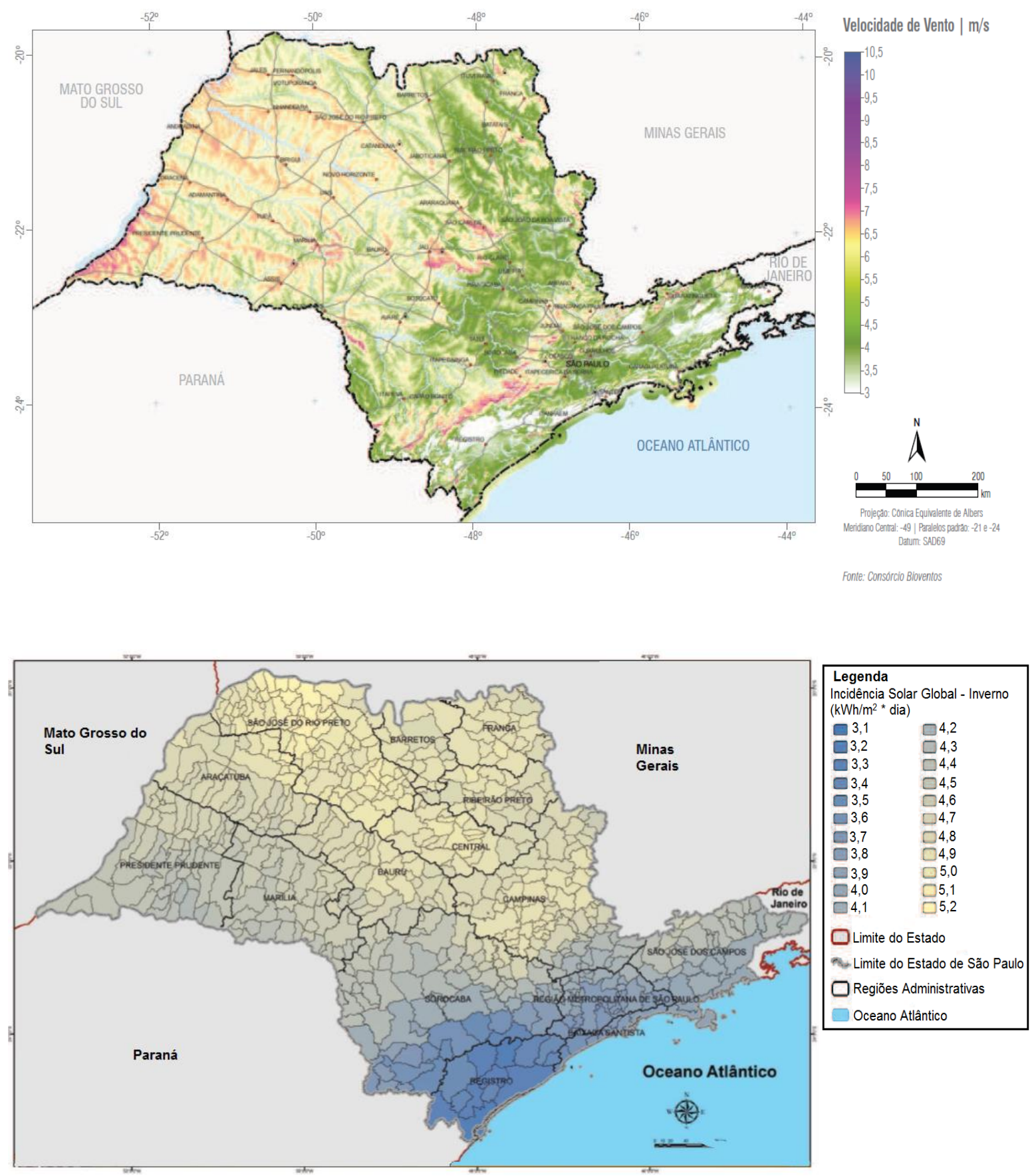

Figura 15: Incidência Solar global média por municípios e Velocidade média do vento no Inverno a 100 m no Estado de São Paulo. Fonte: Adaptação de SEE, 2011 e SEE, 2012. 


\section{Primavera}
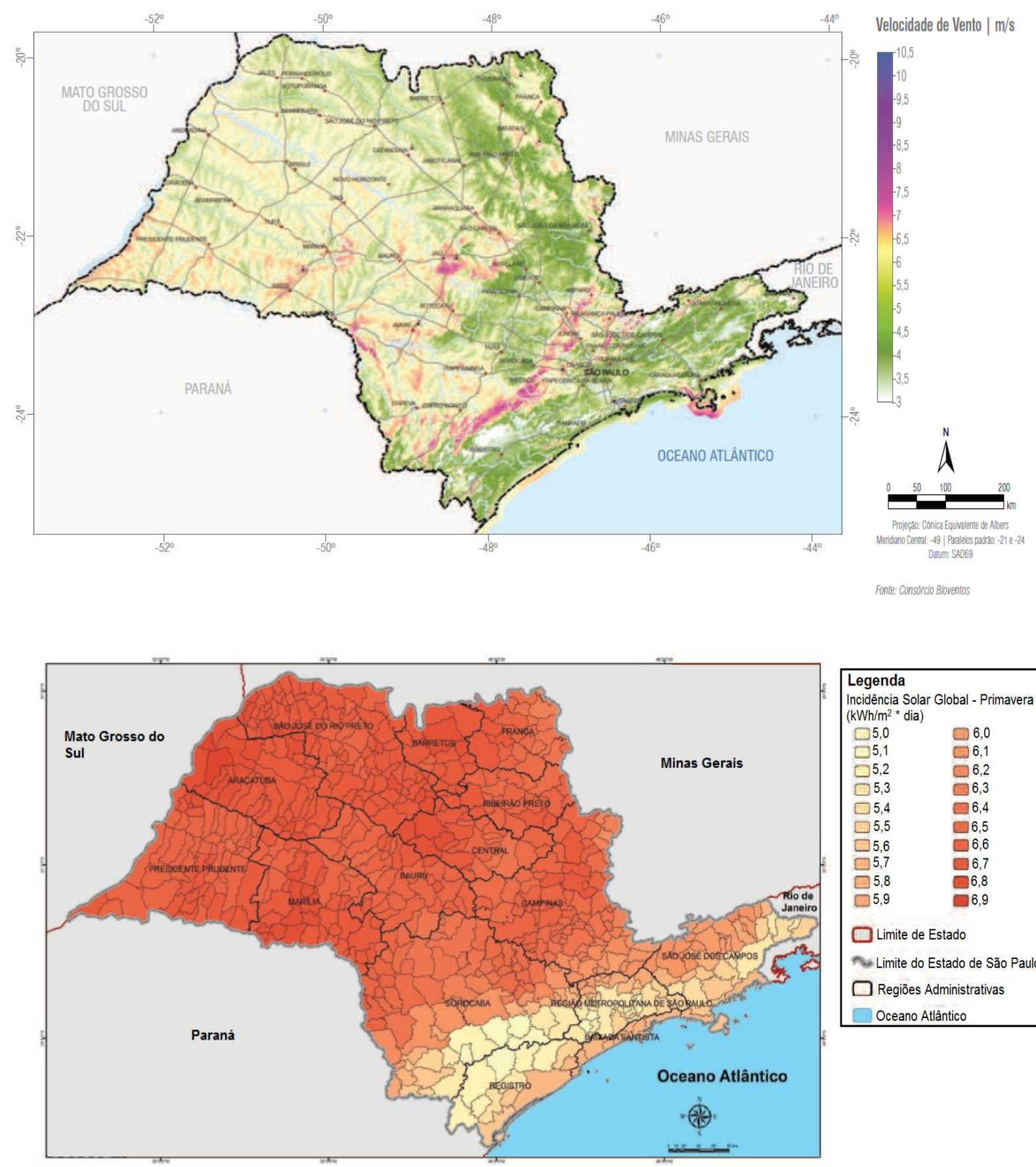

\begin{tabular}{|ll|}
\hline $\begin{array}{l}\text { Legenda } \\
\text { Incidência Solar }\end{array}$ & Global - Primavera \\
(kWh/m ${ }^{*}$ dia) & \\
$\square 5,0$ & $\square 6,0$ \\
$\square 5,1$ & $\square 6,1$ \\
$\square 5,2$ & $\square 6,2$ \\
$\square 5,3$ & $\square 6,3$ \\
$\square 5,4$ & $\square 6,4$ \\
$\square 5,5$ & $\square 6,5$ \\
$\square 5,6$ & $\square 6,6$ \\
$\square 5,7$ & $\square 6,7$ \\
$\square 5,8$ & $\square 6,8$ \\
$\square 5,9$ & $\square 6,9$ \\
$\square$ Limite de Estado \\
Limite do Estado de São Paulo \\
$\square$ Regiôes Administrativas \\
$\square$ Oceano Atlântico \\
\hline
\end{tabular}

Figura 16: Incidência Solar global média por municípios e Velocidade média do vento na Primavera a 100 m no Estado de São Paulo. Fonte: Adaptação de SEE, 2011 e SEE, 2012. 


\subsection{Vinhaça}

A vinhaça é um dos principais resíduos resultantes do processo de fabricação de etanol -13 litros de vinhaça por litro de etanol- e se caracteriza, basicamente, por ser um efluente líquido, orgânico e rico em potássio. Tais características possibilitam seu emprego na lavoura para suprir parte das necessidades de fertilização, assim como, na promoção da irrigação. Estas mesmas características, ademais, podem representar elevado potencial de poluição aos solos e recursos hídricos superficiais e subterrâneos, caso este efluente não seja utilizado de forma correta (SEE, 2011). Mas também possue um potencial energético que pode representar um aumento nos ganhos econômicos do setor sucroalcooleiro e a diminuição no risco de poluição presente neste resíduo.

Estima-se que para o ano 2035 as tecnologias de gaseificação e biodigestão de vinhaça atinjam a maturidade técnica e econômica fazendo possível o uso dessas técnicas para um melhor aproveitamento energético da vinhaça, respondendo por $10 \%$ do total da bioeletricidade gerada em 2030 e alcançando $20 \%$ no final do 2035 (SEE, 2011).

O melhor aproveitamento energético da vinhaça se dá na geração de biogás, por meio do seu processamento em biodigestores denominados "fluxo ascendente", em que a matéria-prima é totalmente fermentada e digerida num período médio de 25 horas, resultando num líquido final com expressiva redução de DBO (Demanda Bioquímica de Oxigênio), da ordem de $99 \%$ em relação ao volume original, o que permite a sua devolução aos lençóis freáticos, sem comprometimento da qualidade da água local, além da geração de biogás, composto basicamente por metano (até $70 \%$ do total) e gás carbônico (30\% restantes).

Segundo o PPE 2020, a estimativa do potencial para a geração do gás proveniente da vinhaça e a consequente utilização desse insumo para geração de eletricidade, pode ser representada por meio da seguinte relação: $1 \mathrm{~m}^{3}$ de vinhaça pode gerar $0,015 \mathrm{MWh}$. Do que se entende que a quantidade de energia obtida da vinhaça dependerá principalmente do método de obtenção de etanol do qual depende, por sua vez, a quantidade residual de vinhaça, como observado na Tabela 2. 
A tabela 2 mostra o potencial de geração para os anos 2012, 2020 e 2035 por método de obtenção do etanol e consequentemente quantidade de vinhaça obtida. $O$ potencial de energia que poderia ter sido obtido pela biodigestão da vinhaça produzida no ano 2012 foi calculado por meio dos dados fornecidos pela UNICA, a estimativa de produção para 2020 foi obtida de PPE 2020, e a estimativa de produção de energia para o ano 2035 foi calculada considerando a projeção da expansão da oferta de etanol do cenário base do SEE, 2011.

Tabela 2: Potencial de produção de eletricidade com a vinhaça por meio da biodigestão a fluxo ascendente. Fonte: Elaboração própria com dados de SEE, 2011, ÚNICA e PPE 2020

\begin{tabular}{l|c|c|c|c|c|c|c|}
\hline \multirow{2}{*}{$\begin{array}{l}\text { Processo de } \\
\text { obtenção do } \\
\text { etanol }\end{array}$} & $\begin{array}{c}\text { Produção de } \\
\text { vinhaça } \\
\text { (L de vinhaça / } \\
\text { de etanol) }\end{array}$ & \multicolumn{2}{|c|}{$\begin{array}{c}\text { Vinhaça requerida } \\
\text { (Milhões de m3) }\end{array}$} & \multicolumn{4}{c|}{$\begin{array}{c}\text { Eletricidade gerada } \\
\text { (MWh) }\end{array}$} \\
\cline { 3 - 9 } & $\mathbf{2 0 1 2}$ & $\mathbf{2 0 2 0}$ & $\mathbf{2 0 3 5}$ & $\mathbf{2 0 1 2}$ & $\mathbf{2 0 2 0}$ & $\mathbf{2 0 3 5}$ \\
\hline $\begin{array}{l}\text { Convencional } \\
13,0\end{array}$ & 153 & 294 & 488 & 2.295 .000 & 4.410 .000 & 7.320 .000 \\
$\begin{array}{l}\text { Fermentação com } \\
\text { alto teor alcoólico }\end{array}$ & 6,5 & 77 & 147 & 244 & 1.155 .000 & 2.205 .000 & 3.660 .000 \\
$\begin{array}{l}\text { Fermentação à } \\
\text { vácuo }\end{array}$ & 3,0 & 35 & 68 & 113 & 525.000 & 1.020 .000 & 1.695 .000 \\
& & & & & & &
\end{tabular}

Se é considerado que a safra se dá entre abril e novembro, a geração da energia produzida pela vinhaça será feita nessa mesma época do ano. A projeção de produção de etanol no 2035, segundo o cenário base de SEE, 2011, será de 37,5 bilhões de litros de etanol e, assumindo que a obtenção do etanol continue sendo pelos métodos convencionais, a vinhaça poderá contribuir com 1.270 MWmed na geração de energia nos meses de safra. 


\subsection{Resíduos sólidos urbanos}

A destinação final dos resíduos sólidos urbanos (RSU) nas grandes cidades do estado de São Paulo se caracteriza como um problema econômico, social e ambiental cada vez mais crítico. A forma de destino final atualmente empregada é a disposição direta, sem tratamento prévio, em aterros sanitários e vazadores de resíduos (sendo que os poucos existentes tendem a um rápido desaparecimento). Mas o RSU tem um potencial energético considerável que, ao ser utilizado para geração de eletricidade, ajudaria a diminuir problemas sociais e ambientais, enquanto resulta em ganhos econômicos e aumenta a disponibilidade de oferta local, ajudando a diversificar a matriz de energia elétrica e aumentando a segurança do sistema elétrico (PPE 2020).

Algumas das alternativas para realizar o aproveitamento energético são mostradas na Tabela 3, por tipo de aproveitamento e capacidade de geração de empreendimentos térmicos.

Tabela 3: Aproveitamentos energéticos de RSU. Fonte: PPE 2020, McCallum, D., 2011, Korai et al 2014 e The World Bank, 1999.

\begin{tabular}{|lc|}
\hline \multicolumn{1}{|c|}{ Tipo de Aproveitamento } & Produção de energia elétrica \\
\hline Biogás de aterro (base metano) & $0,1-0,2 \mathrm{MWh} / \mathrm{t}$ RSU \\
Digestão anaeróbica acelerada & $0,1-0,3 \mathrm{MWh} / \mathrm{t}$ RSU \\
Incineração RSU com geração de energia & $0,4-0,6 \mathrm{MWh} / \mathrm{t} \mathrm{RSU}$ \\
Incineração RSU com geração de energia & $0,75-0,85 \mathrm{MWh} / \mathrm{t} \mathrm{RSU}$ \\
(mais recentes) & $0,8-0,9 \mathrm{MWh} / \mathrm{t} \mathrm{RSU}$ \\
Ciclo combinado RSU + gás natural &
\end{tabular}

Para a estimativa realizada nesse trabalho, será considerado o aproveitamento feito através da incineração do RSU - mas se recomenda uma pesquisa com maior profundidade do processo denominado Ciclo Combinado Otimizado (CCO), uma vez que esse processo aumenta a eficiência da produção de energia e permite que a porcentagem de gás natural participante varie de $0 \%$ a $25 \%$-, já que é um dos tipos a apresentar maior aproveitamento energético, deixando menos resíduos, além de 
ser uma tecnologia com maturidade, mas que continua evoluindo para obter um processo mais eficiente.

O potencial de geração resulta mais interessante nas áreas que apresentam maior concentração de população e, portanto, maior produção de RSU por dia. Para estimar esse potencial foram consideradas somente as áreas metropolitanas de Campinas, a Baixada Santista e São Paulo, dado que nessas áreas reside aproximadamente 58\% da população do estado de São Paulo (PPE 2020). O Poder Calorífico Inferior (PCI) do RSU da região metropolitana de SP é da ordem de 2.000 $\mathrm{kcal} / \mathrm{kg}$ com uma umidade padrão, o que faz com que apresente os parâmetros de viabilidade técnica aceitáveis para a implantação de uma unidade de recuperação de energia, visto que se planeja implantar uma reciclagem de 30\% do RSU.

A Tabela 4 mostra a população, volume de RSU e índice de produção de RSU das três regiões metropolitanas selecionadas. No entanto, nem todo o RSU gerado será utilizado para geração de energia; essa quantidade dependerá principalmente das políticas públicas envolvidas e da restrição de área e capacidade dos aterros no Estado. Para determinar este parâmetro foi analisada a porcentagem do lixo em países europeus que foi reciclada através de processos de tratamento térmico nos últimos dez anos, e foi encontrada uma média de $22,8 \%$, que é colocada como uma meta otimista a ser atingida pelo estado de SP até 2035 (SEE, 2011).

Tabela 4: População e volume de RSU gerado nas principais regiões metropolitanas do Estado de São Paulo. Fonte: SEE, 2011.

\begin{tabular}{|l|c|c|c|}
\hline Região Metropolitana & $\begin{array}{c}\text { População } \\
\mathbf{2 0 1 0} \text { (hab.) }\end{array}$ & $\begin{array}{c}\text { Volume } \\
\text { (t/dia) }\end{array}$ & $\begin{array}{c}\text { Índice } \\
\text { (kg/dia·hab) }\end{array}$ \\
\hline Grande São Paulo (RMSP) & 19.667 .558 & $16.088,9$ & 0,82 \\
Campinas (RMC) & 2.792 .855 & $1.568,3$ & 0,56 \\
Baixada Santista (RMBS) & 1.662 .392 & 936,2 & 0,56
\end{tabular}

A estimativa de produção foi feita com tecnologias de incineração em ciclo Rankine e uma disponibilidade operativa da usina de $90 \%$ que é a média de eficiência das tecnologias disponíveis no mercado. Na Tabela 5, mostra-se a estimativa de RSU e energia gerada por meio da sua incineração para os anos 2014, 2025, 2030 e 2035. 
Tabela 5: Potencial de geração de eletricidade através da incineração do RSU das principais regiões metropolitanas do ESP. Fonte: Elaboração própria.

\begin{tabular}{|c|c|c|c|c|c|c|c|}
\hline \multirow{2}{*}{ Ano } & \multicolumn{4}{|c|}{ Projeção de Geração de RSU (t/dia) } & \multirow{2}{*}{$\begin{array}{l}\text { MWh/t } \\
\text { de RSU }\end{array}$} & \multirow{2}{*}{$\begin{array}{c}\% \text { RSU } \\
\text { incinerado }\end{array}$} & \multirow{2}{*}{$\begin{array}{l}\text { Energia } \\
\text { MWmed }\end{array}$} \\
\hline & RMSP & RMC & RMBS & Total das RM & & & \\
\hline 2014 & 19288 & 1833 & 1274 & 22395 & 0,55 & 22,8 & 95 \\
\hline 2025 & 27561 & 2762 & 1820 & 32144 & 0,78 & 22,8 & 193 \\
\hline 2030 & 31971 & 3329 & 2111 & 37411 & 0,78 & 30 & 295 \\
\hline 2035 & 36767 & 4011 & 2428 & 43206 & 0,78 & 30 & 341 \\
\hline
\end{tabular}

Para a elaboração da tabela 5 foram consideradas as seguintes premissas:

- A estimativa de geração de RSU para cada região metropolitana por ano se obteve a partir do índice de geração de RSU obtido em 2010, com um fator de correção relacionado com o crescimento de PIB e população de cada região.

- Assume-se também que $30 \%$ do RSU gerado é reciclado.

- Para 2014 e 2025 se adquire a meta de SEE, 2011, de incinerar 22,8\% do RSU produzido, já para 2030 e 2035, propõe-sea incineração de 30\% do RSU gerado; estimando-se como uma meta muito otimista, mas se considera adequada dado que essa porcentagem de incineração ajudaria a ter uma melhor gestão dos RSU.

- As projeções de população para 2025, 2030 e 2035 de cada região metropolitana, foram obtidas a partir das informações de crescimento populacional previsto pela SEADE, à exceção da estimativa de 2035 para a qual se estimou o mesmo crescimento da população que o quinquênio anterior.

- Para o potencial de geração de energia estimado para 2014, calculado como exemplo ilustrativo, considerou-se o fator de geração de 0,55 MWh/t de RSU, que é a média de obtenção de energia com tecnologias convencionais (SEE, 2011). Para o potencial de geração calculado para 2025, 2030 e 2035, por outro lado, foi considerado o fator 0,78 MWh/t de RSU, que é a média das tecnologias de incineração mais recentes (Korai, M. S. et al, 2014, McCallum, D., 2011 e The World Bank, 1999). Considerando que a sua implementação seria até dentro de uma década, no mínimo, provavelmente seriam a opção mais adequada para o aproveitamento. 
- As projeções foram obtidas tendo em consideração o crescimento da população de cada região, a mudança no PIB ao longo dos anos e o incremento gradual do uso da porcentagem de RSU produzido em cada região. A projeção de crescimento do PIB considera o cenário base de SEE, 2011.

\subsection{Estimativa total dos potenciais}

A seguir, são mostrados os gráficos que resumem o potencial de geração de energia, no qual é realizada uma soma das estimativas de produção por mês do ano por tipo de geração e assumindo que esses potenciais serão aproveitados em $100 \%$ no ano de 2035. Nos potenciais em que a oferta do recurso varia segundo a produção de etanol e RSU, foram utilizadas as projeções de produção facilitadas em SEE, 2011.

Nos resultados, estimou-se a importação para o ano 2023, com base nos dados disponíveis, sendo possível assumir que as necessidades de importação deverão ser maiores no ano 2035 , assumindo não haver aumento da oferta local até esse ano, ressaltando assim a importância do aproveitamento dos potenciais existentes localmente. Estima-se o aproveitamento das potencialidades apresentadas para 0 ano 2035, considerando o tempo de implementação dos projetos e a possibilidade da disposição do governo para facilitar incentivos de geração com fontes renováveis.

\subsubsection{Resultado 1}

O resultado 1 é apresentado no Gráfico 21 , a estimativa de geração considera as seguintes premissas:

a. Segundo dados obtidos das Figura 13 - Figura 16, pode-se observar que as velocidades maiores a $7 \mathrm{~m} / \mathrm{s}$ se apresentam nos meses correspondentes às estações de inverno e primavera, e no resto dos meses será considerada como energia média a gerada pelas velocidades de $6,5-7 \mathrm{~m} / \mathrm{s}$. A área total onde a média anual da velocidade é maior a $6,5 \mathrm{~m} / \mathrm{s}$ é de $1.134 \mathrm{~km}^{2}$, o que representa $0,46 \%$ da área do estado de São Paulo. 
b. A partir dos dados obtidos das Figura 13 - Figura 16, foram consideradas uma radiação média na primavera de $6,8 \mathrm{kWh} /\left(\mathrm{m}^{2}\right.$.dia), no verão de 6,4 $\mathrm{kWh} /\left(\mathrm{m}^{2} \cdot \mathrm{dia}\right)$, no outono de $4,5 \mathrm{kWh} /\left(\mathrm{m}^{2} \cdot \mathrm{dia}\right)$ e no inverno de 4,7 $\mathrm{kWh} /\left(\mathrm{m}^{2} \cdot \mathrm{dia}\right)$.

c. A projeção do potencial de geração da vinhaça, foi feita com base na projeção de produção de etanol e, segundo o cenário base de SEE, 2011, é de 37,5 bilhões de litros de etanol e, assumindo que a obtenção do etanol continue sendo pelos métodos convencionais, a vinhaça poderá contribuir com 1.270 MWmed na geração de energia do estado no ano de 2035 nos meses de safra.

d. Para a projeção de geração de eletricidade com RSU são utilizados os dados da Tabela 5 para o ano de 2035.

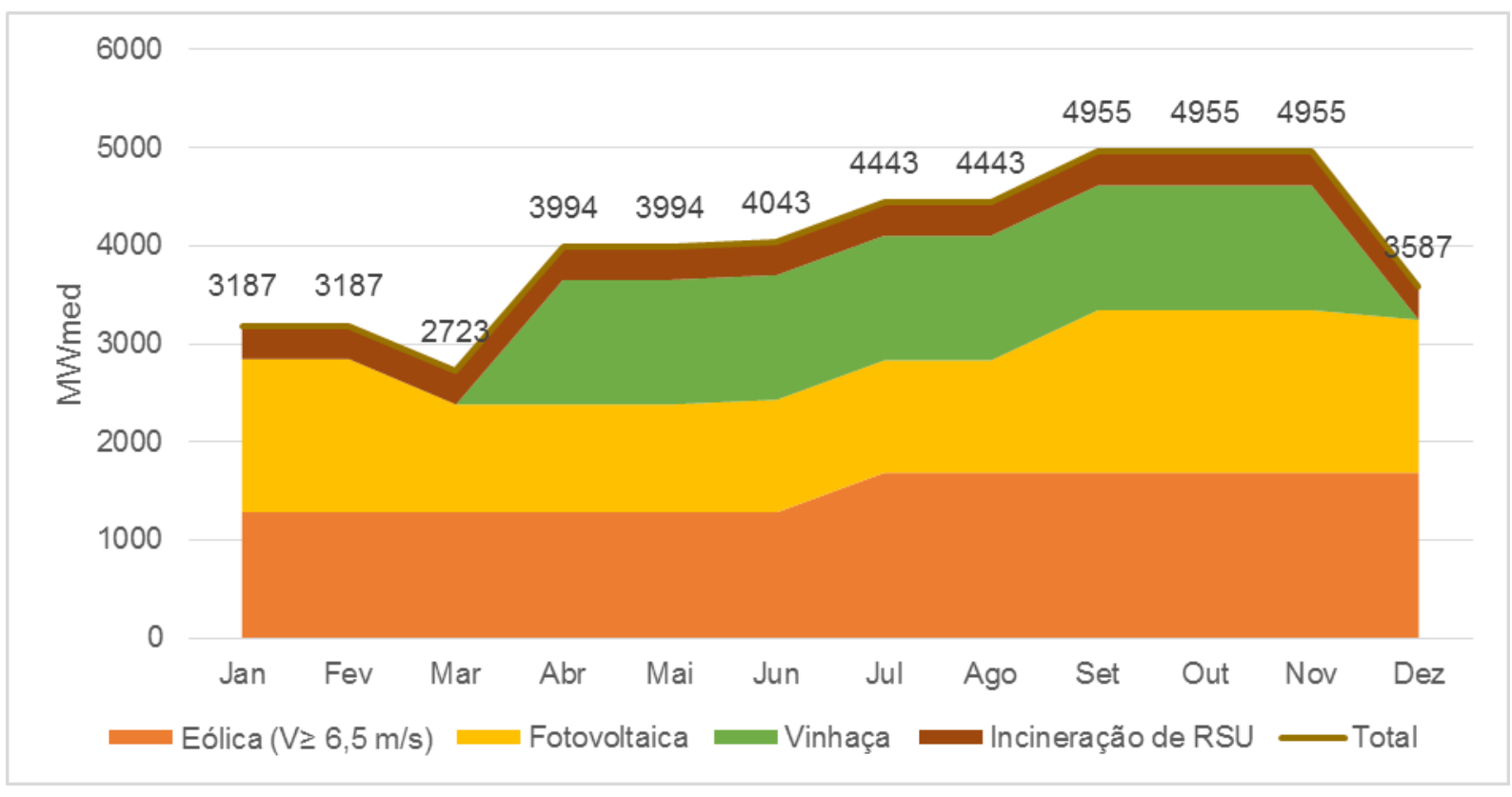

Gráfico 21: Resultado 1. Potencial de geração das fontes fotovoltaicas, eólica, incineração de RSU e geração de biogás com vinhaça. Fonte: Elaboração própria.

No Gráfico 21 mostra-se a importância da variação sazonal de cada uma das fontes, o que no caso do biogás obtido da vinhaça poderia ser mitigado ao implementar-se sistemas de armazenamento do biogás fazendo com que seja um recurso com maior flexibilidade. Nota-se também um incremento no potencial de geração nos 
meses correspondentes à primavera, meses em que existe uma maior carga devido ao incremento nas temperaturas próprio da estação.

Ao comparar o Gráfico 21 com o Gráfico 15 observa-se a complementaridade da oferta entre o aproveitamento dos potenciais de geração sugeridos no Gráfico 21 e a disponibilidade dos recursos hidroelétricos atualmente instalados no ESP que tem uma redução entre os meses de maio e novembro, a qual se apresenta em todo o $\mathrm{SE} / \mathrm{CO}$, incluindo Itaipu, mostrando assim a conveniência da implementação desses recursos. $\mathrm{O}$ aproveitamento dos recursos apresentados, não contribuirão apenas à para diminuir as importações necessárias para o atendimento da carga do ESP, como também ajudarão a incrementar a segurança do sistema ao evitar sobrecargas na rede básica e contribuir para manter um nível adequado dos reservatórios das hidroelétricas.

No Gráfico 22 mostra-se a comparação dos potenciais de geração descritos no Gráfico 21, a energia importada pelo ESP no ano 2013 e a estimativa de importação para o ano de 2023. Para a sua elaboração foram feitas as seguintes considerações:

e. A estimativa de potencialidades de geração presentes no ESP com o aproveitamento dos recursos utilizados no Gráfico 21.

f. A estimativa de consumo foi obtida da projeção do consumo do SE/CO para 2023 (Gráfico 8) e a participação do 47\% do ESP no consumo do SE/CO, que representaria $26.750 \mathrm{MWmed}$.

g. Considerando o histórico de geração e assumindo o montante de produção de energia mais favorável das hidroelétricas do ESP, além do uso contínuo das termoelétricas instaladas localmente, obtemos que o potencial de geração das centrais de serviço público será de $10.050 \mathrm{MWmed,} \mathrm{com} \mathrm{o} \mathrm{que}$ se observa que será preciso uma importação mínima de 16700 MWmed no ano 2023.

h. Os principais fornecedores das importações ao ESP serão Itaipu e AC/RO de acordo com as informações do Gráfico 19. Estimou-se a importação máxima de Itaipu + AC/RO considerando um potencial de geração do $A C / R O$ em 
2023 de 7 GW e um consumo médio de 1000 MW, por meio da interligação com a capacidade de escoamento dos 6 GW excedentes; e com a série histórica de geração de Itaipu de $10 \mathrm{MWmed}$ por ano, além de se estar considerando 1400 MWmed a menos de disponibilidade devido ao incremento do uso da parcela de geração do Paraguai, do que decorre que para 2023 a energia máxima a ser entregue para o Brasil será de 8600 MWmed (cálculos feitos a partir de dados do PDE 2023) e, portanto, o máximo de energia que poderá ser obtido dessas hidroelétricas será de $14600 \mathrm{MWmed}$, desde que se assuma, para tanto, uma transferência constante no transcurso do ano de $6000 \mathrm{MW}$ desde $\mathrm{AC} / \mathrm{RO}$.

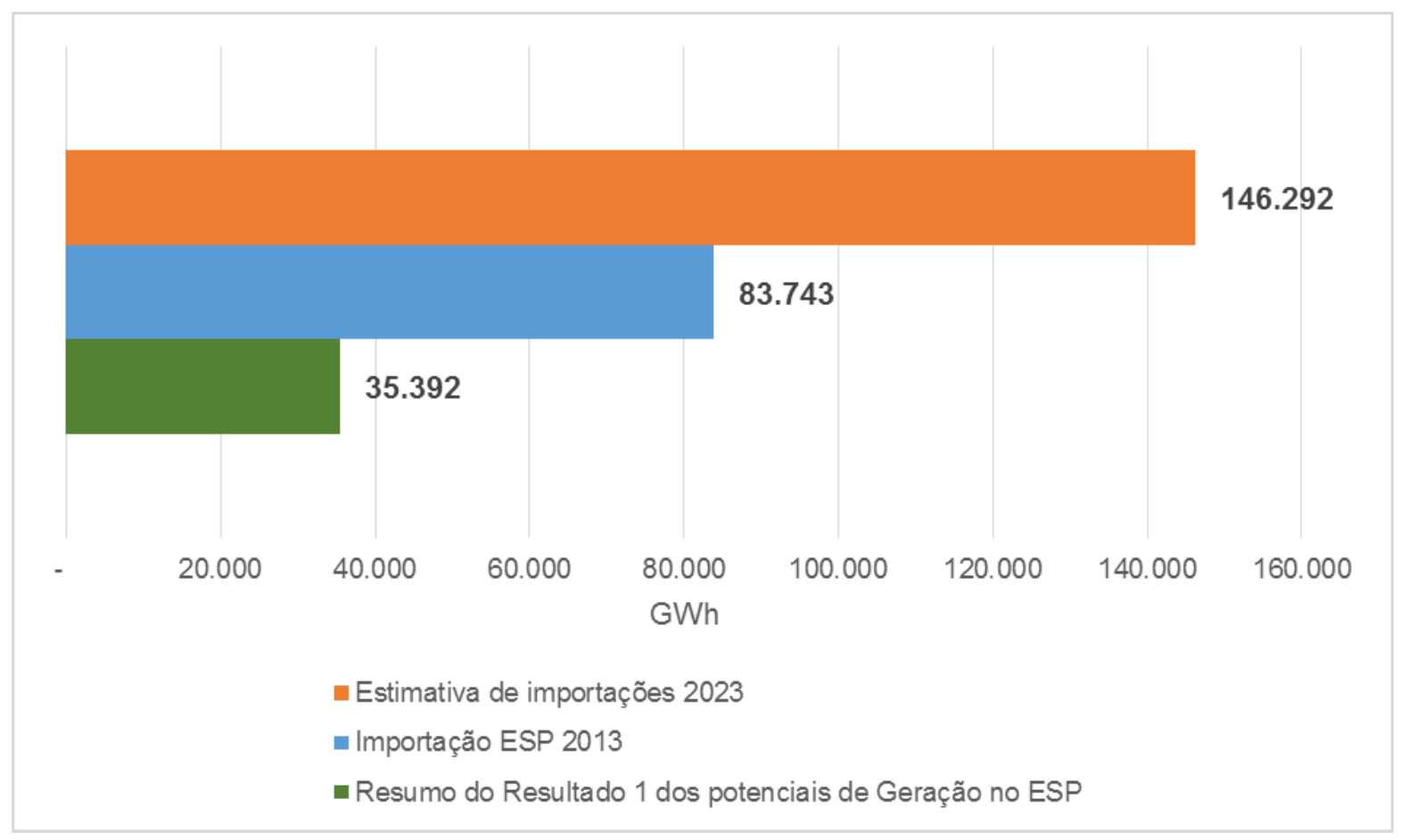

Gráfico 22: Comparação do levantamento do potencial do Gráfico 21, importações 2013 e possibilidade de importação 2023. Fonte: Elaboração própria.

Observa-se que mesmo considerando o uso contínuo das usinas termelétricas instaladas até 2023 no ESP e que a disponibilidade máxima de Itaipu+ $A C / R O$ fosse de $14600 \mathrm{MWmed}$ e fosse inteiramente dedicada ao atendimento do ESP, ainda serão precisos mais $2100 \mathrm{MWmed}$ de importação do resto do SE/CO ou de outros subsistemas. O ESP, com os potenciais contabilizados no Gráfico 21, tem a 
capacidade de produzir 4040 MWmed, que ajudarão a afrontar as variações climáticas que afetam sazonal e anualmente a produção de energia hidroelétrica, além de fazer que o acionamento das térmicas instaladas no estado seja menor do que o estimado no item g, ajudando assim a manter uma matriz limpa.

Se for considerado unicamente o melhor histórico de geração das hidroelétricas instaladas localmente (já que não existe projeção de crescimento para esse tipo de geração), e com a mesma disponibilidade de fornecimento de Itaipu+ $A C / R O$, caso se obtenha então uma projeção de necessidade de importação de outros subsistemas ou do resto do SE/CO no ano 2023, o alcance será de 3750 MWmed. Esta necessidade pode ser maior no ano 2035 se não existir expansão na oferta de energia do ESP. Portanto, o aproveitamento dos potenciais mostrados no gráfico 21 têm valor estratégico não apenas para o adequado atendimento do ESP, senão também para os subsistemas SE/CO+Itaipu+AC/RO.

Os Gráfico 21 e 22, mostram que uma maior disponibilidade de fontes de geração locais ajudará a complementar a sazonalidade dos recursos existentes e a mitigar a variabilidade das principais fontes de importação que se têm projetadas (Itaipu e $\mathrm{AC} / \mathrm{RO}$ ). Ademais, mostra-se que se possui disponibilidade de recursos para gerar $\mathrm{o}$ $43 \%$ da energia que foi importada no ano 2013 , com o que se reduziram as perdas no sistema ao se diminuir as perdas de transmissão para um dos maiores centros de consumo do país. Isto aumentará a segurança do subsistema SE/CO ao ajudar a manter os níveis dos reservatórios de regulação e colaborará para diversificar a matriz energética. Com as implementações dos recursos mostrados no Gráfico 21, diminuir-se-ia a quantidade de energia térmica necessária para atender os patamares de carga média e pesada.

\subsubsection{Resultado 2}

O resultado 2 é apresentado no Gráfico 23 , esse resultado está mais orientado realizar o aproveitamento dos recursos por meio de uma usina virtual, dada o menor fator de capacidade dos aproveitamentos eólicos propostos. A estimativa de geração considera as seguintes premissas: 
i. Neste caso será considerado o potencial de geração disponível para velocidades anuais médias maiores a $6 \mathrm{~m} / \mathrm{s}$ a uma altura de $100 \mathrm{~m}$. Nessas condições existe um potencial de $71.918 \mathrm{GWh}$ por ano, com um fator de capacidade de $26,6 \%$ numa área de $7.420 \mathrm{~km}^{2}$, que corresponde a $3 \%$ da área total do estado de São Paulo (SEE, 2012). Segundo dados obtidos das Figura 13 - Figura 16, considera-se que a energia gerada pelas velocidades no intervalo de 6,0 - 6,5 $\mathrm{m} / \mathrm{s}$ será distribuída ao longo do ano todo, já que essa é a média anual de velocidade nessas zonas. Considera-se também que a energia produzida pelo aumento da velocidade de 6,5-7,0 m/s se distribuirá uniformemente ao longo do outono, inverno e primavera, já a energia produzida pelas velocidades maiores a $7 \mathrm{~m} / \mathrm{s}$, dado que se apresentam nos meses correspondentes as estações de inverno e primavera, se distribuirá nos meses correspondentes a essas estações. Primavera e inverno apresentam a maior geração.

ii. As premissas b, c e d utilizadas para obter o resultado 1 continuam sendo válidas.

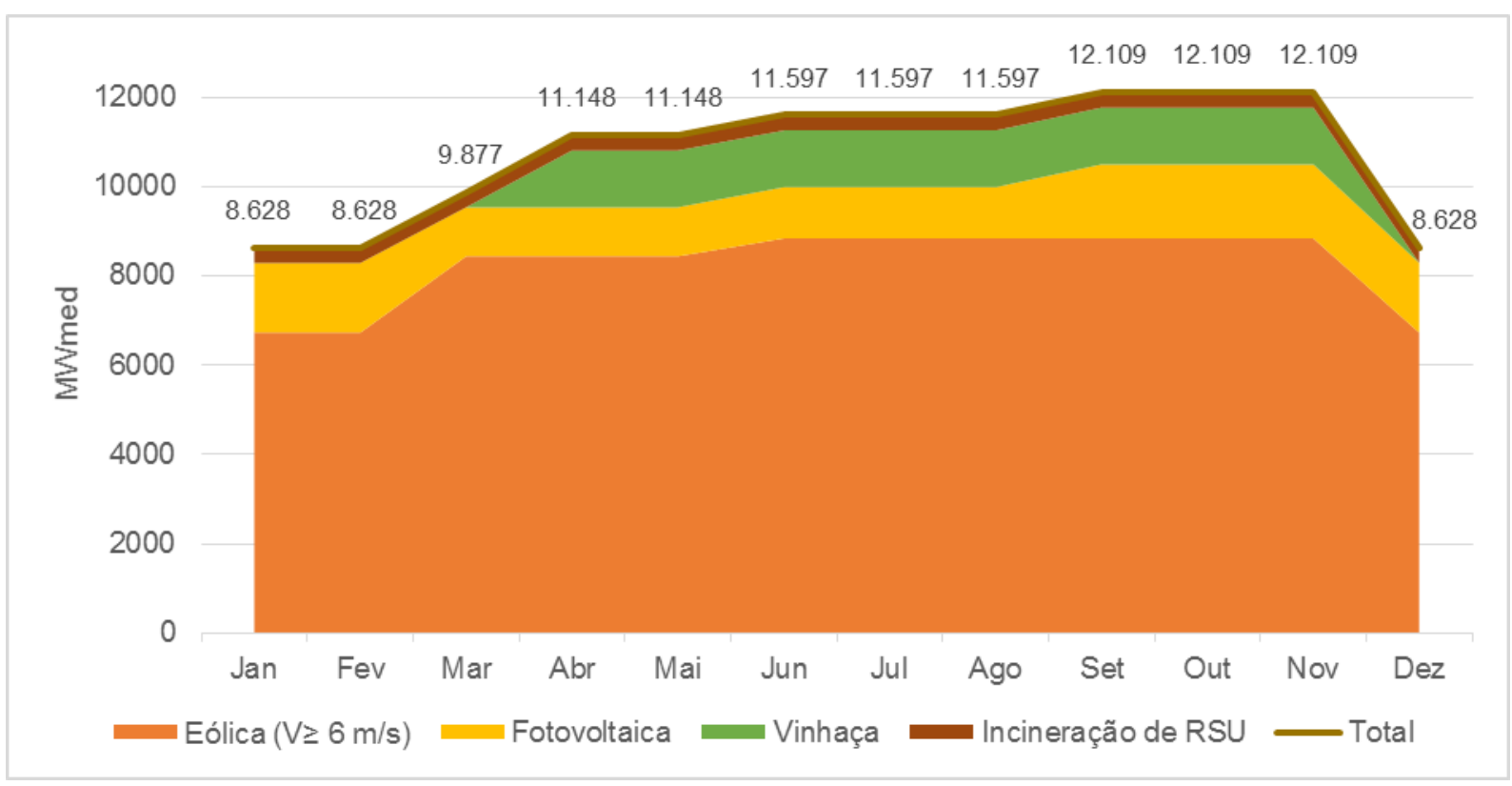

Gráfico 23: Resultado 2: Potencial de geração das fontes fotovoltaicas, eólica, incineração de RSU e geração de biogás com vinhaça. Fonte: Elaboração própria. 
Nota-se no Gráfico 23 a importância da inserção do potencial de eólico presente no ESP com velocidades anuais médias maiores a $6 \mathrm{~m} / \mathrm{s}$ e menores que $6,5 \mathrm{~m} / \mathrm{s}$, as quais embora não sejam consideradas interessantes para serem aproveitadas em parques eólicos, são interessantes para participarem numa usina virtual. Observa-se que, neste caso, o potencial de geração contabilizado ultrapassa a geração mensal média do ESP quando comparados com a geração feita desde 2012 até 2014 (Gráfico 15). Também é possível ver uma maior disponibilidade de recursos nos meses em que a geração das hidroelétricas no subsistema SE/CO diminui, fato que demonstra que o aproveitamento desses recursos seria uma boa estratégia para afrontar a sazonalidade das hidroelétricas predominantes no atendimento da carga de São Paulo e do resto do Brasil.

O aproveitamento das potencialidades mostradas no Gráfico 23 ajudará a trazer maior segurança energética ao ESP e ao resto do subsistema SE/CO, ao proporcionar fontes capazes de atender a carga nos patamares de maior demanda, ajudando a evitar, assim, problemas de funcionamento na rede básica. Podendo também facilitar o adequado atendimento do subsistema Sul que é caracterizado por ser um subsistema importador de energia e que apresenta riscos de déficit de potência já para o ano de 2019 embora exista folga com a interligação N/NE (Gráfico 13).

No Gráfico 24 mostra-se a comparação dos potenciais de geração descritos no Gráfico 23, a energia importada pelo ESP no ano de 2013 e a estimativa de importação para o ano de 2023. Para a sua elaboração foram feitas as seguintes considerações:

iii. A estimativa de potencialidades de geração presentes no ESP com o aproveitamento dos recursos utilizados no Gráfico 23.

iv. As premissas $\mathrm{f}, \mathrm{g}$ e $\mathrm{h}$, continuam sendo consideradas válidas. 


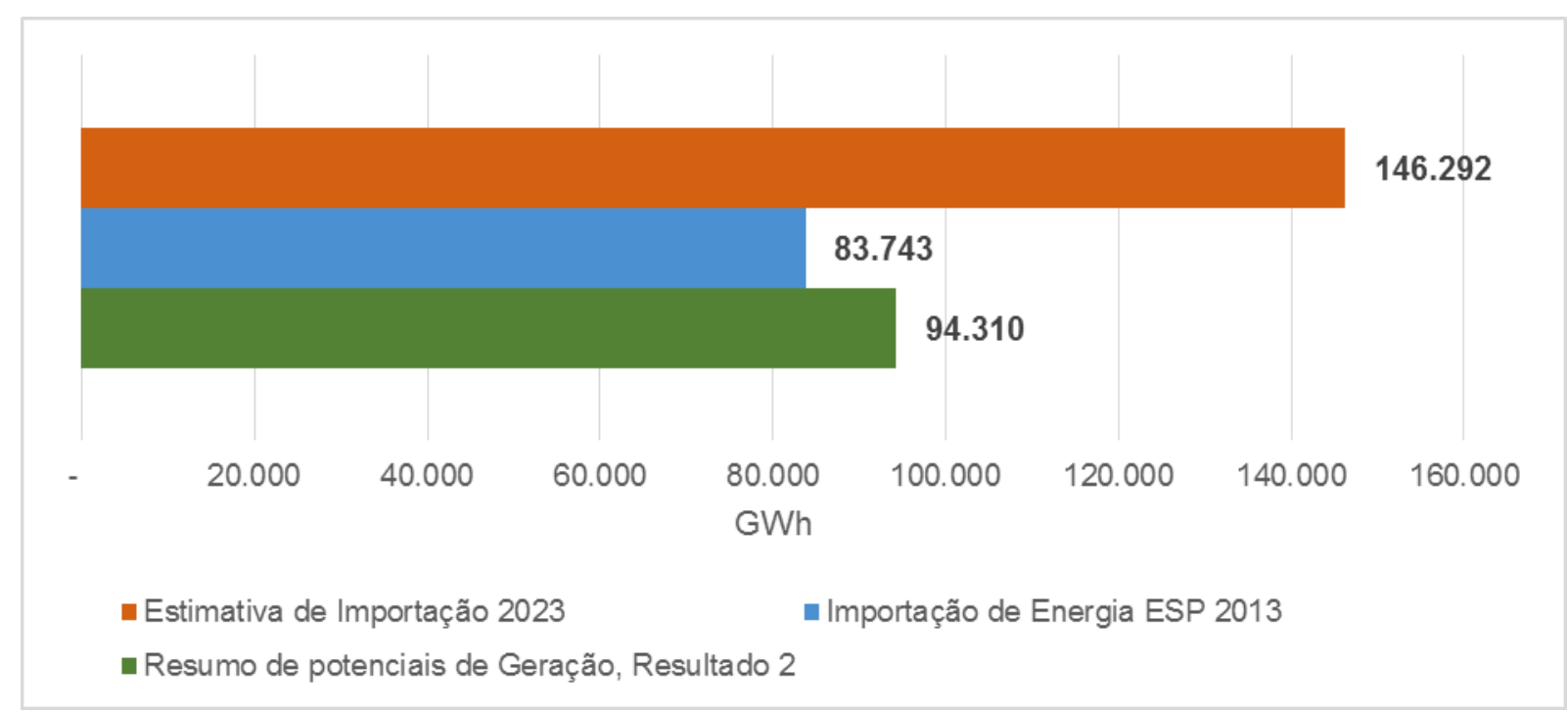

Gráfico 24: Comparação do levantamento do potencial do Gráfico 23, importações 2013 e possibilidade de importação 2023. Fonte: Elaboração própria

No Gráfico 24 é possível perceber a importância que possui a inserção da geração eólica com velocidades anuais médias entre 6 e $6,5 \mathrm{~m} / \mathrm{s}$. Com a implementação das potencialidades apresentadas no Gráfico 23 será possível gerar 10766 MWmed, com o que não apenas seria possível suprir a necessidade de importação extra mínima de 2100 MWmed do ano de 2023, mas também facilitaria o atendimento dos mais de $31.000 \mathrm{MW}$ correspondentes à carga média e pesada já existentes em 2023 - deve-se lembrar que o aproveitamento total dos recursos do Gráfico 23 está proposto para 2035, ano em que o consumo de energia e requerimentos de potência do ESP deverá ser maior - o que colaborará para diminuir a carga na rede básica, ajudando assim a diminuir os riscos de sobrecarga nas interconexões e as perdas de transmissão, incrementando a confiabilidade e eficiência do sistema elétrico do ESP.

O aproveitamento desses potenciais permitirá também adiar a construção de linhas de transmissão que possibilitam o aproveitamento de fontes localizadas a grandes distâncias dos centros de carga.

Considerando o anterior, observa-se o importante papel que poderá representar o uso dos recursos apresentados nos Gráfico 21 e 23, ainda mais quando são considerados também os Gráficos 9, em que se mostra que o conjunto dos subsistemas SE/CO + Itaipu + AC/RO, a partir de 2023, precisará importar pelo 
menos 1742 MWmed (mesmo fazendo uso de todas as usinas térmicas convencionais do conjunto), e o Gráfico 13, que mostra as possibilidades de faltas de potência no subsistema sul já presentes em 2019 e que poderiam chegar a aproximadamente 3500 MW em 2020. Além disso, uma vez que as projeções de expansão para o subsistema Sul não conseguem acompanhar a demanda, as necessidades de importações desde o N+NE serão maiores, o que poderá fragilizar - SIN. Quando comparamos esses resultados, vemos que uma grande porcentagem das importações do SE/CO projetadas para o 2023 serão para conseguir atender ao ESP.

$\mathrm{Na}$ tentativa de colaborar com a segurança energética do SIN, pode-se observar que embora as possibilidades de blackouts -uso ao 100\% do limite de transferência da interligação N/NE para SE/CO/S- possam ocorrer devido a que as restrições de transferência de energia dos subsistemas N/NE para os subsistemas SE/CO/S se reduzem consideravelmente a partir do ano 2018, por conta, por sua vez da expansão do limite prevista para entrar em operação esse ano, é sempre conveniente ter disponibilidade de oferta de energia local, que seja capaz assim de diminuir a quantidade de energia necessária para satisfazer adequadamente as necessidades do sistema local ou de exportar energia para outros subsistemas ou, que seja capaz ainda, tanto de colaborar para satisfazer a sua demanda de energia, quanto para poupar água nas hidroelétricas que tenham reservatórios.

Deve ser dito que no caso da vinhaça é possível considerar a possibilidade de ser utilizado como uma usina despachável dependendo da disponibilidade do armazenamento da vinhaça ou do biogás gerado a partir dela, mas isso pode encarecer o preço da energia gerada e, portanto, o preço de venda da energia também. Vale a pena ressaltar que os potenciais aqui listados são apenas uma pequena parte dos existentes no estado de São Paulo, lembrando que existem, por exemplo, o potencial de geração de biogás através do esgoto, de dejetos de suínos, gado, PCHs e outros. Ademais, deve-se dizer também que o aproveitamento dos potenciais aqui apresentados é considerado a ser realizado com tecnologias básicas e de baixo custo (tecnologias maduras), com exceção da vinhaça e que, portanto, se espera que no decorrer dos anos apresentem-se tecnologias que possam aprimorar os aproveitamentos das potencialidades existentes. Finalmente, no caso do aproveitamento da energia eólica, não foi considerado o potencial de geração 
com velocidades anuais médias menores a $6 \mathrm{~m} / \mathrm{s}$ das quais se pode fazer um aproveitamento com turbinas eólicas de pequeno porte que podem ser aproveitadas em empreendimentos de geração distribuída.

Para realizar uma estimativa mais detalhada é preciso ter em consideração os sistemas de armazenamento de energia que se adequariam à rede, com dados mais específicos de curvas de geração, e a possibilidade de participação dos clientes em programas de resposta à demanda. Além disso, deve se considerar a inclusão de usinas como as PCHs as Centrais hidroelétricas, geração por meio de biogás provenientes de aterros, efluentes, resíduos pecuários, resíduos florestais e resíduos agrícolas. Os aproveitamentos com biogás representam um especial interesse, já que poderiam ser operados como usinas despacháveis. 


\subsubsection{Eventualidades do SIN}

Como uma mostra da fragilidade pela qual passa o sistema elétrico brasileiro, temos o blackout do dia 19 de janeiro de 2015 que, segundo a nota de imprensa do ONS, "deveu-se as restrições na transferência de energia das Regiões Norte e Nordeste para o Sudeste, aliadas à elevação da demanda no horário de pico, provocaram a redução na frequência elétrica[...]". Visando restabelecer a frequência elétrica às suas condições normais, o ONS adotou medidas operativas em conjunto com os agentes distribuidores das regiões Sul, Sudeste e Centro-Oeste, impactando menos de $5 \%$ da carga do Sistema (o que quer dizer que 0 atendimento de aproximadamente $4200 \mathrm{MW}$, foi interrompido, e esta ocorrência atingiu estados dos subsistemas SE, S e CO).

AES Eletropaulo informou que, "seguindo determinação do ONS, cortou, na tarde do 19 de janeiro do 2015, mais de 700 Megawatts de energia distribuída em sua área de concessão, deixando alguns pontos sem luz" (nota de imprensa AES Eletropaulo).

Nessas circunstâncias, ressalta-se também a importância da implementação de programas de gerenciamento do lado da demanda (DSM), já que segundo as declarações de imprensa, o alto consumo devido às altas temperaturas foi uma das condições que provocaram o apagão do dia 19/01/2015. No Brasil existem já alguns equipamentos capazes de interagir com as cargas instaladas num ambiente com intranet - por exemplo, tomadas e medidores inteligentes e displays interativos -, mas atualmente estão sendo desenvolvidos dispositivos que sejam capazes de controlar os equipamentos via internet ou até por meio de aplicativos dos smartphones, os quais viabilizariam implantação de programas de resposta à demanda. 


\section{Conclusões}

- a integração dos recursos de geração distribuída por meio das usinas virtuais proporciona controle sob a qualidade de geração desses recursos, viabilizando assim a diminuição da presença dos possíveis efeitos adversos da inserção de recursos intermitentes e facilitando a detecção de problemas na rede, caso que se apresentarem, além de facilitar a gestão comercial desses recursos.

- A implementação das VPPs pode adiar não só novos investimentos em construção de linhas de transmissão e distribuição, mas também a construção de novas usinas de geração de energia, ajudando assim a um melhor planejamento de recursos.

- Observa-se que há uma redução de geração de energia hidroelétrica no ESP, assim como no subsistema SE/CO e Itaipu, entre os meses de maio e novembro (Ver Gráfico 3 e Gráfico 15). Esses meses coincidem com aqueles de maior potencial de geração de eletricidade com as fontes renováveis propostas, segundo pode ser observado nos Gráfico 21 e 24. Essa característica de disponibilidade pode contribuir para diminuir as importações, ou como estratégia para aumentar a segurança do sistema ao se armazenar energia nos reservatórios, ou para diminuir a carga no sistema de transmissão nos patamares de carga média e pesada, ou, ainda, para diminuir o uso de termoelétricas para além dos limites de inflexibilidade.

- Para os resultados obtidos, especialmente o resultado 2, deve-se realizar uma análise cuidadosa com respeito a priorização de geração com recursos disponíveis localmente, que poderão a reduzir a porcentagem de perdas na rede básica, dado que a estimativa do potencial aproveitável tem como principais recursos a geração fotovoltaica e eólica, os quais devem ser aproveitados quando disponíveis, ao igual que as usinas a fio d'agua que estão projetadas para fornecer a energia a ser importada pelo ESP.

- O resultado 1 mostra que o aproveitamento dos recursos propostos possibilitará mitigar as variações na disponibilidade dos recursos instalados localmente e dos principais fornecedores da energia importada pelo ESP, mas sua contribuição no escopo da análise -até 2035- poderá não ser o suficiente para manter o adequado atendimento dos requerimentos projetados para o ESP. 
- As usinas virtuais viabilizam técnica e economicamente o aproveitamento de recursos com baixa atratividade inicial, seja pelo seu pequeno porte ou sua irregularidade no suprimento. Sendo esse o caso da proposta do resultado 2, em que o aproveitamento dos recursos por meio de uma usina virtual, resulta ser muito mais atrativa para o atendimento da carga do ESP. Uma vez que não apenas proporcionaria maior capacidade de energia senão que neste caso também poderão ser considerados -mais realisticamente- a aplicação de programas de resposta à demanda, e de outros sistemas de armazenamento de energia -visto que apenas foram considerados os reservatórios das hidroelétricas- que proporcionarão um melhor controle do sistema do estado, já que a rede passaria a ser mais interativa. Sendo assim capazes de trazer, além disso, outros benefícios colaterais como a redução de perdas na transmissão, alívio nas interligações e no uso de termelétricas e grandes investimentos na transmissão e na geração e benefícios ambientais.

- Cabe ressaltar a complementaridade sazonal entre a energia fotovoltaica e a eólica que, além disso, também apresentam complementaridade nos horários de maior geração já que as velocidades dos ventos sofrem uma redução considerável durante as horas de luz solar favoráveis a geração fotovoltaica; o que poderá facilitar o gerenciamento das variações de geração ou a identificação dos SAEs adequados para essa aplicação.

- É possível apreciar na Tabela 5 que o potencial de geração com o biogás obtido da vinhaça não é nada desprezível. Assim sendo, neste trabalho considerado seu uso para geração somente na temporada de safra, mas também é conveniente considerar a possibilidade de armazenar o biogás, o que proporcionaria maior flexibilidade para a geração com essa fonte e poderia dar mais ganhos ao sistema elétrico do ESP, ao ser mais gerenciável do que as outras fontes apresentadas, o que, por fim, agregaria um valor estratégico importante na hora de implementar parte de uma usina virtual.

- a utilização da vinhaça e do RSU como energéticos, proporcionam externalidades como a diminuição da contaminação dos lençóis freáticos e do solo, redução de gases de efeito estufa e no uso e ocupação do solo, e redução de riscos sociais.

- A inserção de novas fontes de energia no ESP tem grande importância e valor estratégico, não apenas para o ESP mas também para o conjunto de subsistemas 
$\mathrm{SE} / \mathrm{CO} / \mathrm{S}$, visto que estão sendo projetados a serem importadores de energia (mesmo contando com a importação desde $\mathrm{AC} / \mathrm{RO}$ ), dependentes dos subsistemas N/NE os quais possuem uma marcada variação na disponibilidade de exportação ao longo do ano e essa característica pode representar riscos no adequado atendimento dos SE/CO/S, além de poder incrementar o preço da energia se as condições climáticas forem desfavoráveis.

- No contexto atual, dada a tendência ao incremento no valor da energia elétrica e o incremento no interesse dos diversos participantes do setor elétrico em adquirir caraterísticas das redes inteligentes nos seus ativos, pode surgir o interesse econômico na implementação das usinas virtuais, visto que com elas será possível incrementar o potencial de exploração de recursos existentes e o gerenciamento da rede. 


\section{Recomendações}

- Incluir em trabalhos decorrentes o potencial de geração com usinas de pequeno porte que podem funcionar com velocidades anuais médias maiores a $5 \mathrm{~m} / \mathrm{s}$ e menores a $6 \mathrm{~m} / \mathrm{s}$, já que não foi possível obter uma estimativa neste trabalho.

- Considerar o uso do processo denominado Ciclo Combinado Otimizado (CCO), já que esse processo aumenta a eficiência da produção de energia elétrica e permite que a porcentagem de gás natural participante varie de $0 \%$ a $25 \%$, o que representaria maior flexibilidade de geração com essa fonte e uma maior potência a ser instalada.

- Dado que as usinas virtuais podem ser conformadas por fontes renováveis e não renováveis, é possível considerar para futuras pesquisas a inclusão das usinas de geração com gás natural usadas em cogeração na indústria, comércio ou incluso em prédios residenciais para fornecer independência energética.

- Como sugestão para estudos adicionais, podem ser elencados estudos econômicos de viabilidade econômica de usinas virtuais, à luz da resolução Normativa 482 (Aneel, 2012), de compensação do valor da tarifa para várias situações, como diferentes fontes de geração ou, ainda, a participação em leilões de energia renovável.

Dada a situação atual do sistema de elétrico brasileiro, espera-se um aumento nos incentivos à geração distribuída e novos empreendimentos de médio porte, tanto com o objetivo de aumentar a capacidade de geração local, quanto para ajudar a aumentar a segurança energética do sistema, já que isso, além de reduzir as importações do estado, ajudará a manter o nível dos reservatórios no subsistema SE/CO, bem como a diminuir a necessidade de importação do mesmo, sobretudo tendo em conta as limitações de intercâmbio de energia nos subsistemas, que apresentarão possibilidades de se manter ao limite da sua capacidade, o que poderá apresentar riscos de déficit de potência nos subsistemas importadores de energia (SE/CO/S) que levarão a recortes de carga de diferentes profundidades. 


\section{Referências bibliográficas}

A. Aggarwal, S. Kunta, P.K Verma, A proposed communications infrastructure for the Smart Grid, in: 2010 Innovative Smart Grid Technologies ISGT 2010.

ADHI, E. "Concept And Controllability Of Virtual Power Plants." Tesis da Universidad Kassel, Alemanha, 2007.

AES Eletropaulo, 2015. "Comunicado à Imprensa", disponível em: https://www.aeseletropaulo.com.br/imprensa/nossos-releases/conteudo/comunicado\%C3\%A0-imprensa---16h-. Acessado em 26/02/2015.

ANEEL- AGÊNCIA NACIONAL DE ENERGIA ELÉTRICA, "RESOLUÇÃO NORMATIVA № 482", abril 2012, disponível em: http://www.aneel.gov.br/.

Barton, J. P. e Infield D. G. "Energy Storage and Its Use With Intermittent Renewable Energy". IEEE TRANSACTIONS ON ENERGY CONVERSION, VOL. 19, NO. 2, JUNE 2004.

BASSO, T. IEEE 1547 Interconnection Standards, IEEE PES Meeting, Colorado June 2004. Disponível em:

$<$ http://www.nrel.gov/eis/pdfs/interconnection_standards.pdf >. Visitado em: 18/08/2012.

Beaudin M, Zareipour H, Schellenberglabe A, Rosehart W. "Energy storage for mitigating the variability of renewable electricity sources: An updated review". Energy for Sustainable Development, Volume 14, pag 302-314, 2010.

CORERA, J. Virtual Power Plants Concept In Electrical Networks. 2nd Conference on Integration of Renewable and Distributed Energy Resources Napa 2006, Disponível em: <http://fenix.iwes.fraunhofer.de/html/documents.htm> Visitado em: 18/08/2012.

Depuru S, Wang L. e Devabhaktuni V. "Smart meters for power grid: Challenges, issues, advantages and status". Renewable and Sustainable Energy Reviews Volume 15, August 2011. 
El Bakari, K., and Kling, W. L. "Virtual Power Plants: an Answer to Increasing Virtual Power Plants: an Answer to Increasing Distributed Generation", Innovative Smart Grid Technologies Conference Europe (ISGT Europe), 2010 IEEE PES. Disponível em: < http://ieeexplore.ieee.org/stamp/stamp.jsp?tp=\&arnumber=5638984>. Acessado em: 15/08/2012.

El-Khattam W. e Salama M.M.A., 2004. "Distributed generation technologies, definitions and benefits", Electric Power Systems Research, Volume 71, Issue 2, October 2004, Pages 119-128.

EUR 23234 EN, 2007. " Distributed Power Generation in Europe: technical issues for further integration". Joint Research Centre. Institute For Energy. Disponível em: $<$ http://ses.jrc.ec.europa.eu/sites/ses.jrc.ec.europa.eu/files/documents/dg_jrc_report. pdf $>$

Fundação do Desenvolvimento Administrativo - Fundap. "Plano estratégico de desenvolvimento para a Região Metropolitana De Campinas", Dezembro 2010. Disponível em: <http://www.agemcamp.sp.gov.br/midia/PlanoEstrategico_da_RMC.pdf>.

Gaoa J, Xiao Y, Liu J, Liang W. e Chenc C.L.P., "A survey of communication/networking in Smart Grids". Future Generation Computer Systems, Volumem 28, 2012.

Güngör V., Sahin D., Kocak T., Ergüt S., Buccella C., Cecati C. e Hancke G. P., "Smart Grid Technologies: Communication Technologies and Standards", IEEE Transactions On Industrial Informatics, Vol. 7, 2011.

FENIX, "Resultados", Proyecto FENIX, 2009, Disponível em: <www.fenixproject.org> acceso el 28/08/2012.

Hadjipaschalis, L., Poullikkas, A. e Efthimiou, V. "Overview of current and future energy storage technologies for electric power applications". Renewable and Sustainable Energy Reviews, Volume 13, Issues 6-7, September 2009.

IEADSM-Task XVII, "Integration Of Demand Side Management, Distributed Generation, Renewable Energy Sources And Energy Storages", International Energy 
Agency Program of Demand Side Management Volume 1: Main Report, Finlândia. Disponível em: < http://www.ieadsm.org/Files/Tasks/Task\%2017\%20\%20Integration\%20of\%20Demand\%20Side\%20Management,\%20Energy\%20Efficie ncy,\%20Distributed\%20Generation\%20and\%20Renewable\%20Energy\%20Sources/ Final\%20reports/Synthesis\%20Report\%20Final.pdf>.

IEA ENARD, 2011. " Annex II - DG System Integration in Distribution Networks".

IEA b, "Technology Roadmap: Smart Grids". Francia, 2011

IEEE Std 1547.2-2008, "IEEE Standard for Interconnecting Distributed Resources with Electric Power Systems", IEEE Standards Coordinating Committee 21, abril 2009.

IEEE Std 2030, "IEEE Guide for Smart Grid Interoperability of Energy Technology and Information Technology Operation with the Electric Power System (EPS), EndUse Applications, and Loads" , IEEE Standards Coordinating Committee 21, Nova York, USA., setembro 2011.

IEEE 1547.6-2011. "IEEE Recommended Practice for Interconnecting Distributed Resources with Electric Power Systems Distribution Secondary Networks", IEEE Setembro 2011. Disponível em: <http://ieeexplore.ieee.org/stamp/stamp.jsp?tp=\&arnumber=6022734\&tag=1>

Instituto Nacional de Eficiência Energética - INEE, "Geração distribuída e sua conexão à rede elétrica", 2002.

Kapsali M, Kaldellis JK. Combining hydro and variable wind power generation by means of pumped-storage under economically viable terms. Applied Energy 2010; 87(11):3475-85.

Khan R. H. e Khan J. Y., "A comprehensive review of the application characteristics and traffic requirements of a smart grid communications network", Computer Networks, Volumem 57, 2013.

Koeppel, G. "Distributed Generation: Literature Review And Outline Of Swiss Situation", ETH, Internal Report, 2003. Disponível em: 
$<$ http://www.eeh.ee.ethz.ch/uploads/tx_ethpublications/LitReview_DG.pdf> Visitado 20-01-2013

Koohi-Kamali S, Tyagi V, Rahim N, Panwar N, Mokhlis H. "Emergence of energy storage technologies as the solution for reliable operation of smart power systems: A review". Renewable and Sustainable Energy Reviews, Volume 25, pages 135-165, 2013.

Korai, M. S., Mahar, R B. e Uqaili , M. A. "Assessment of Power Generation Potential from Municipal Solid Wastes: A Case Study of Hyderabad City, Sindh, Pakistan" Pakistan Journal of Analytical and Environmental Chemistry, Volume 15, No. 1, junho 2014. Disponível em:

<http://www.ceacsu.edu.pk/PDF\%20file/Volume\%2015\%20No\%201/18-27-PJAEC22042014-07.pdf>. Acessado: 10/04/2015.

Marihart, D. "Communications Technology Guidelines for EMS/SCADA Systems", IEEE TRANSACTIONS ON POWER DELIVERY, VOL. 16, NO. 2, APRIL 2001, Disponível em: < http://ieeexplore.ieee.org/stamp/stamp.jsp?arnumber=00915480> revisado: $27 / 01 / 2013$

Markovic, D.S., Zivkovic, D., Branovic, I., Popovic, R. and Cvetkovic, D., 2013. "Smart power grid and cloud computing", Renewable and Sustainable Energy Reviews, Volume 24, August 2013, Pages 566-577.

McCallum, D. "waste to energy background paper" Yukon Energy Charrette, March 6-9, 2011. Disponível em:

$<$ https://www.yukonenergy.ca/media/site_documents/charrette/docs/papers/WASTE_ TO_ENERGY_YEC_Background_Paper.pdf >. Acessado em: 10/04/2015

Ministério de Minas e Energia. Empresa de Pesquisa Energética. "Plano Decenal de Expansão de Energia 2023 -PDE 2022", Brasília 2013.

Ministério de Minas e Energia. Empresa de Pesquisa Energética. "Plano Decenal de Expansão de Energia 2023 -PDE 2023", Brasília 2014.

NISTIR 7628, "Guidelines for Smart Grid Cyber Security: Vol. 1, Smart Grid Cyber Security Strategy, Architecture, and High-Level Requirements", the Smart Grid Interoperability Panel - Cyber Security Working Group, 2010. 
O. Abarratégui, J. Marti, A. Gonzalez, "Constructing the Active European Power Grid", World Congress on Power and Energy Engineering, 2009. Disponível em: <http://fenix.iwes.fraunhofer.de/docs/documents/Project_Fenix_2009-11-

24_Constructing_the_Active_European_Power_Grid_Juan_Marti_v1.pdf>

ONS, 2015. "Nota de imprensa", disponível em: http://www.ons.org.br/download/sala_imprensa/notaaimprensa_19012015.pdf. Acessado em: 26/02/2015.

Operador Nacional do Sistema, "Sumário Executivo do Programa Mensal de Operação", Dezembro 2014.

Pepermans, G., Driesen, J., Haeseldonckx, D., Belmans, R., D'haeseleer, W., 2005, "Distributed generation: definition, benefits and issues", Energy Policy, Volume 33, Issue 6, Pages 787-798

Plano Paulista de Energia 2020 - PPE 2020, São Paulo 2012.

PUDJIANTO, D., RAMSAY, C. \& STRBAC, G. "The FENIX vision: The Virtual Power Plant and system integration of distributed energy resources". Imperial College, Dezembro 2006. Disponível em:

<http://fenix.iwes.fraunhofer.de/docs/documents/Project_Fenix_2008-06-

19_The_FENIX_vision_Christophe_Kieny_v1.pdf >. Visitado em: 18/08/2012.

Rabiee A, Khorramdel H, Aghaei J. "A review of energy storage systems in microgrids with wind turbines". Renewable and Sustainable Energy Reviews 18 (2013) 316-326.

Römer B, Reichhart P, Kranz J, and Picot A. "The role of smart metering and decentralized electricity storage for smart grids: The importance of positive externalities". Energy Policy, Volume 50, November 2012.

RWE, "Case Study". Disponível em: <http://ec.europa.eu/enterprise/archives/ebusinesswatch/studies/case_studies/documents/Case\%20Studies\%202009/CS09_Energy1_ RWE.pdf> 
Saboori, H., Mohammadi, M. and Taghe, R. "Virtual Power Plant (VPP), Definition, Concept, Components and Types", Power and Energy Engineering Conference (APPEEC). 2011. Asia-Pacific. Disponível em: <http://ieeexplore.ieee.org>. Visitado: 18/08/2012.

Secretaria de Energia de São Paulo, "Atlas Eólico do Estado de São Paulo", São Paulo, 2012.

Secretaria de Energia de São Paulo, "Energia solar paulista: Levantamento do Potencial", Fevereiro 2013.

Secretaria de Energia de São Paulo, "Matriz Energética do estado de São Paulo 2035", São Paulo, 2011.

Stjepan Sučić, Tomislav Dragičević, Tomislav Capuder, Marko Delimar, 2011. "Economic dispatch of virtual power plants in an event-driven service-oriented framework using standards-based communications" Electric Power Systems Research, Volume 81, Issue 12, December 2011, Pages 2108-2119, Disponível em: <http://www.sciencedirect.com/science/article/pii/S0378779611001957>

The World Bank. "Municipal Solid Waste Incineration", Washington, D.C, United States of America, agosto 1999. Disponível em: < http://www.worldbank.org/urban/solid_wm/erm/CWG\%20folder/Waste\%20Incineratio n.pdf $>$.

Usman A. e Shami S.H., "Evolution of Communication Technologies for Smart Grid applications", Renewable and Sustainable Energy Reviews, Volumem 19, 2013.

Wang W. e Lu Z., "Cyber security in the Smart Grid: Survey and challenges", Computer Networks Volumem 57, 2013.

Wang W, Xu Y. e Khanna M., "A survey on the communication architectures in smart grid". Computer Networks, Volumem 55, 2011. 


\section{Glossário}

\section{Rede passiva e rede ativa}

A rede passiva é a forma mais comumente usada para gerir as redes de média e baixa tensão, onde um alimentador é conectado a um transformador e esse transformador é a única fonte de controle no alimentador (por exemplo: controle de tensão). Numa rede ativa, as cargas, geradores e nós da rede podem ser controlados em tempo real por meio de tecnologias de informação e comunicação (ICT).

\section{Agregação}

A agregação de recursos energéticos flexíveis significa que uma terceira parte, chamada agregador de DER, coleta e implementa um portfólio de recursos energéticos flexíveis e os opera combinados como um recurso flexível no mercado de energia, como o mercado atacadista de eletricidade. O agregador pode também oferecer os recursos flexíveis agregados ao mercado como reservas do sistema ou como serviços auxiliares para os operadores das redes de distribuição.

\section{Bridging Energy}

A área de aplicação para os armazenamentos de energia, onde a energia armazenada é usada por intervalos de tempo que compreendem desde segundos até minutos para assegurar a continuidade do serviço quando se muda de uma fonte de geração de energia à outra.

\section{Modelo comum de informação}

O modelo comum de informação (CIM) é a norma desenvolvida pela indústria de energia elétrica que tem sido adotada oficialmente pela Comissão Eletrotécnica Internacional (IEC). O seu objetivo é permitir que as aplicações de software intercambiem informação sobre a configuração e estado de uma rede elétrica desde o ponto de vista da empresa de serviços públicos e os operadores do sistema. Uma linguagem relacionada é a linguagem de descrição de configuração (SCL) a qual especifica o modelo de informação no Sistema de Automação da Subestação (SAS). 


\section{Congestão}

Condição que ocorre na rede quando não se encontra disponível suficiente capacidade de transferência de energia para trazer a eletricidade dos geradores até os consumidores.

\section{Resposta à demanda (DR)}

Também conhecido como gerenciamento do lado da demanda (DSM). São os programas e atividades projetados para incentivar os consumidores a mudar os padrões de uso de energia elétrica, incluindo tempo e nível de demanda de eletricidade, cobrindo todos os objetivos dos consumidores e da curva de carga. DR inclui tarifas ou preços dinâmicos e tempos de uso, programas de confiabilidade tais como controle direto de carga de dispositivos e cargas instantâneas interrompíveis, e outras opções do mercado para gerir mudanças na demanda.

\section{Controle direto de carga (DLC)}

As cargas são controladas externamente pelas ações configuradas no DR/DSM quando os usuários finais são providos de hardware e infraestrutura de comunicação requeridos para permitir o controle direto da carga. Nos programas de DLC as cargas dos clientes são interrompidas desligando-as remotamente, ou mediante aparelhos elétricos com horários de funcionamento cíclicos, como ar condicionado e aquecedores de água.

\section{Recursos Energéticos Distribuídos (DER)}

É um termo comum para geração distribuída (incluindo pequenas plantas de cogeração e renováveis), armazenamentos de energia e cargas flexíveis (também denominadas como demanda ativa) conectados na rede de transmissão ou distribuição. As cargas flexíveis são geralmente usadas por meio das atividades de gerenciamento da demanda.

\section{Gestão de Energia}

São as operações relacionadas com a redução do custo do consumo de energia e/ou incremento da renda da geração de energia e calor. 
A gestão de energia é também uma área de aplicação dos sistemas de armazenamento de energia. Nesta aplicação o armazenamento de energia é usado para desacoplar o tempo de geração e consumo de energia elétrica. Uma aplicação típica é o nivelamento de carga, o qual envolve o armazenamento quando o custo da energia é baixo e se faz uso desta carga quando for preciso. Isto permite também que os consumidores sejam independentes do uso da energia fornecida pela rede por várias horas. Os armazenamentos de calor também podem ser usados como desacopladores de geração de energia das plantas de cogeração e o seu consumo de calor associado.

\section{Flexibilidade}

A flexibilidade do cliente é a habilidade de adaptar rapidamente sua geração e demanda de energia em resposta aos preços variáveis da eletricidade, condições do mercado de eletricidade, condições do sistema de transmissão e distribuição e regulamentações.

Flexibilidade da rede é definida como ter a suficiente capacidade na rede de transmissão e distribuição, ou capacidade para incrementar o armazenamento de energia disponível na rede, ou por ter a capacidade de usar ferramentas tais como monitoramento e análises em tempo real para gerenciar os ativos da rede de maneira a incrementar o seu rendimento e flexibilidade operacional sem comprometer a sua confiabilidade.

\section{Monitoramento digital de alta velocidade}

Usado para monitorar o estado da rede ou de alguns elementos nela presentes em tempo real, o qual permite uma resposta rápida (automatizada ou não) quando é necessário. É comum nos países europeus monitorar o estado das redes de alta tensão desta forma.

\section{Controle indireto de carga}

O controle indireto de carga é classificado como o conjunto de iniciativas que requerem que os usuários finais modifiquem o seu consumo com ações executadas pelos mesmos clientes. Isto inclui todos os casos nos quais o operador do sistema não tem a capacidade de controlar a carga diretamente. 


\section{Interoperabilidade}

É a habilidade de dois ou mais sistemas ou componentes do sistema de intercambiar informação e de usar as informações que foram trocadas de forma eficaz sem a intervenção por parte do utilizador ou operador.

\section{Mercado de energia (Power exchange)}

Também conhecido como spot ou pool market, onde são realizados leilões entre geradores que buscam vender energia ou cargas servidas por contratos bilaterais. $O$ mercado de energia determina os preços de referência de energia, e aqueles geradores que ofertam valores iguais ou abaixo do preço de referência são priorizados para a geração (conhecido como ordem de mérito - merit order). $\mathrm{O}$ mercado de energia é também frequentemente responsável pelos contratos e pagamentos.

\section{Cargas Pesada, Média e Leve}

Período de tempo em que as características de consumo de energia elétrica tendem a ser semelhantes; o valor máximo de consumo, que é denominado de carga pesada, ocorre normalmente por volta das 19 horas e constitui a chamada ponta de carga, com cerca de 2 a 3 horas de duração; o valor mínimo de consumo, denominado carga leve, dá-se por volta das 4 horas da madrugada; tem-se também um período de carga média ou intermediária. Podem ocorrer variações nos períodos de tempo de ocorrência da carga pesada e da carga leve de acordo com a região, os dias da semana e as estações do ano. 